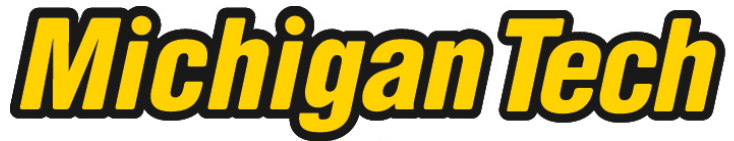 \\ Michigan Technological University Create the Future Digital Commons @ Michigan Tech
}

2010

Characterization of legacy organic carbon in a culturally eutrophic lake : the role of the historic carbon deposition in the time course and extent of lake recovery

Phillip A. DePetro

Michigan Technological University

Follow this and additional works at: https://digitalcommons.mtu.edu/etds

Part of the Civil and Environmental Engineering Commons

Copyright 2010 Phillip A. DePetro

Recommended Citation

DePetro, Phillip A., "Characterization of legacy organic carbon in a culturally eutrophic lake : the role of the historic carbon deposition in the time course and extent of lake recovery ", Master's Thesis, Michigan Technological University, 2010.

https://doi.org/10.37099/mtu.dc.etds/230

Follow this and additional works at: https://digitalcommons.mtu.edu/etds

3 Part of the Civil and Environmental Engineering Commons 


\title{
Characterization of Legacy Organic Carbon in a Culturally Eutrophic Lake: The Role of the Historic Carbon Deposition in the Time Course and Extent of Lake Recovery
}

\author{
Phillip A. DePetro
}

\begin{abstract}
A Thesis
Submitted in partial fulfillment of the requirements for the degree of MASTER OF SCIENCE IN ENVIRONMENTAL ENGINEERING

MICHIGAN TECHNOLOGICAL UNIVERSITY
\end{abstract}

2010 
This thesis, "Characterization of Legacy Organic Carbon in a Culturally Eutrophic Lake: The Role of the Historic Carbon Deposition in the Time Course and Extent of Lake Recovery", is hereby approved in partial fulfillment of the requirements for the Degree of MASTER OF SCIENCE IN ENVIRONMENTAL ENGINEERING.

Department of Civil and Environmental Engineering

Thesis Advisor:

Dr. Martin T. Auer

Department Chair:

Dr. W.M. Bulleit

Date: 


\section{Abstract}

The time course of lake recovery after a reduction in external loading of nutrients is often controlled by conditions in the sediment. Remediation of eutrophication is hindered by the presence of legacy organic carbon deposits, that exert a demand on the terminal electron acceptors of the lake and contribute to problems such as internal nutrient recycling, absence of sediment macrofauna, and flux of toxic metal species into the water column. Being able to quantify the timing of a lake's response requires determination of the magnitude and lability, i.e., the susceptibility to biodegradation, of the organic carbon within the legacy deposit. This characterization is problematic for organic carbon in sediments because of the presence of different fractions of carbon, which vary from highly labile to refractory.

The lability of carbon under varied conditions was tested with a bioassay approach. It was found that the majority of the organic material found in the sediments is conditionally-labile, where mineralization potential is dependent on prevailing conditions. High labilities were noted under oxygenated conditions and a favorable temperature of $30^{\circ} \mathrm{C}$. Lability decreased when oxygen was removed, and was further reduced when the temperature was dropped to the hypolimnetic average of $8^{\circ} \mathrm{C}$. These results indicate that reversible preservation mechanisms exist in the sediment, and are able to protect otherwise labile material from being mineralized under in situ conditions. 
The concept of an active sediment layer, a region in the sediments in which diagenetic reactions occur (with nothing occurring below it), was examined through three lines of evidence. Initially, porewater profiles of oxygen, nitrate, sulfate/total sulfide, ETSA (Electron Transport System Activity- the activity of oxygen, nitrate, iron/manganese, and sulfate), and methane were considered. It was found through examination of the porewater profiles that the edge of diagenesis occurred around $15-20 \mathrm{~cm}$. Secondly, historical and contemporary TOC profiles were compared to find the point at which the profiles were coincident, indicating the depth at which no change has occurred over the (13 year) interval between core collections. This analysis suggested that no diagenesis has occurred in Onondaga Lake sediment below a depth of $15 \mathrm{~cm}$. Finally, the time to $99 \%$ mineralization, the $t_{99}$, was viewed by using a literature estimate of the kinetic rate constant for diagenesis. A t $t_{99}$ of 34 years, or approximately $30 \mathrm{~cm}$ of sediment depth, resulted for the slowly decaying carbon fraction. Based on these three lines of evidence, an active sediment layer of $15-20 \mathrm{~cm}$ is proposed for Onondaga Lake, corresponding to a time since deposition of $15-20$ years.

While a large legacy deposit of conditionally-labile organic material remains in the sediments of Onondaga Lake, it becomes clear that preservation, mechanisms that act to shield labile organic carbon from being degraded, protects this material from being mineralized and exerting a demand on the terminal electron acceptors of the lake. This has major implications for management of the lake, as it defines the time course of lake recovery following a reduction in nutrient loading. 


\section{Acknowledgements}

They say that it takes a village to raise a child, and the same can be said for getting a graduate student to a Masters Degree. I wouldn't be writing this page today if it weren't for a number of people that have been a part of my life over my eight years as a student of Michigan Tech.

- $\quad$ First, I would like to thank my parents, for their support and encouragement through every endeavor that I have undertaken in my life.

- I have been blessed to have all four of my grandparents with me on my walk of life thus far, and for that I am extremely thankful.

- To Sarah, who has been along for the ride through this thesis and has been there for me no matter what. I look forward to our future chapters together, no matter what uncertainties we are facing now.

- My immediate and extended family deserve to be put here, even though I only seem to see them on occasion, which is mostly my fault. Who knew that two hours could be as far away as Texas at times? Who knew that Texas was in fact this far away?

- To Albert, Brandon, Ken, and Kevin. I consider them to be my brothers in the project, and they have never failed to pick me up when needed and celebrate the successes. And thank you to Rasika for all of the Sed2K work that assisted me to the end of this work.

- To the friendly graduate students not directly involved in the project, such as Adam and Jennifer, who made the department a better place to be.

- To the Huskies Pep Band and all of the characters that I have had the pleasure of performing with, another set of heartfelt thanks.

- To Nikki, who shared her love of photography with me and was a great friend to guide me through the every day occurrences of Michigan Tech. May you find the motivation and strength to find the path to the end of your thesis and Masters Degree.

- To Andy, who was there as a friend from Day 1 at Tech, and will someday be a great best man.

- To Jacquie, who was the partner on some interesting adventures to waterfalls, sunsets, thunderstorms, and the Keweenaw.

- To all of the people that I call 'mom' and 'dad', despite the obvious lack of biological relation. You can never have enough people to look up to in that respect.

This thesis also would not have been remotely possible without:

- God. Thank you for the beautiful natural setting that I was blessed with in getting my education, and for the strength to find success in the academic path. This in addition to 'thank you' for everything else.

- My advisor, Dr. Auer. A mentor, a fellow sports fan, and at so many times, an additional father figure to me. Inside the world of academics and out, there are few greater men than this.

- All of my professors, who share the world of knowledge in a way that even I can understand it.

- My thesis committee, who have provided a great body of insight and correction that have allowed for the creation of a stronger research document.

- $\quad$ The dedicated, friendly, and knowledgeable people at the Upstate Freshwater Institute.

It took a lot of work to get to this point, and it honestly took a lot longer than I had originally expected. But I agree with the statement of Dr. Auer when he said that everything has its time, and it was not this thesis's time until now. I am proud of the efforts that I have made, but it would have all been impossible without the people listed above (and the many other lives that have touched my own).

This work is dedicated to my son Brennan and any other future children. May I leave the environment a better place for you in the future, both through this work and in my career. More importantly, may I be a father figure that you can be proud of and look to when needed. 


\section{Contents}

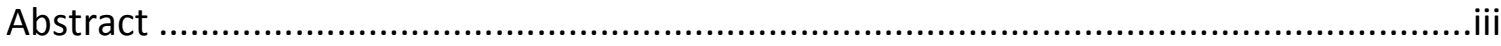

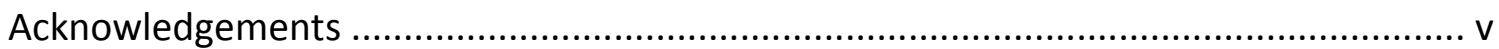

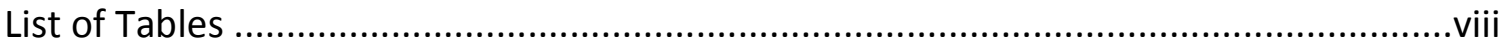

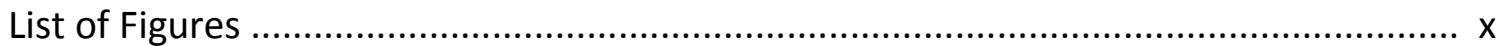

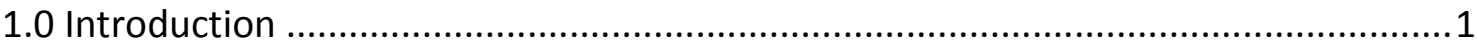

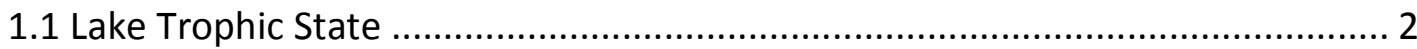

1.2 Eutrophication, Organic Matter Diagenesis and Oxygen Resources ................. 3

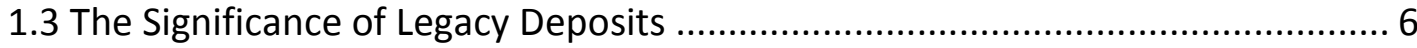

1.4 Organic Carbon Diagenesis ...................................................................... 8

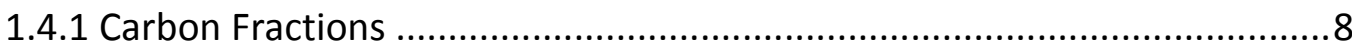

1.4.2 Terminal Electron Acceptors and Methanogenesis ............................... 9

1.4.3 The Rate of Diagenesis .................................................................. 13

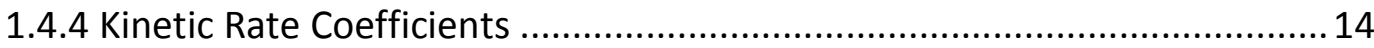

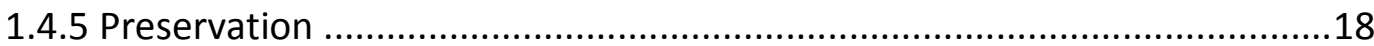

1.4.5.1 Direct Adsorption ..................................................................20

1.4.5.2 Aggregation, Occlusion, and Encapsulation in the Mineral Microfabric

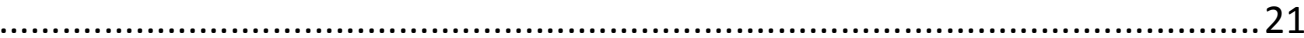

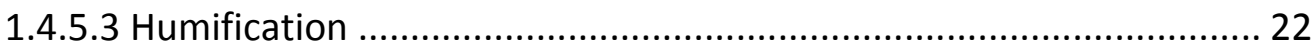

1.4.5.4 Biological Protection ................................................................... 23

1.4.5.5 The Role of Redox Conditions and Reversibility of Preservation ...... 24

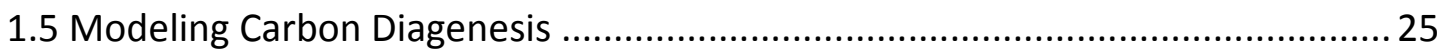

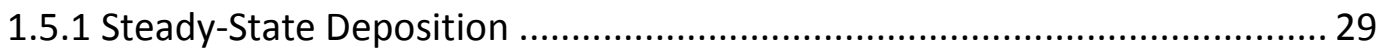

1.5.2 Non Steady-State Deposition .............................................................. 32

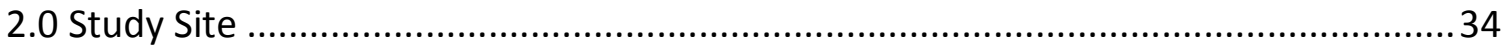

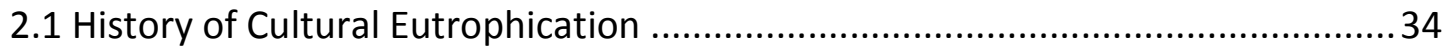

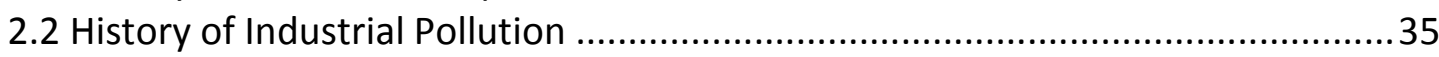

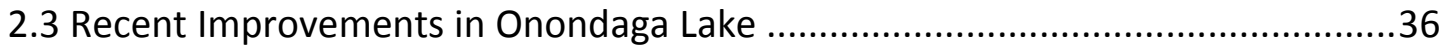

2.4 Organic Carbon Diagenesis and the Remediation of Mercury Pollution ............. 36

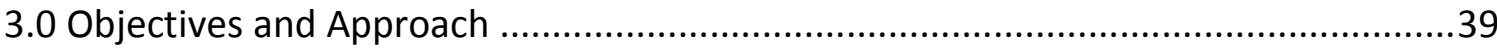

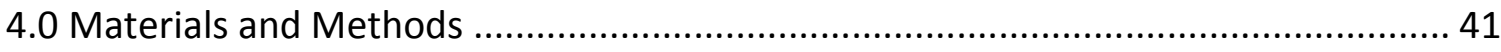

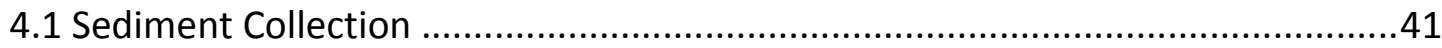

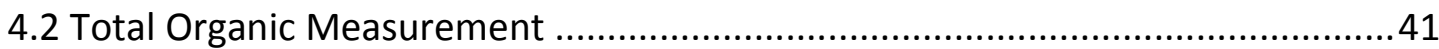

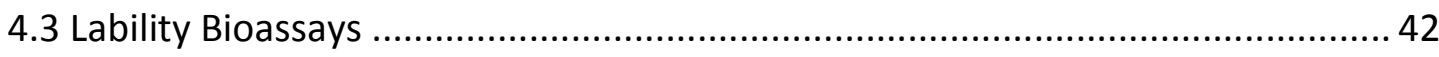

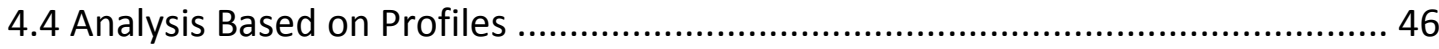

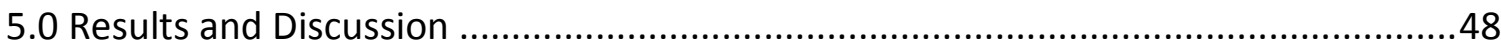




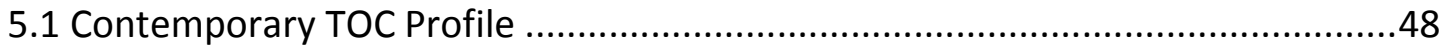

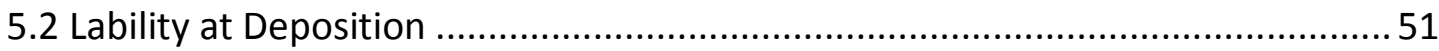

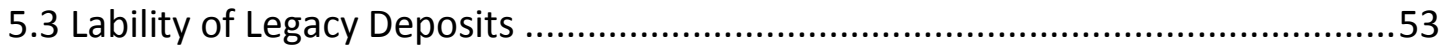

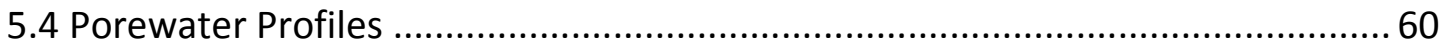

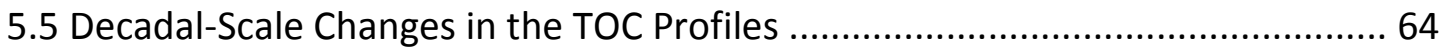

5.6 The Active Sediment Layer and Kinetic Rate Coefficients ................................65 65

5.7 Management Implications Under a Preservation Scenario .............................. 66

5.8 Modeling Diagenesis Under a Preservation Scenario ..................................67 67

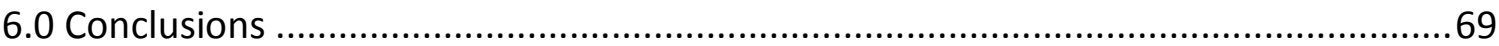

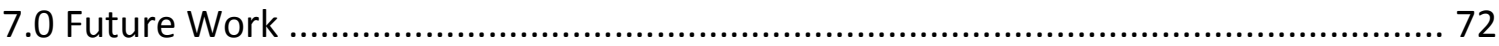

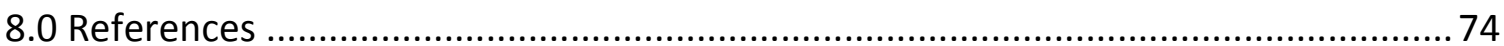

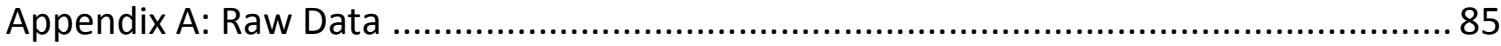

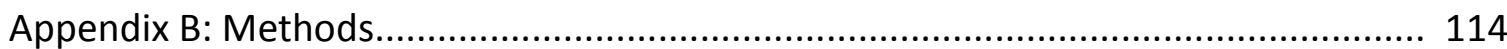

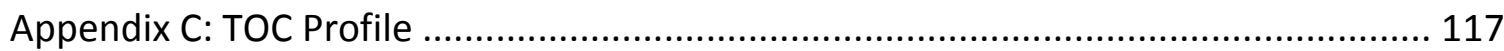

Appendix D: Artificial Lake Water Recipe ............................................................. 118

Appendix E: Calculation of Burial Velocity Using Sed2K ..................................... 119 


\section{List of Tables}

Table 1: Lost Beneficial Uses and Detrimental Effects of Eutrophication ..................... 2

Table 2: Manifestations of Eutrophication and Metrics Used to Measure Extent.......... 3

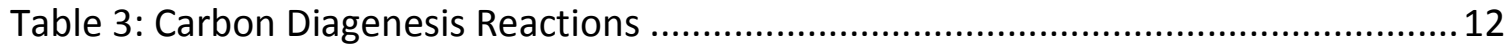

Table 4: Literature Values for Kinetic Coefficients ............................................... 15

Table 5: Lability of Freshly Deposited Material ...................................................... 51

Table A.1 30 Degree Oxygen Summary of Results ................................................ 86

Table A.2 $0.5-1$ cm Sediment Slice Lability .............................................................. 87

Table A.3 $3-3.5 \mathrm{~cm}$ Sediment Slice Lability ....................................................... 88

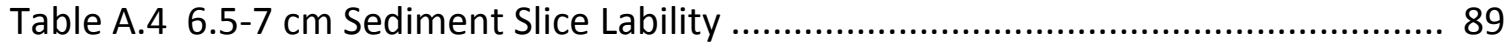

Table A.5 8.5-9 cm Sediment Slice Lability ........................................................... 90

Table A.6 $12.5-13 \mathrm{~cm}$ Sediment Slice Lability ....................................................... 91

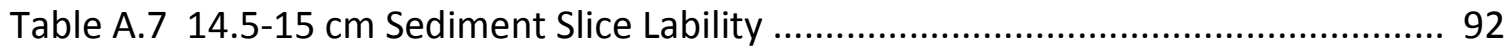

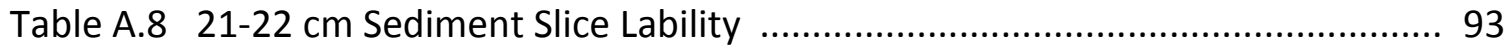

Table A.9 25-26 cm Sediment Slice Lability ........................................................ 94

Table A.10 29-30 cm Sediment Slice Lability .......................................................... 95

Table A.11 34-35 cm Sediment Slice Lability ....................................................... 96

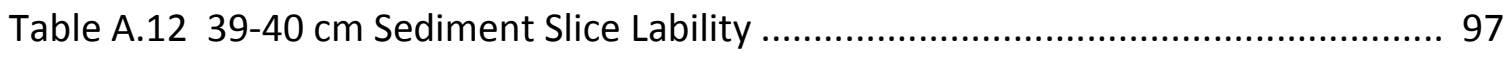

Table A.13 50-51 cm Sediment Slice Lability ....................................................... 98

Table A.14 55-56 cm Sediment Slice Lability ...................................................... 99

Table A.15 60-62 cm Sediment Slice Lability ..................................................... 100 
Table A.16 70-72 cm Sediment Slice Lability .................................................... 101

Table A.17 30 Degree Anoxic Summary of Results .............................................. 103

Table A.18 8 Degree Anoxic Summary of Results ................................................. 109

Table A.19 Lability of the Sediment Trap Material Under Oxic Conditions ................. 113

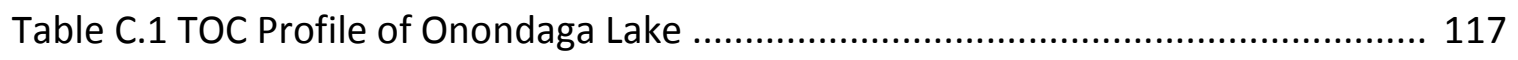

Table D.1 Artificial Lake Water ..................................................................... 118 


\section{List of Figures}

Figure 1: Steady-State Carbon Deposition Sediment System ......................................30

Figure 2: The Labile Carbon Fraction ............................................................... 31

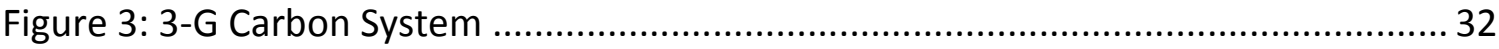

Figure 4: Idealized Non-Steady State Lake TOC Profile ............................................ 33

Figure 5: Representative results of the oxic bioassays conducted on sediment collected

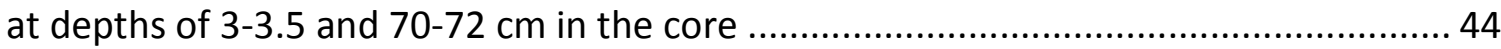

Figure 6: Validation of Oxygen Consumption Method ........................................... 45

Figure 7: Representative results of anoxic bioassays conducted on sediment collected at

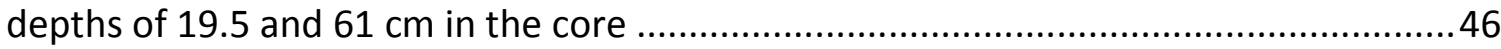

Figure 8: Example of Profile Comparison ........................................................... 47

Figure 9: The Total Organic Carbon Profile for Onondaga Lake ................................. 49

Figure 10: Total Phosphorus Profile for Onondaga Lake ........................................... 50

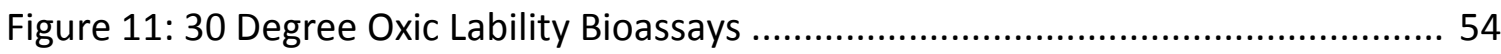

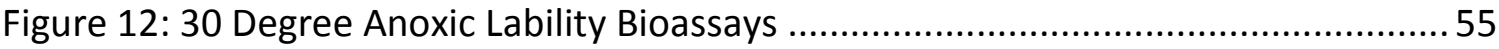

Figure 13: 8 Degree Anoxic Lability Bioassays ............................................................ 56

Figure 14: Porewater Profiles of Sleceted Electron Acceptors and Reduced Species End Products

Figure 15: Porewater Profiles of (a) ETSA and (b) Methane Concentration .................. 62

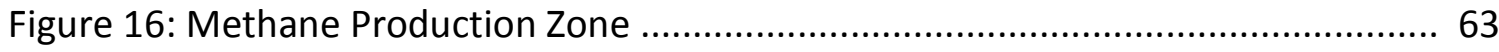

Figure 17: Comparison of the measured contemporary TOC profile (2008) with a simulation of that profile assuming that no diagenesis occurs. .................................. 65

Figure A.1 Oxygen consumed from the $0.5-1 \mathrm{~cm}$ slice ...................................... 87

Figure A.2 Oxygen consumed from the $3-3.5 \mathrm{~cm}$ slice .................................... 88 
Figure A.3 Oxygen consumed from the $6.5-7 \mathrm{~cm}$ slice ....................................... 89

Figure A.4 Oxygen consumed from the $8.5-9 \mathrm{~cm}$ slice ......................................... 90

Figure A.5 Oxygen consumed from the $12.5-13 \mathrm{~cm}$ slice .................................... 91

Figure A.6 Oxygen consumed from the $14.5-15 \mathrm{~cm}$ slice ........................................... 92

Figure A.7 Oxygen consumed from the $21-22 \mathrm{~cm}$ slice .......................................... 93

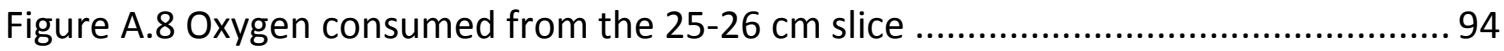

Figure A.9 Oxygen consumed from the $29-30 \mathrm{~cm}$ slice ........................................ 95

Figure A.10 Oxygen consumed from the $34-35 \mathrm{~cm}$ slice ...................................... 96

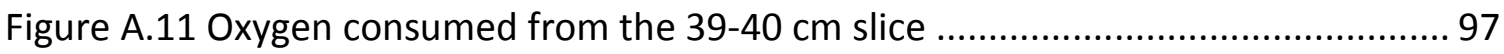

Figure A.12 Oxygen consumed from the $50-51 \mathrm{~cm}$ slice ....................................... 98

Figure A.13 Oxygen consumed from the $55-56 \mathrm{~cm}$ slice ...................................... 99

Figure A.14 Oxygen consumed from the $60-62 \mathrm{~cm}$ slice ...................................... 100

Figure A.15 Oxygen consumed from the $70-72 \mathrm{~cm}$ slice ..................................... 101

Figure A.16 TOC measurements from the $7.5-8.0 \mathrm{~cm}$ slice .................................. 104

Figure A.17 TOC measurements for the $19.5-20.0 \mathrm{~cm}$ slice ................................... 104

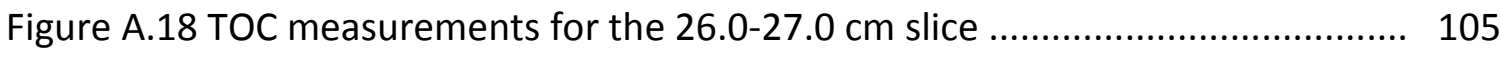

Figure A.19 TOC measurements for the $31.0-32.0 \mathrm{~cm}$ slice ................................ 105

Figure A.20 TOC measurements for the $38.0-39.0 \mathrm{~cm}$ slice ................................ 106

Figure A.21 TOC measurements for the $44.0-45.0 \mathrm{~cm}$ slice ............................... 106

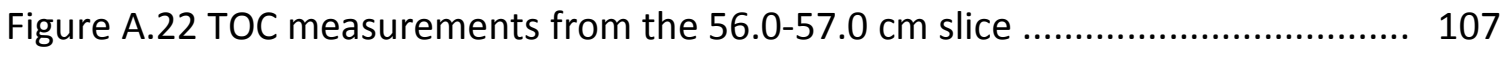

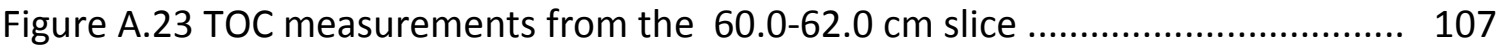

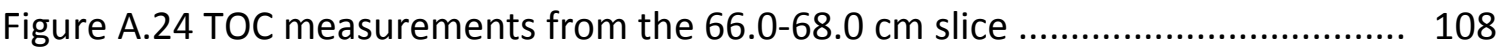

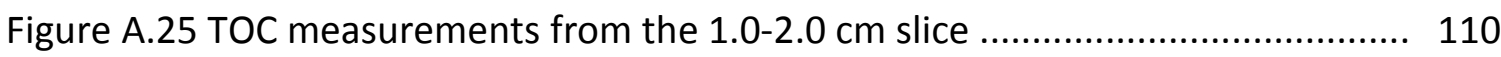


Figure A.26 TOC measurements from the $15.0-17.0 \mathrm{~cm}$ slice

Figure A.27 TOC measurements from the $29.0-31.0 \mathrm{~cm}$ slice ............................. 111

Figure A.28 TOC measurements from the $39.0-41.0 \mathrm{~cm}$ slice .............................. 111

Figure A.29 TOC measurements from the $52.0-53.0 \mathrm{~cm}$ slice ............................... 112

Figure A.30 TOC consumed from the sediment trap material ................................ 113

Figure E.1 The ratio of seasonal sedimentation rates .......................................... 121

Figure E.2 Porosity profile for a sediment core collected in 2009 ........................... 121

Figure E.3 Dry sediment density profile for a sediment core collected in 2009 .......... 122 


\subsection{Introduction}

The anthropogenic input of nutrients into waterways has caused severe degradation of many aquatic systems. In most freshwater lakes this problem, termed eutrophication, results from excessive discharges of phosphorus (Correll 1998). This nutrient is supplied from point and nonpoint sources. Point sources are direct inflows that include effluent from wastewater treatment facilities, leachate from waste disposal beds, and overflows from combined sewers (Smith et al. 1999). Non-point sources, for which there is no single inflow location, include runoff from agricultural and urban land and atmospheric deposition (Smith et al. 1999). In addition to external sources of phosphorus, internal sources (i.e. recycling of nutrients from the sediment) are important in eutrophic lakes that experience periods of anoxia (Correll 1998).

Eutrophication is the most wide-spread water quality problem in the United States (over half of the impaired surface waters are impacted by eutrophication; US EPA 1996) and around the world (Carpenter et al. 1999). Many lakes have undergone a transformation in trophic state from unproductive oligotrophic systems to highly-productive eutrophic or hypereutrophic state as human population density and land use have changed within their watersheds (Correll 1998). Phosphorus enrichment results in poor aesthetics and detrimental effects leading to lost beneficial use (Correll 1998; see also Table 1). 


\begin{tabular}{|l|l|}
\hline \multicolumn{2}{|l|}{ Table 1: Lost Beneficial Uses and Other Detrimental Effects of Eutrophication } \\
\hline Lost Beneficial Uses & Detrimental Effects \\
\hline $\begin{array}{l}\text { Loss of Contact Recreation/ } \\
\text { Swimming }\end{array}$ & Taste and Odor Problems \\
\hline Lost Fisheries & Decreased Biodiversity \\
\hline Lost Aesthetics & Toxic Cyanobacteria Blooms \\
\hline Physical Impairments to Boating & Decreased Property Values \\
\hline Lost Tourism Potential & Hypolimnetic Anoxia \\
\hline Source: Dodds et al. 2009 & \\
\hline
\end{tabular}

There are significant costs associated with eutrophication and the attendant effects of increased production (Carpenter et al. 1997). Dodds et al. (2009) conservatively estimated that the annual cost of anthropogenic eutrophication is approximately 2.2 billion dollars in the freshwaters of the United States, with the greatest cost associated with a reduction in lake front property values and lost recreational opportunities. Lake management thus becomes a balance between the costs of controlling point and nonpoint pollution and the damaging ecological and economic effects of eutrophication (Carpenter et al. 1999).

\subsection{Lake Trophic State}

The trophic state of a lake is mediated by the inputs of a limiting nutrient. As mentioned above, phosphorus is most often the limiting nutrient in lakes (Hutchinson 1973). For such systems, the trophic state of the lake is directly correlated with the phosphorus concentration, with eutrophication occurring at concentrations greater than 
$20 \mu \mathrm{g}$ total $\mathrm{PL}^{-1}$ (Chapra 1997). There are many manifestations of eutrophication; the primary indicators, and their metrics, are listed in Table 2.

Lake rehabilitation efforts often concentrate on managing inputs of the limiting nutrient through control of point and non-point sources. The goal is to limit nutrient enrichment to the point that a lake recovers lost beneficial uses. An example of this type of remediation is that of Lake Washington (Seattle, Washington). For many years, the lake had received wastewater treatment plant effluent, resulting in eutrophication. In 1963, the point source was diverted from the system. A significant reduction in summer chlorophyll and a return of the lake to a mesotrophic state was observed in subsequent years (Correll 1998).

\begin{tabular}{|l|l|}
\hline Table 2: Manifestations of Eutrophication and Metrics Used to Measure the Extent \\
\hline Manifestation & Metric \\
\hline $\begin{array}{l}\text { High Primary } \\
\text { Production }\end{array}$ & Chlorophyll, Algal Biomass \\
\hline Low Transparency & Secchi Disk Depth \\
\hline & $\begin{array}{l}\text { Areal Hypolimnetic Oxygen Deficit, Sediment Oxygen } \\
\text { Demand }\end{array}$ \\
\hline
\end{tabular}

Source: Chapra 1997

\subsection{Eutrophication, Organic Matter Diagenesis and Oxygen Resources}

A fraction of the organic matter produced in the water column is not biologically degraded in the water column and is ultimately deposited at the sediment-water interface. Within the sediment, particulate organic matter undergoes diagenesis (the sum of all the processes that cause a change to a sediment upon deposition, Berner 
1980; degradation, mineralization) and is converted to ammonia, carbon dioxide and methane. Oxygen consumed in the conversion of ammonia to nitrate, organic carbon to carbon dioxide and reduced species end products of diagenesis $\left(\mathrm{Mn}^{2+}, \mathrm{Fe}^{2+}, \mathrm{S}^{2-}\right.$ and $\left.\mathrm{CH}_{4}\right)$ to their oxidized counterparts is termed sediment oxygen demand (SOD). Two classes of SOD may be recognized. The resulting demand due to the diagenesis of recently deposited material, oxidized as it passes through the sediment's near-surface oxic microlayer may be termed surficial SOD (Matthews and Effler 2006). In certain systems, e.g. those with low primary production, all of the organic matter may be consumed as surficial SOD. However, in shallower and/or more productive systems, organic matter mineralization may extend further into an anoxic zone where deep SOD is exerted (Matthews and Effler 2006).

Within the oxic sediment microlayer, oxygen may be consumed both in direct heterotrophic respiration (mineralization of organic carbon to $\mathrm{CO}_{2}$ ) and in oxidizing reduced species (end products) formed during diagenesis (e.g. $\mathrm{Mn}^{2+}, \mathrm{Fe}^{2+}, \mathrm{H}_{2} \mathrm{~S}, \mathrm{CH}_{4}$ ). Ammonia formed in the diagenesis of organic nitrogen may also exert an oxygen demand when oxidized to nitrate (nitrification). Organic carbon mineralized using nitrate as the electron acceptor (denitrification) yields nitrogen gas as an end product and does not exert an oxygen demand (Canfield et al. 1993)

The contribution of anaerobic degradation to SOD becomes increasingly important in lakes that experience high rates of organic matter deposition and that thermally stratify ( i.e. the hypolimnion becomes isolated from the atmosphere; Wijsman et al. 2002). 
Here, a greater fraction of the SOD is exerted through oxidation of reduced species. Canfield et al. (1993) found that most of the oxygen flux into sediments is not used for the direct oxidation of organic carbon, but rather for the oxidation of reduced species. This is the case in the target system (Onondaga Lake, New York) where methane oxidation accounts for up to half of the oxygen consumption occurring through insediment reactions (Matthews et al. 2008).

If the SOD exceeds the rate of oxygen supply to the hypolimnion, the sediments and bottom water may become anoxic. Such conditions result in the death or extirpation of fauna (Gupta et al. 1996) and have significant impacts on chemical processes. For example, the burial efficiency of nutrients, namely phosphorus, is dependent on the overlying water oxygen concentration, with high rates of nutrient regeneration observed in anoxic waters (Ingall and Jahnke 1997). Similarly, bottom water oxygen concentrations control the flux of metal species, including methylmercury, from the sediment (Beutel et al. 2008). Finally, persistence of anaerobic conditions in the sediment leads to the accumulation of reduced species in the hypolimnion, creating an oxygen debt. At fall turnover, the reduced species are oxidized, creating a demand on oxygen resources that may influence the entire water column (Gelda and Auer 1996).

In addition to placing a demand on the oxygen resources of the lake, reduced species produced through diagenesis negatively impact the water column, the sediments and the atmosphere in other ways. Ammonia, the end product of organic nitrogen diagenesis and hydrogen sulfide, the end product of carbon mineralization with sulfate 
as the terminal electron acceptor, are toxic to aquatic life (Wijsman et al. 2002). Other gaseous products of diagenesis of organic carbon $\left(\mathrm{CO}_{2}, \mathrm{CH}_{4}\right.$, and $\left.\mathrm{N}_{2} \mathrm{O}\right)$ are potent greenhouse gases (Likkanen et al. 2002).

In this manner, the organic matter deposited at the sediment-water interface serves to mediate the environmental quality not only of the lake, but also inter-connected systems (e.g., air and soil). Further, the rate of organic matter deposition and its subsequent degradation play an important role in controlling the timing and extent of lake restoration. Here, legacy deposits of organic matter can be particularly important.

\subsection{The Significance of Legacy Deposits}

Sedimenting organic matter may undergo decomposition in the water column, in oxic surface sediments and in anoxic sediments at depth. Much of the labile organic carbon may be decomposed in the water column and surface sediments of even moderately productive lakes (Matthews and Effler 2006). However, rates of organic matter deposition in shallower, more productive systems often exceed the assimilative capacity of the water column and surface sediment, resulting in the accumulation and subsequent processing of labile organic matter in the deeper, anoxic layer. If inputs to the sediment remain constant for a sufficiently long period of time, the chemical character of those sediments (and the attendant diagenetic fluxes) will attain an equilibrium condition. The timing of the response of a lake to reductions in deposition rates (e.g., as may occur for organic matter through nutrient management) will be 
governed by the magnitude of non-equilibrium (legacy) deposits and the rate at which those deposits are purged through diagenesis and burial (preservation).

The lake response to loading reductions may be significantly slowed by the presence of legacy deposits. For example, it was noted by Larsen et al. (1979) that Shagawa Lake (a hypereutrophic system in Minnesota), did not respond as predicted to an $80 \%$ reduction in phosphorus loading from an adjoining wastewater treatment plant. This was especially notable during the months of July and August, when bottom waters were anoxic and there was significant recycling of phosphorus from the sediment. The lack of response to phosphorus loading reductions reflects the past culture of eutrophication for the lake. Thus, while it is certain that a lake must improve following loading reductions, the question remains, "when and to what extent" (see Cooke et al. 2005). The timing of the lake response to loading reductions has been quantified for ammonia and phosphorus in the target system, Onondaga Lake. The time to equilibrium following changes in external loading were predicted to be 20 (Wickman 1996) and 19-26 (Lewis et al. 2007) years for ammonia and phosphorus, respectively.

The response of legacy deposits of organic carbon to changes in deposition has not been similarly quantified. The considerations outlined above serve to identify the tasks associated with modeling organic carbon diagenesis and attendant processes in support of lake management. At its most fundamental, that effort requires a quantification of legacy organic carbon deposits, the rate of organic carbon deposition resulting from a 
particular management strategy and an understanding of the biogeochemical kinetics driving diagenesis.

\subsection{Organic Carbon Diagenesis}

A conceptual model for the fate of particulate organic carbon deposited at the sediment-water interface must take into account the susceptibility to decay of various carbon fractions, the ability of the sediment environment to support diagenetic processes (e.g. redox reactions and methanogenesis) and transformative processes such as preservation.

\subsubsection{Carbon Fractions}

The particulate organic carbon deposited at the sediment-water interface is heterogeneous in its composition, consisting of a diverse assortment of chemical entities. This carbon is not mineralized at a single and constant rate, but rather represents a continuum in susceptibility to decomposition. For this reason, diagenesis occurs over a broad spectrum of time scales ranging from days to millennia. In lake management applications, two fractions representing the endpoints of susceptibility to degradation are typically considered. The first represents carbon undergoing diagenesis over a time scale of decades. Referred to as the labile fraction, this carbon is biologically available and metabolized through aerobic and anaerobic processes (Froelich et al. 1979). The second class is termed refractory, and is stable over this

decadal timescale. Refractory carbon is advected through the sediment profile and 
ultimately buried without participating in biogeochemical reactions, e.g. the exertion of a sediment oxygen demand.

The labile carbon fraction includes substances having a variety of cellular origins and chemical structures, suggesting further categorization based on susceptibility to degradation. For example, Hedges et al. (1988) observed that phytoplankton-derived carbon was as much as five times more reactive in lake sediments than carbon originating from riverine sources. At a finer scale, Henrichs and Doyle (1986) found that specific structural components within an algal cell may decay at different rates. These results mirror those of Harvey et al. (1995) who found that decay rates differed for cellular proteins, carbohydrates, and amino acids and that the most labile portions became exhausted in near-surface sediments with the less labile fractions carried deeper into the profile. This pattern is consistent with the results of incubation experiments performed by Garber (1984; and references therein) showing a rapid reduction in carbon mineralization rates over a period of weeks as the more easily degradable carbon fractions became exhausted. In order to accommodate this range in degradability, from highly labile to refractory, labile carbon is sometimes partitioned into (sub)fractions $\left(G_{1}, G_{2}\right.$, etc; Berner 1980), each with a specific kinetic rate constant. Termed the multi-G approach, this conceptual model will be revisited subsequently.

\subsubsection{Terminal Electron Acceptors and Methanogenesis}

The rate at which organic carbon decomposition proceeds is a function of both the availability of metabolizable carbon fractions (differences in lability) and the nature of 
the chemical environment supporting diagenesis. Diagenesis occurs sequentially through a series of oxidation-reduction reactions followed by methanogenesis, the final step in organic matter decomposition. These redox processes require an electron donor (organic carbon) and a terminal electron acceptor (TEA, various) both of which are consumed in the reaction, generating carbon dioxide, methane and reduced species end products, often of environmental interest. The order in which the terminal electron acceptors are utilized (Table 3 ) is determined thermodynamically, with the electron acceptor having the highest free energy yield used first and subsequent reactions proceeding in order of decreasing free energy yield (Froelich et al. 1979). More thermodynamically favorable TEAs mediate faster and more efficient reactions (Capone and Kiene 1988). Oxygen is the most favorable electron acceptor, and thus is the first used. Once oxygen is consumed, nitrate, oxidized iron and manganese, and finally sulfate, may be utilized. While oxic mineralization happens as a one-organism process, anoxic mineralization requires multiple steps and multiple organisms(Kristensen 2000). These multiple steps include the fermentative breakdown of high molecular weight organic material to low molecular weight molecules that are mineralized (Kristensen 2000).

Below the layer of sulfate reduction, diagenesis continues via methanogenesis. Similar to other anaerobic carbon mineralization processes, the breakdown of organic carbon resulting in methanogenesis in sediments occurs as a step-wise process. The initial step of methanogenesis is the hydrolysis or fermentation of complex organic molecules into 
low-molecular weight compounds (Kristensen and Hansen 1995) that serve as intermediates in the process. As a result, methanogenesis requires other microorganisms in the sediment to form the necessary substrates (Zinder 1993). Methanogens can only utilize a limited number of substrate precursors, the most important of which in sediments are acetate and $\mathrm{H}_{2}$ (Zinder 1993; Capone and Kiene 1998).

Acetate-dependent methanogenesis usually contributes more to total methanogenesis than does $\mathrm{H}_{2}$-dependent methanogenesis, but the proportion varies (Conrad 1999). Whereas acetate-dependent methanogenesis is often found to be occurring at near the maximum rate, as proven by little increase in methanogenesis in sediments artificially amended with acetate in the laboratory (Winfrey and Zeikus 1979), methanogenesis via hydrogen utilization is often substrate limited (Strayer and Tiedje 1978). Proof of hydrogen limitation was provided by Winfrey et al. (1977) when hydrogen addition to sediments stimulated a higher rate of methanogenesis. Furthermore, Strayer and Tiedje (1978) showed that high hydrogen concentrations in the sediments were rapidly lowered to a small pool size also suggesting that the rate of methanogenesis in the sediments was controlled by the concentration of hydrogen.

Winfrey and Zeikus (1979) determined that the pool size of methanogenic precursors is small and turnover times rapid, suggesting that methane production is limited by precursor pool size. Therefore, the rate of methane production, and thus anaerobic carbon mineralization through methanogenesis, is controlled by the ability of 


\begin{tabular}{|c|c|c|c|}
\hline Process & Reaction & $\begin{array}{l}\text { Reduced } \\
\text { Species } \\
\text { Produced }\end{array}$ & $\begin{array}{l}\text { Moles of Oxygen } \\
\text { Required to Oxidize One } \\
\text { Mole of Reduced } \\
\text { Species }\end{array}$ \\
\hline $\begin{array}{l}\text { Oxic } \\
\text { Mineralization }\end{array}$ & $\begin{array}{l}\mathrm{CH}_{3} \mathrm{COOH}+2 \mathrm{O}_{2} \rightarrow 2 \mathrm{CO}_{2}+ \\
\mathrm{H}_{2} \mathrm{O}\end{array}$ & & None \\
\hline Denitrification & $\begin{array}{l}\mathrm{CH}_{3} \mathrm{COOH}+1.6 \mathrm{NO}_{3}^{-}+1.6 \\
\mathrm{H}^{+} \rightarrow 2 \mathrm{CO}_{2}+0.7 \mathrm{~N}_{2}+2.8 \\
\mathrm{H}_{2} \mathrm{O}\end{array}$ & $\mathrm{N}_{2}$ & None \\
\hline $\begin{array}{l}\text { Manganese } \\
\text { Reduction }\end{array}$ & $\begin{array}{l}\mathrm{CH}_{3} \mathrm{COOH}+4 \mathrm{MnO}_{2}+6 \mathrm{CO}_{2} \\
+\quad 2 \mathrm{H}_{2} \mathrm{O} \rightarrow 4 \mathrm{Mn}^{2+}+8 \\
\mathrm{HCO}_{3}^{-}\end{array}$ & $\mathrm{Mn}^{2+}$ & 0.50 \\
\hline Iron Reduction & $\begin{array}{l}\mathrm{CH}_{3} \mathrm{COOH}+8 \mathrm{Fe}(\mathrm{OH})_{3}+ \\
14 \mathrm{CO}_{2} \rightarrow 8 \mathrm{Fe}^{2+}+16 \mathrm{HCO}_{3}- \\
+6 \mathrm{H}_{2} \mathrm{O}\end{array}$ & $\mathrm{Fe}^{2+}$ & 0.25 \\
\hline $\begin{array}{l}\text { Sulfate } \\
\text { Reduction } \\
\end{array}$ & $\begin{array}{l}\mathrm{CH}_{3} \mathrm{COOH}+\mathrm{SO}_{4}{ }^{2-} \rightarrow 2 \mathrm{CO}_{2}+ \\
\mathrm{S}^{2-}+2 \mathrm{H}_{2} \mathrm{O}\end{array}$ & $\mathrm{H}_{2} \mathrm{~S}$ & 2 \\
\hline Methanogenesis & $\mathrm{CH}_{3} \mathrm{COOH} \rightarrow \mathrm{CH}_{4}+\mathrm{CO}_{2}$ & $\mathrm{CH}_{4}$ & 1 \\
\hline \multicolumn{2}{|c|}{ Source: Kristensen 2000, van Cappellen and Wang 1996} & & \\
\hline
\end{tabular}

microorganisms to ferment/hydrolyze particulate organic matter into methane precursors

(Winfrey and Zeikus 1979).

The traditional perspective for consideration of diagenesis, a sequence in time, is manifested in the sediments as a sequence in depth (downcore distance in the sediment is analogous to time since deposition). Thus, in sediments, the thermodynamic order of terminal electron acceptor consumption is represented by a vertical stratification. Exceptions exist to the idealized stratigraphy of electron acceptor consumption presented here. For example, there may be an overlap between the sequential terminal electron acceptor utilization zones (Kristensen 2000), which can be described using Monod inhibition kinetics. Infaunal burrowing, extending across the oxic-anoxic 
interface in the sediments, may supply oxygen to anaerobic regions, promoting the decay of oxygen-sensitive organic matter that had been advected below the oxic microzone (Kristensen 2000). Further complexity in redox stratigraphy may be imparted through deposition of fecal pellets, a form of particulate organic carbon with a high labile content. The electron acceptor demand of such particles is sufficient to create a localized terminal electron acceptor (TEA) deficiency, e.g. pockets of anaerobic sediment within the oxic layer (Kristensen 2000).

\subsubsection{The Rate of Diagenesis}

The availability of oxygen is considered to be the most important factor in determining the rate at which diagenesis proceeds. Aerobic degradation of labile organic matter may be performed by a variety of organisms, including bacteria, fungi, and micro- and macro fauna (Fenchel et al. 1998). The majority of these organisms have the ability to totally mineralize labile carbon, i.e. the process is completed by one organism (Kristensen 2000). On the other hand, there seems to be no single anaerobic organism capable of complete mineralization, thus a consortium of bacteria is required to accomplish anaerobic decomposition (Fenchel et al. 1998). Here, carbon mineralization proceeds stepwise, from the initial hydrolytic or fermentative breakdown of large organic molecules to smaller organic acids to the final conversion to water, carbon dioxide and reduced species end products by involving several different types of bacteria (Kristensen 2000). Stepwise diagenesis has been hypothesized as one reason that anoxic diagenesis proceeds more slowly than mineralization taking place in the 
presence of oxygen. Support for this hypothesis has been provided by Sun et al. (1993) who demonstrated experimentally that chlorophyll, a component of the organic carbon deposited at the sediment surface, decays at a much greater rate under oxic than under anoxic conditions. Further, Kristensen and Holmer (2001) reported that experimental trials suggested two stages of carbon decomposition. The first stage represented easily leachable, rapidly reacting POC that decayed at the same rate regardless of the terminal electron acceptor present. The second stage represented a slower-leaching fraction that decayed at a rate 5 to 10 times faster under oxic conditions than under anaerobic conditions.

\subsubsection{Kinetic Rate Coefficients}

Information on reaction rate coefficients (k-values) provides an important quantification of the descriptive and conceptual material presented above, shedding light on the dynamics of kinetic processes in the sediments. Kristensen and Holmer (2001) performed laboratory experiments exploring differences in $k$ values for three diagenetic pathways (oxic mineralization, denitrification and sulfate reduction; Table 4). Their experiments utilized fresh and aged diatom cultures as sources of organic matter. For fresh material a fast mineralization pathway was identified where the value of the rate coefficient $\left(k_{1}\right)$ was independent of the terminal electron acceptor available. For a parallel slow mineralization pathway, the value of the rate coefficient $\left(k_{2}\right)$ was five times greater in the presence of oxygen than with nitrate or sulfate serving as the 


\begin{tabular}{|c|c|c|}
\hline \multicolumn{3}{|c|}{ Fresh Material } \\
\hline & $\mathrm{k}_{1}$ & $\mathrm{k}_{2}$ \\
\hline Oxygen & $263+/-37 y^{-1}$ & $5.95+/-1.03 \mathrm{yr}^{-1}$ \\
\hline Nitrate & $277 \mathrm{yr}^{-1} *$ & $1.23 \mathrm{yr}^{-1} *$ \\
\hline Sulfate & $368+/-121 \mathrm{yr}^{-1}$ & $1.08+/-0.32 \mathrm{yr}^{-1}$ \\
\hline \multicolumn{3}{|c|}{ Aged Material } \\
\hline & $\mathrm{k}_{1}$ & $\mathrm{k}_{2}$ \\
\hline Oxygen & $306+/-156 \mathrm{yr}^{-1}$ & $8.59+/-1.02 \mathrm{yr}^{-1}$ \\
\hline Nitrate & $55.5 \mathrm{yr}^{-1} *$ & $0.60 \mathrm{yr}^{-1} *$ \\
\hline Sulfate & $84.2+/-17.2 \mathrm{yr}^{-1}$ & $0.79+/-.42 \mathrm{yr}^{-1}$ \\
\hline \multicolumn{3}{|c|}{ Source: Kristensen and Holmer 2001} \\
\hline \multicolumn{3}{|c|}{ * Only 2 data points available for analysis } \\
\hline
\end{tabular}

terminal electron acceptor. For aged material, values for both $k_{1}$ and $k_{2}$ were 5-10 times greater with oxygen than with nitrate or sulfate.

These results suggest the presence of two organic carbon fractions in both the fresh and aged material: one fraction $\left(k_{1}\right)$ exhibiting rapid decay and the other $\left(k_{2}\right)$ proceeding more slowly. For the fast fraction, rates for fresh and aged material are comparable with oxygen present, but are faster for fresh than for aged material when nitrate and sulfate serve as electron acceptors. For the slow fraction, differences between fresh and aged material are modest, but oxygen supports higher rates of mineralization than do nitrate or sulfate.

The work of Kristensen and Holmer (2001) serves to emphasize two important features of organic matter diagenesis. First, for the most part, oxic diagenesis proceeds more rapidly than does anoxic diagenesis. This is likely due to the fact that the organisms mediating oxic diagenesis produce stronger oxidizing agents than do the organisms performing diagenesis under anoxic conditions (Hulthe et al. 1998). The second is that susceptibility to degradation lessens with residence time in the sediment. This change is 
thought to result from the action of preservation mechanisms (see Section 1.4.5 below) which alter the nature of the organic matter over time. The single exception to this summary is the observation of Kristensen and Holmer (2001) that rate coefficients for fast mineralization of fresh material is the same, regardless of the electron acceptor (Table 4, k for fresh material; see also Kristensen et al. 1995), suggesting that anaerobes and oxic microorganisms are equally adept, at least initially, in leaching POC and hydrolyzing organic matter (Hulthe et al. 1998). This, however, may be explained by the fact that, initially, the organic matter has not been acted upon by preservation mechanisms.

Methanogenesis kinetics, not treated in the experimental work of Kristensen and Holmer (2001), are well described in the literature. The overall process occurs in steps, in a manner similar to other anaerobic pathways for organic carbon mineralization. Particulate organic carbon is solubilized through enzymatic hydrolysis yielding complex organic molecules that undergo further hydrolysis or fermentation to form low molecular weight methane precursors (Kristensen and Hansen 1995), most importantly acetate and hydrogen (Zinder 1993; Capone and Kiene 1998). Within this stepwise process, the methane precursors, turn over rapidly (less than 1 hour; Winfrey and Zeikus 1979), suggesting a high rate coefficient. This observation is consistent with the work of Strayer and Tiedje (1978) who found that sequential additions of hydrogen to the precursor pool were depleted rapidly, again suggesting a high rate of conversion, even at incubation temperatures of $10^{\circ} \mathrm{C}$ and $14^{\circ} \mathrm{C}$. Precursor formation, on the other hand, 
proceeds more slowly and is thus the rate-limiting step in methanogenesis (Winfrey and Zeikus 1979). Further, if it is the initial breakdown of organic matter feeding the dissolved organic carbon that controls the rate (see Kristensen 2000; Winfrey and Zeikus 1979), then all of the anoxic pathways should have similar reaction rate coefficients. This is precisely the case for diagenesis by nitrification and sulfate reduction as demonstrated in the work of Kristensen and Holmer (2001) as outlined above.

Care should be exercised in extrapolating specific rates from laboratory (e.g. Harvey et al. 1995, Kristensen and Holmer 2001, Lehmann et al. 2002) to field conditions, however, as experimental artifacts may significantly impact results. Confidence in rate constant estimates may be improved by examining in-place deposits collected as sediment cores. For example, Middelburg et al. (1996) looked at intertidal sediments of the Westerschelde Estuary and found first order decay coefficients averaging from 0.2 $\mathrm{yr}^{-1}$ to $7 \mathrm{yr}^{-1}$, with variations due to temperature and location within the estuary. More applicable to our research, Gälman et al. (2008) used the varved sediments of Lake Nylandssjön in northern Sweden to produce first order kinetic rate coefficients for diagenesis with respect to organic carbon mineralization. The analysis was completed by analyzing the changes in carbon and nitrogen over 27 years in each sediment varve, with ten cores collected between 1979 and 2007. The value for $k_{1}$ was $1.47 \mathrm{yr}^{-1}$ and $\mathrm{k}_{2}$ was $0.134 \mathrm{yr}^{-1}$. 


\subsubsection{Preservation}

At its simplest level, the accepted approach to understanding organic carbon diagenesis assumes that all of the labile carbon eventually undergoes diagenesis yielding carbon dioxide and/or methane, and that all of the refractory carbon is be buried. Recent research has demonstrated, however, that while the majority of the particulate organic carbon produced in the water column is highly labile and subject to mineralization, a fraction of it becomes protected from heterotrophic attack by various physical and chemical preservation mechanisms (Mayer 2004). It is known from the marine literature (see Hedges and Keil 1995) that such transformations occur at shallow sediment depths along the continental margins with environmental factors apparently "turning off" mineralization. The remaining organic carbon is thus 'preserved' and stored in the sediment matrix as it is buried. A rapidly evolving body of evidence from the marine literature (as reviewed below) suggests some of the mechanisms operative in the preservation process. This phenomenon has significant implications with respect to understanding and modeling the fate of organic carbon in sediments and especially in quantifying the significance of legacy deposits. These preservation mechanisms go beyond the characteristics of the carbon itself, as organic molecules of the same structure have been found to be present as both labile and refractory, indicating that protective matrices and environmental conditions must be involved in preservation (Wakeham and Canuel 2006). 
The rate and extent of that loss is determined by a suite of characteristics and processes defining the biological stability of the organic carbon: biochemical recalcitrance, sediment biological capability and capacity, physical methods of organic material protection, and duration of exposure to specific electron acceptors (Baldock et al. 2004). Biochemical recalcitrance is imparted to the carbon pool through incorporation of the labile fraction into the biomass of the sediment biota, making it unavailable for further reaction (Mayer 2004). Sediment biological capability describes the ability of the microbial community of the sediment to produce the enzymes necessary to degrade the organic matter, while capacity describes the magnitude of this capability (Baldock et al. 2004). Physical phenomena yielding protection of organic matter involve association with mineral particles (Hedges and Oades 1997; Baldock et al. 2004), where the total amount of carbon preserved varies with the surface area of the minerals (Mayer 1994a; Hedges and Keil 1995; Kennedy et al. 2006). Mechanisms identified as providing physical shelter from diagenesis include: direct sorption to the mineral surface, encapsulation in mineral microfabric signatures, and humification of material on the mineral surface (Curry et al. 2007).

These preservation methods are not to be considered mutually-exclusive. Rather, each mechanism is believed to act in a cumulative manner, contributing to the overall development of refractory material (Baldock et al. 2004; Mayer 2004). This cooccurring, cumulative process was verified by Curry et al. (2007), where the use of 
transmission electron microscopy identified carbon that was both sorbed to the mineral surface and encapsulated. These processes are explored in greater detail below.

\subsubsection{Direct Adsorption}

Organic matter has been observed (transmission electron microscopy) on the surface of large mineral pores where no organic carbon remained on the inside. This implies that surface adsorption alone plays a role in the protection of carbon from biological attack (Curry et al. 2007). The association of carbon with the mineral sediment matrix begins at deposition with organic carbon-mineral interactions occurring at the benthic boundary layer (Thompsen et al. 2002). Initially a low density aggregate, organic matter is removed through diagenesis leaving a higher density aggregate that becomes more and more resistant to carbon mineralization (Arnarson and Keil 2007). Eventually, the carbon-mineral aggregate reaches a point where the carbon is protected from biological degradation (Curry et al. 2007).

Multiple mechanisms have been proposed with respect to carbon preservation through surface adsorption. Each of these offers an acceptable explanation for the reduction in enzymatic activity associated with the adsorption hypothesis: steric hindrance of enzymes due to organic matter-mineral chemosorptive bonds (Clark 1974), enzyme adsorption into the mineral structure, and localized changes in $\mathrm{pH}$ close to the mineral surface (Naidja et al. 2000; Zimmerman et al. 2004).

1.4.5.2 Aggregation, Occlusion, Encapsulation in the Mineral Microfabric 
Mayer $(1994 a, b)$ first proposed that organic matter may be preserved in small nanopores through a process termed occlusion. While Mayer et al. (2004) showed that very little organic matter was found in such pores (casting some doubt on the significance of this preservation mechanism), Zimmerman et al. (2004) provided experimental evidence that the presence of nanopores does enhance the protection of organic carbon from degradation. They observed that less organic carbon was mineralized by digestive enzymes for minerals containing nanopores than with nonporous minerals.

The presence of organic molecules protected in pores was visually noted by Curry et al. (2007) using transmission electron microscopy. It was proposed that there exists a porosity that is accessible to organic material, but not to digestive enzymes. This hypothesis was based on the volume of a pore as it influences the encapsulation of organic matter in the microfrabric structure of the minerals where enzymes are unable to enter the confined pore space. The 'throat' of such pores may also play a major role in determining the overall carbon storage due to encapsulation and occlusion, i.e. pore throats that are small enough to block enzyme entrance to larger pore volumes (Mayer et al. 2004, Curry et al. 2007).

The encapsulation of organic matter happens through two ways, the formation of organic matter-mineral aggregates and occlusion of organic matter through compaction, which results in a decrease in sediment porosity. Aggregation of materials represents an authigenic mineral formation, where up to a $70-85 \%$ increase in resistance to 
mineralization is noted through the interaction of organic matter with mineral grains (Arnarson and Keil 2005). Occlusion, on the other hand, represents protection of the organic matter through the compaction of materials around it, creating small pores containing organic material that are inaccessible to enzymes (Mayer $1994 \mathrm{a}, \mathrm{b}$ ).

\subsubsection{Humification}

The extracellular formation of organic-organic linkages on mineral surfaces yields molecules that may be resistant to diagenesis. Such abiotic bonding of organic material, termed humification, produces strong covalent bonds that are difficult to break (Mayer 2004). It was noted by Hedges (1988) that high concentrations of organic molecules on mineral surfaces could lead to condensation reactions and the attendant production of organic macromolecules, i.e., humification that is often the first step in the formation of kerogens (Collins et al. 1995). Under the reducing conditions that prevail in anoxic sediments, these macromolecules would be protected from hydrolytic breakdown and considered refractory (Hedges and Keil 1995). The macromolecules would, however, be sensitive to the conditions prevailing in the sediment (Keil et al. 1994; Nguyen et al. 2002) behaving as labile constituents under oxic conditions and as refractory material below the limits of oxygen penetration (Hedges et al. 1999).

\subsubsection{Biological Protection}

Incorporation into biomass and necromass that persists within the sediment provides an additional mechanism for protection against mineralization (Mayer 2004). Even upon 
cell death (necromass; Ladd and Paul 1973) protection from degradation may be afforded through the inherent indigestibility of certain cell materials, especially those polymers that are difficult to hydrolyze or contained within biochemical matrices that are difficult to disassemble (Mayer 2004), especially under anoxic conditions.

The reversible storage of organic matter within bacterial biomass impacts not only preservation, but also the response of aquatic systems to reduced deposition (loadings). When organic matter is present in excess in the sediments, substrate availability promotes the storage of nutrients in biomass, reducing the amount of nutrient present in the dissolved phase and available to support internal loading (Schultz and Urban 2008). With reduced deposition (loading), bacteria enter a starvation phase and nutrients are released from the biomass, prolonging the time course of lake recovery (Schultz and Urban 2008).

While the incorporation of organic material into biomass represents a form of diagenesis (i.e. change), it does not result in an electron acceptor demand, as it is simply a conversion of carbon from one organic form to another. Rather, incorporation can provide a temporary refuge from mineralization for a fraction of the organic material, delaying the electron acceptor demand until starvation results in release. It is important to note that not all of the incorporated organic matter is released during starvation, as necromass remains as a refractory form of carbon even during this interval. 


\subsubsection{The Role of Redox Conditions and Reversibility of Preservation}

The availability of oxygen plays an important role in both the rate of diagenesis and in the degree of preservation. Harvey et al. (1995) reported that the percentage of the total carbon pool mineralized under anoxic conditions was considerably less than that undergoing diagenesis with oxygen, resulting in incomplete oxidation of the organic carbon pool. Gälman et al. (2008) reported that up to $30 \%$ more carbon is consumed in a permanently oxic system than in one that experiences seasonal anoxia: Lake Lugano (seasonally anoxic) degraded $15-20 \%$ of the total organic carbon within the first three years of deposition, compared to $25-28 \%$ for Lake Baldeggersee (aerated). Similarly, Lehmann et al. (2002) reported that the non-reactive carbon fraction maintained under sulfate-enriched anaerobic conditions was three times greater than that for oxygenated trials. Materials that are degraded in the oxic microlayer, but that are inert in the absence of oxygen, are termed conditionally labile (Keil et al. 1994, Nguyen et al. 2002).

Thus, the total amount of time that sediment is exposed to oxygen (OET, oxygen exposure time) before being removed from the oxic layer through burial directly determines the amount of organic material available for diagenesis (or that which is ultimately buried). Arnarson and Keil (2007) reported that as OET increases, less labile carbon remains. In addition, the relative role of the various preservation mechanisms is changed as the OET increases. For example, concentrations of organic macromolecules are less in systems with a longer OET (decreasing the importance of this form of preservation), while mineral (adsorption, encapsulation) and biota (biological 
protection) storage become more significant. This variation in the relative importance of the various preservation mechanisms with changes in OET suggest that the amount of conditionally-labile material present is related to the sediment residence time in the oxic horizon.

The idea that oxygen plays an important role in the preservation of organic material in the sediments is validated through the concept of reversibility. Keil et al. (1994) exposed deep sediment, some of which had been buried away from oxygen for a period of almost 500 years, to oxygen and rapid mineralization of carbon occurred within days. Thus, labile organic material can be protected from diagenesis through the mechanisms proposed above. Hulthe et al. (1998) also found that enhanced oxidation of older organic material was possible through exposure to oxygen.

\subsection{Modeling Carbon Diagenesis}

In its application to lake management, interest in the diagenesis of organic matter typically focuses on the consumption of electron acceptors important to ecosystem health (e.g. oxygen) and the production of metabolic end products that may have negative impacts on water quality (e.g. ammonia and hydrogen sulfide). Viewed in the broadest sense, the task becomes one of quantifying the rate of organic carbon diagenesis and the attendant rates of TEA consumption. A mass balance particulate organic carbon in a slice of the sediment would include terms for transport (i.e. burial) and reaction (i.e. diagenesis), 


$$
\frac{\partial C}{\partial t}=\underset{\substack{\text { transport reaction } \\ \text { reans }}}{-\omega \cdot \frac{\partial C}{\partial z}-k \cdot C}
$$

where: $\quad \omega=$ sediment burial velocity, $\mathrm{m} \cdot \mathrm{yr}^{-1}$

$$
\begin{array}{ll}
\mathrm{C}= & \text { particulate organic carbon concentration, } \mathrm{mgC} \cdot \mathrm{gDW}^{-1} \\
\mathrm{k}= & \text { rate constant for organic carbon diagenesis, } \mathrm{yr}^{-1} \\
\mathrm{t}= & \text { time, } \mathrm{yr} \\
\mathrm{z}= & \text { depth in sediment, } \mathrm{m}
\end{array}
$$

Here, the reaction rate is assumed to be first order with respect to the carbon concentration (Berner 1980) and the burial velocity is a function of the sedimentation rate, thus,

$$
\omega=\frac{S}{\rho \cdot(1-\phi)}
$$

where: $\quad S=$ sedimentation rate, $\mathrm{gDW} \cdot \mathrm{m}^{-2} \cdot \mathrm{yr}^{-1}$

$\rho=\quad$ sediment dry density, $\mathrm{gDW} \cdot \mathrm{m}^{-3}$

$\phi=$ porosity, dimensionless

Equation 1 reduces to a first order differential equation when the slice is followed in time,

$$
\frac{d C}{d t}=-k \cdot C
$$

The analytical solution for the diagenetic equation presented above as Equation 3 describes the labile carbon remaining at time $t$ as a function of the initial labile carbon content $\left(C_{0}\right)$, the rate constant, and the time since deposition, 
$C_{t}=C_{0} \cdot e^{-k \cdot t}$

In sediments, the time since deposition is related to the depth in the sediment through the burial velocity. Therefore, each location in the sediment is a representation not only of depth below the surface, but also of the time since deposition,

$t=\frac{Z}{\omega}$

As previously noted, the organic matter deposited at the sediment-water interface is not homogeneous. Inherent variations in reactivity may be accommodated by identifying sub-fractions (G) with differing lability and assigning sub-fraction-specific diagenesis rate constants. Westrich and Berner (1984) partitioned organic carbon into three components: fast and slow reacting labile fractions, undergoing diagenesis according to first order kinetics, and a refractory fraction that does not react over the decadal time scale. Mathematically, the time of rate of change in particulate organic carbon is described using the general form of Equation 4, with each sub-fraction described individually,

$C_{t}=C_{l, \text { fast }, 0} \cdot e^{-k_{\text {fast }} \cdot t}+C_{l, \text { slow }, 0} \cdot e^{-k_{\text {slow }} \cdot t}+C_{\text {refractory }}$

This approach may be extended to any number of sub-fractions (i), e.g.

$C_{t}=\sum\left(C_{l, i, 0} \cdot e^{-k_{i} \cdot t}\right)+C_{\text {refractory }}$ 
In some applications (e.g. Tromp et al. 1995, Boudreau 1996, and Van Cappellen and Wang 1996) only a single labile fraction and a refractory fraction are utilized. However, it is more common to employ a multi-G approach (Equation 6; Klump et al. 1989; Carignan and Lean 1991; Harvey et al. 1995; Soetaert et al. 1996; Kristensen and Holmer 2000; and Canavan et al. 2006) with fast and slow decaying fractions that have kinetic rate coefficients differing by one to two orders of magnitude (Kristensen and Holmer 2001).

As adopted by a variety of researchers, the level of complexity of such models (e.g. treatment of bioturbation and mineral phase development) varies dramatically. These are powerful tools that, once parameterized, calibrated and validated, may be applied in testing water quality management scenarios (Tromp et al. 1995). In such applications, the models seek to integrate biological, chemical and physical processes in the sediment as they influence organic carbon fate and water column dynamics in electron acceptors and reduced species end products following changes in external nutrient loads (Tromp et al. 1995).

As previously stated, the G-model assumes that first order kinetics (rate is controlled only by the concentration of organic carbon) drive the mineralization of organic carbon. Applied in this fashion (Equations 8 and 9), the approach to quantification of diagenesis implies that the mineralization of organic carbon is solely a first-order function of the labile organic carbon concentration. Variations in rate due to such factors as microbial biomass, the diagenetic pathway and the electron acceptor concentration are not 
accommodated (Tromp et al. 1995). Thus, the fraction-specific rate coefficient for organic carbon diagenesis is constant over the profile and the rate of diagenesis varies only with amount of organic carbon remaining. Despite not accommodating important components of the diagenetic picture, there has been some degree of success in reproducing the downcore organic profile independent of the distribution of porewater species (Soetaert et al. 1996).

\subsubsection{Steady-State Deposition}

Application of the model framework represented in Equations 6 and 7 requires specification of an initial condition defining the relative contributions of the labile and refractory carbon pools. The challenge presented here is best understood through a consideration of downcore sediment profiles of organic carbon under conditions of steady state and non-steady state deposition.

Assuming the presence of a single labile organic carbon fraction, a lake that has experienced a constant rate of organic carbon and sediment deposition over a long period of time (i.e. the sediment is at steady state with the deposition rate) will have a downcore organic carbon profile as described by Equation 7 and illustrated in Figure 1. The concentration at the surface is equal to that at deposition and decreases exponentially with depth due to diagenesis of the labile fraction. The asymptote of the total organic carbon profile (labile carbon is exhausted) is equal to the refractory carbon fraction. 


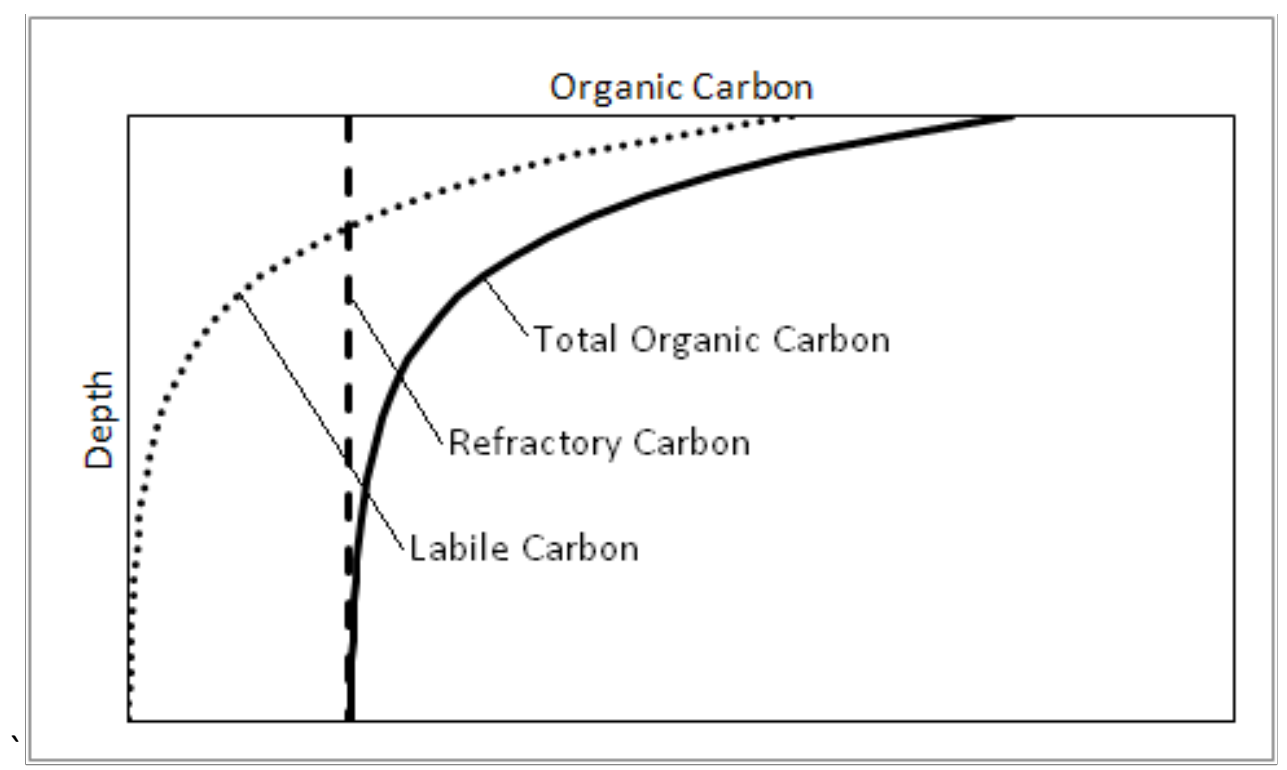

Figure 1: Steady-State Carbon Deposition Sediment System. The organic carbon content of a hypothetical sediment system as a function of depth. The shape represents a rectangular hyperbola with carbon mineralized as a function of depth (time). The asymptote is equal to the refractory fraction of carbon.

The labile carbon reservoir of the sediment is described by the area between the total organic carbon curve and that for refractory carbon (shaded area in Figure 2). The electron acceptor demand of the sediment is proportional to the shaded area and will vary in time only as the rate of particulate organic carbon deposition changes. 


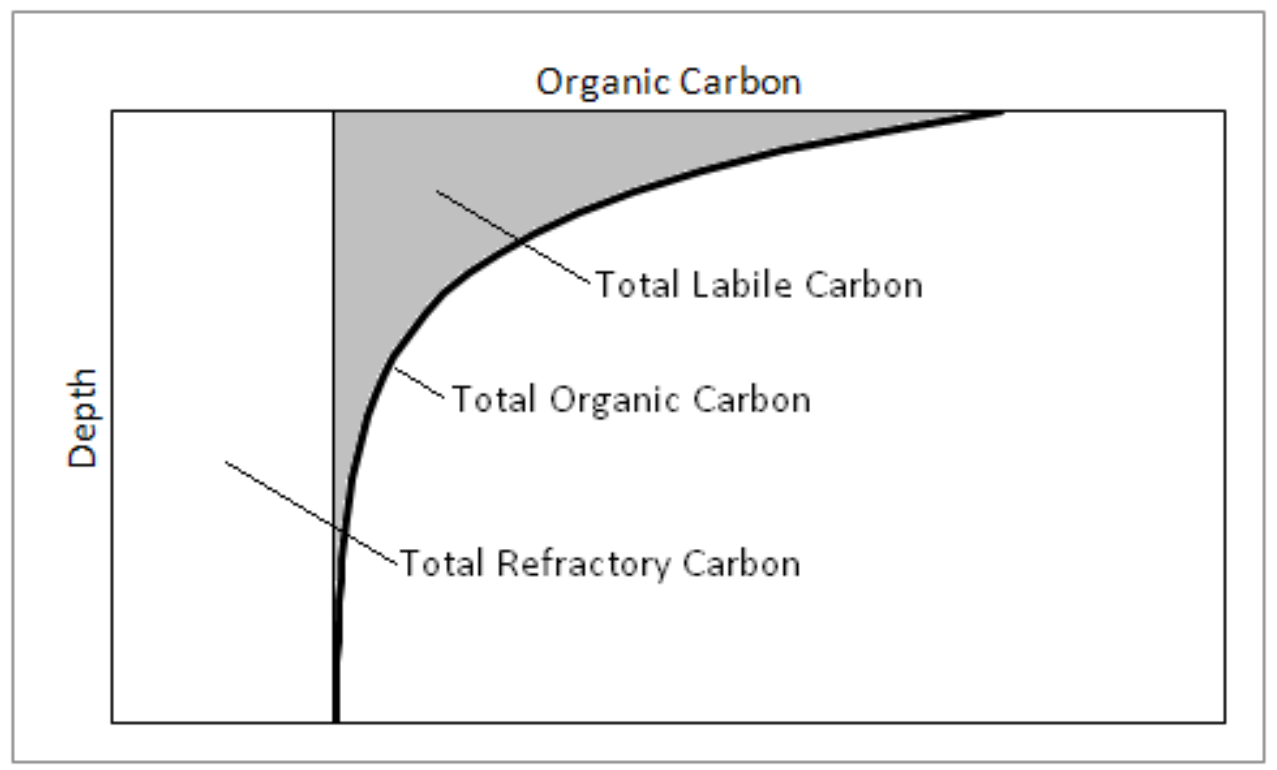

Figure 2: The Labile Carbon Fraction. The total labile fraction of carbon is depicted as the difference between the total carbon curve and the total refractory pool. The shaded area, the total labile carbon, is responsible for exerting SOD.

This treatment may be expanded to include a second labile fraction as illustrated in Figure 3. Such an approach is important where carbon of differing labilities is present and a single rate constant does not appropriately describe the profile. 


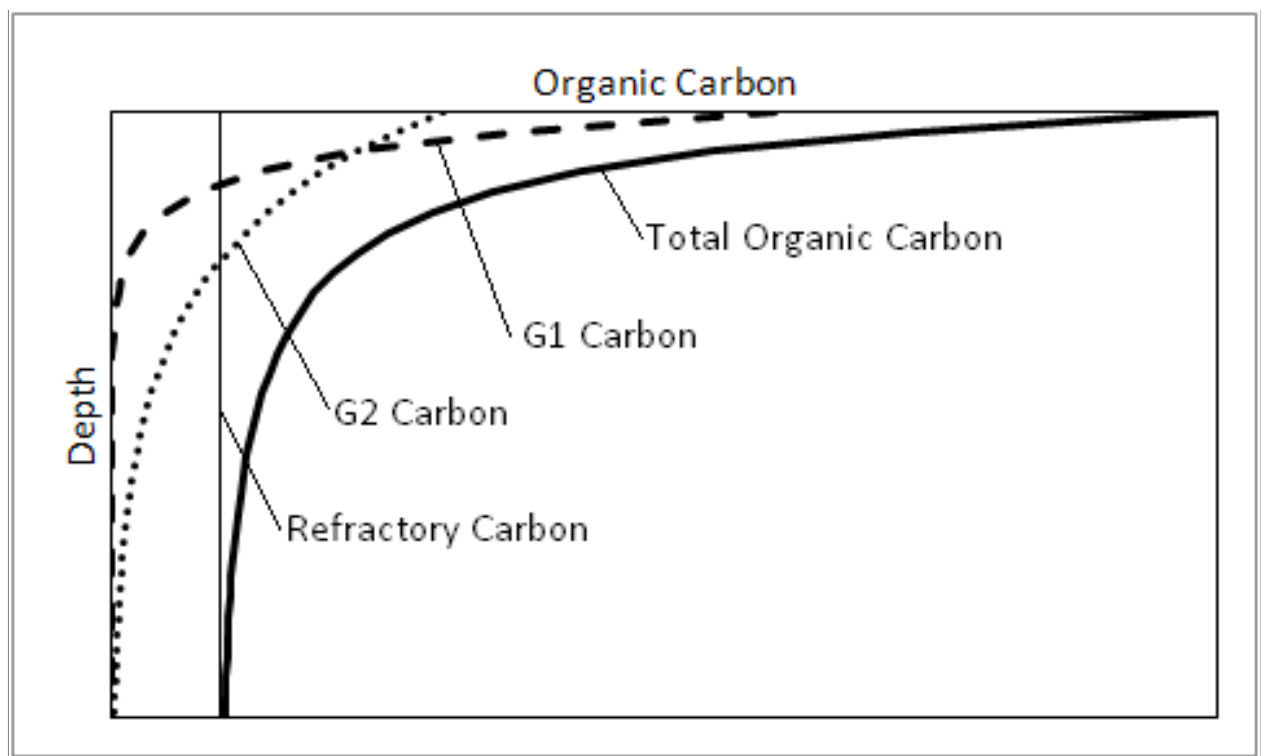

Figure 3: 3G Carbon System. A graphical depiction of a three fraction carbon diagenesis system, based on the traditional Berner model. The total carbon is the summation of the $G 1, G 2$, and refractory fractions.

\subsubsection{Non Steady-State Deposition}

This quantification of an initial condition for a system maintained at steady state with its inputs is reasonably straightforward. However, few natural systems exhibit this steady state due to changes in sedimentation rate (e.g. inputs of terrigenous solids) and/or organic carbon deposition (e.g. nutrient loading and attendant water column primary production). The carbon profile for a system experiencing non-steady-state deposition will depart markedly from the simple exponential decay characteristic of the steady state case. The idealized profile presented as Figure 4 represents a system that historically experienced eutrophication and was subsequently subjected to nutrient 


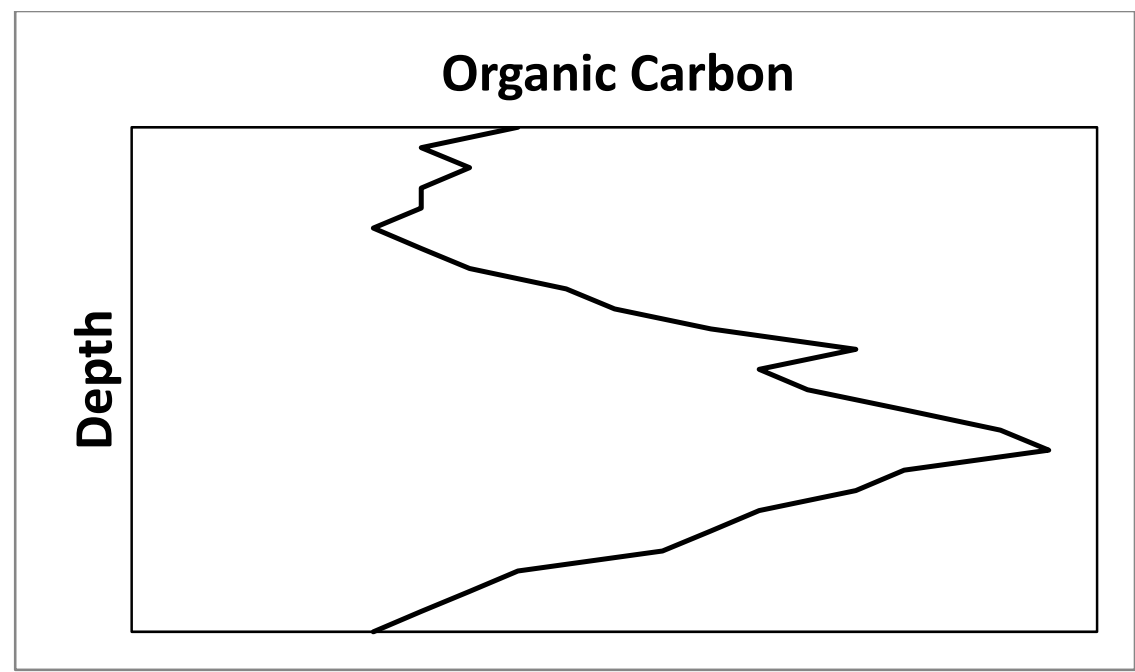

Figure 4: Idealized Non-Steady State Lake TOC Profile.

management. The challenge of quantifying legacy deposits of organic carbon, i.e. spatially defining and quantifying the labile carbon pool for the case of non-steady-state deposition, provides the motivation for this research. 


\subsection{Study Site}

Onondaga Lake is located in central New York in and adjacent to the city of Syracuse. The lake is a dimictic system with a surface area of $12 \mathrm{~km}^{2}$, a volume of $1.31 \times 10^{8} \mathrm{~m}^{3}$, a mean depth of $10.9 \mathrm{~m}$, and a maximum depth of $19.5 \mathrm{~m}$. The lake flushes rapidly, with a hydraulic residence time of about 3 months on a completely mixed basis (Effler 1996). As a result, the water column of Onondaga Lake has the capacity to respond quickly to external loading changes and the system response to restoration efforts is governed largely by the sediments.

\subsection{History of Cultural Eutrophication}

Paleolimnological studies (Rowell 1996) have shown that Onondaga Lake was an oligomesotrophic system prior to settlement in the late 1700s. Anthropogenic inputs, including domestic and industrial wastes, severely damaged the water quality of Onondaga Lake through the twentieth century (Effler 1996). The major discharger of domestic effluent is the Metropolitan Wastewater Treatment Plant (METRO) which provides, on an annual basis, $20 \%$ of the lake inflow and $85 \%$ of the bioavailable phosphorus (Effler et al. 2002). This nutrient loading has resulted in hypereutrophic conditions, as manifested in high levels of algal biomass and primary production (Matthews 2008). The areal hypolimnetic oxygen deficit is high as well and hypolimnetic anoxia has historically been realized by late June or early July (Matthews and Effler 2006). Anoxia is typically accompanied by accumulation of reduced species end 
products (associated with diagenesis) in the hypolimnion (Gelda et al. 1995) and, in some cases, evasion to the atmosphere (Likkanen et al. 2002).

\subsection{History of Industrial Pollution}

Direct and indirect inputs of waste materials from a soda ash manufacturing facility operating on the west shore of the lake from 1884 to 1986 are the primary source of ionic industrial pollutants. Compared to other systems in the region, the lake is uncharacteristically saline (Effler and Matthews 2003), a result of the discharge of ionic industrial wastes (including $1.0 \times 10^{9} \mathrm{~kg}$ annually in the forty-six years before closure). High concentrations of certain ions, particularly $\mathrm{Ca}^{2+}$, enhanced particle coagulation and increased the depositional flux (Weilenmann et al. 1989). This accelerated the removal of phytoplankton from the trophogenic layer of the lake (Effler et al. 2001), resulting in an increased downward flux of organic carbon.

The other major source of industrial pollution is a chlor-alkali facility, also located on the western shores of the lake. It is estimated that approximately $78,000 \mathrm{~kg}$ of mercury was discharged to Onondaga Lake from this facility between 1946 and 1970 (Wang and Driscoll 1995). While mercury inputs were decreased substantially after 1970, the concentrations of mercury are high in the water, sediments and fish of Onondaga Lake (Wang and Driscoll 1995). Mercury pollution is the focus of a major remediation program presently under way at upland, shoreline and nearshore sites along the lake (United States District Court 2007; see discussion following). 


\subsection{Recent Improvements in Onondaga Lake}

Closure of the soda ash facility and treatment upgrades at METRO have resulted in significant improvements to water quality in Onondaga Lake. A 61\% decrease in salinity was noted following the closure of the soda ash facility, accompanied by a $65 \%$ reduction in calcium ion concentrations (Effler et al. 2001). Reduced coagulation of particles associated with the change in calcium levels has been proposed as the primary explanation for an observed $37 \%$ reduction in the downward flux of particulate organic carbon (Jackson and Lochmann 1992; Matthews et al. 2008;). A 14-fold reduction in the METRO phosphorus load between 1978 and 2005 has resulted in a 3-fold reduction in primary production, further contributing to changes in the rate of organic carbon deposition (Effler et al. 2008). The lake's areal hypolimnetic oxygen deficit has been more than halved over the twenty-seven year period from 1978 to 2004 (Matthews et al. 2008) as sediment oxygen demand approaches equilibrium with contemporary rates of organic carbon flux to the sediments (Matthews and Effler 2006).

\subsection{Organic Carbon Diagenesis and the Remediation of Mercury Pollution}

Mercury contamination of Onondaga Lake sediments and attendant recycling to the water column represent the greatest unresolved barrier to lake recovery. This issue merits further attention here as carbon diagenesis plays an important role in mediating mercury transformation and cycling. Ionic mercury may undergo microbial conversion to methylmercury, a form that bioaccumulates and is potentially toxic to aquatic organisms and humans. In some systems, including Onondaga Lake, methylmercury 
formation is localized in the sediment, creating a legacy impact tied to historical mercury pollution.

The principal pathway for methylmercury formation involves sulfate-reducing bacteria (Compeau and Bartha 1985) and requires biologically-available mercury, sulfate (as the electron acceptor) and organic carbon (as the electron donor) (Lambertsson 2006). The presence of electron acceptors with a thermodynamic favorability greater than that of sulfate will inhibit sulfate reduction (Van Cappellen and Wang 1996). Thus, sulfate reduction (and mercury methylation) occurs downcore from the heterotrophic decomposition and denitrification fueled by oxygen and nitrate, respectively. Methylmercury formed at depth diffuses upward (and downward) encountering such other redox environments as may be present seasonally. When oxygen and/or nitrate are present, methylmercury diffusing toward the sediment-water interface is either demethylated biotically and abiotically, yielding methane and ionic mercury (Morel et al. 1998), or adsorbed to iron (hydr)oxides and manganese oxide (which are only present in non-reduced sediments; Desauziers et al. 1997). In the absence of these sink processes, i.e. oxygen and nitrate being depleted, methylmercury diffuses from the sediments and accumulates in the water column (Todorova et al. 2009).

Rates of organic carbon deposition and subsequent diagenesis impact this process in two ways. First, a reduction in the organic matter deposition rate will be accompanied by a reduction in electron acceptor demand, extending the time interval over which oxygen and nitrate are available in the sediment to promote methylmercury absorption 
and/or demethylation. Second, a reduction in the input of organic carbon will mean that less carbon will be available to support sulfate reduction/methylation. This, together with deep burial of legacy deposits of ionic mercury, may represent a viable approach to the long term remediation of mercury contamination. Interim control of methylmercury flux may be achieved through a program of electron acceptor augmentation (nitrate and/or oxygen; Effler et al. 2009). It has recently been observed that increases in the nitrate loading to the lake from METRO (resulting from enhanced nitrification) have extended the duration of nitrate presence in the hypolimnion and reduced methylmercury flux from the sediments (Effler and Matthews 2008). 


\subsection{Objectives and Approach}

The research presented here will ultimately support development of a model of organic carbon diagenesis, electron acceptor consumption and reduced species end product generation in the sediments of Onondaga Lake. More specifically, this research will focus on the diagenetic component of the generalized sediment mass balance presented above as Equation 1, conceptualizing and quantifying that kinetic framework and establishing,

- the labile fraction of organic carbon at deposition;

- the contemporary distribution of labile organic carbon in the sediment profile; and

- $\quad$ kinetic rate coefficients for carbon diagenesis

Fundamental to this task is the ability to partition particulate organic carbon (POC) into labile and refractory fractions. It is these requirements, conceptually characterizing an appropriate diagenetic framework and populating that framework with model coefficients and inputs derived on a site-specific basis, that form the objectives of this research.

The approach applied here proceeds from measurement of the POC content of sedimenting material (as determined from sediment trap collections) and at depth within the sediment (as determined through analysis of cores). Next bioassays are performed to assess the lability of the POC in the trap collections and in the cores. Bioassays are conducted under oxic and anoxic conditions to explore differences in 
lability in the presence and absence of oxygen. Finally, a contemporary POC profile (2008) and a historical POC profile (1995) are examined in light of bioassay results and considered within the context of a proposed kinetic framework incorporating the processes and coefficients outlined above. 


\subsection{Materials and Methods}

This research effort combines laboratory measurements and bioassays performed at Michigan Technological University between 2008 and 2009 with historical data available for Onondaga Lake provided by Upstate Freshwater Institute (Syracuse, New York) and findings of an earlier study of carbon diagenesis in Onondaga Lake (Stromquist 1996).

\subsection{Sediment Collection}

Gravity cores, $\sim 60-75 \mathrm{~cm}$ in length, were collected at the South Deep station $(19 \mathrm{~m}$ depth) in Onondaga Lake on 20 May 2008 and on 25 May 2009 and stored on ice for transport to the laboratory. Sediment was extruded under aerobic conditions at the laboratories of Upstate Freshwater Institute (2008) and Michigan Tech (2009), collecting slices $0.5(0-20 \mathrm{~cm}), 1.0(20-60 \mathrm{~cm})$ and $2.0(>60 \mathrm{~cm}) \mathrm{cm}$ in thickness. The extruded sediments were placed in Whirl-Paks and stored in a climate-controlled chamber at $4{ }^{\circ} \mathrm{C}$ until analyzed or utilized in laboratory bioassays. Sediment trap samples were provided by Upstate Freshwater Institute from collections made at the South Deep station in June and July 2009.

\subsection{Total Organic Carbon Measurement}

The theoretical development of carbon diagenesis presented above focuses on POC, the form deposited at the sediment-water interface. Once resident in the sediment, organic carbon is leached from the particulate phase and a dissolved organic carbon (DOC) pool is established. The analytical approach to measuring organic carbon applied here 
determines total organic carbon (TOC). For samples generated from lability bioassays, TOC POC as the particulate carbon is separated from the liquid medium prior to analysis. Core samples contain both $\mathrm{DOC}$ and $\mathrm{POC}$ and the TOC analysis performed here thus includes both fractions. For a typical eutrophic lake sediment $(\phi=0.9, \mathrm{POC}=10 \%$ $\mathrm{DW}$ and $\mathrm{DOC}=10 \mathrm{mgC} / \mathrm{gDW})$, however, the mass of carbon present as DOC is negligible $(<<1 \%)$ and the assumption that TOC POC remains valid.

Total organic carbon was determined, in triplicate, using a Thermo Electron Corporation Flush EA1112 Series NC Soil Analyzer (TOC Profile) or a Fisons NA 1500 Elemental Analyzer (TOC Profile, Sediment Bioassays). Sample preparation is required to remove carbonate (an inorganic form of C) what would otherwise be included in the measurement. Carbonate removal was accomplished through fumigation with concentrated $\mathrm{HCl}$ for samples derived from sediment trap samples and sediment bioassays (low sample mass) and through addition of $1 \mathrm{~N} \mathrm{HCl}$ (Stromquist 1996) for sediment profile samples (high sample mass).

\subsection{Lability Bioassays}

The guiding paradigm for lability bioassays was that a sediment sample, dispersed within a liquid medium mimicking the ambient environment and maintained at a favorable temperature will undergo mineralization with the metric for labile carbon (carbon or oxygen consumption) reaching an asymptote over time indicating completion of the reaction. Assays were performed under oxic and anoxic conditions in recognition of the reported difference in rates of diagenesis for those conditions (Kristensen and 
Holmer 2001). The liquid medium was artificial lake water (ALW) having an ionic composition similar to that of Onondaga Lake (Appendix D).

Assays were performed on particulate matter derived from sediment trap collections (to determine lability at deposition) and on samples obtained at selected depths (to determine lability of legacy deposits) over the entire length of a core. For oxic bioassays, an aliquot of sample (0.1-0.3 g wet weight sediment) was placed into a 300 $\mathrm{mL}$ BOD bottle filled with ALW. The bottle was aerated for twenty minutes to remove any accumulated reduced species through reaction or evasion to the atmosphere, then sealed and incubated at either $30{ }^{\circ} \mathrm{C}$ or $8^{\circ} \mathrm{C}$ in a revolving chamber that provided continuous mixing at a rotational rate of about 30-45 revolutions per minute. Oxygen concentrations were measured daily (initially and at intervals of several days as the reaction rate slowed) and the bottles were aerated following measurement to ensure that oxygen levels remained above $2.0 \mathrm{mg} / \mathrm{L}$ to avoid the potential of anoxia. The total amount of oxygen consumed (shown by the examples presented in Figure 5), expressed as carbon via stoichiometric conversion $\left(1\right.$ mole $\mathrm{O}_{2}$ consumed per 1 mole of carbon consumed), was then compared to the initial sample TOC and a labile fraction (\%) calculated. Nitrification was accounted for by measuring the change in the nitrate concentration and subtracting the resultant oxygen consumption from the bioassay results. 


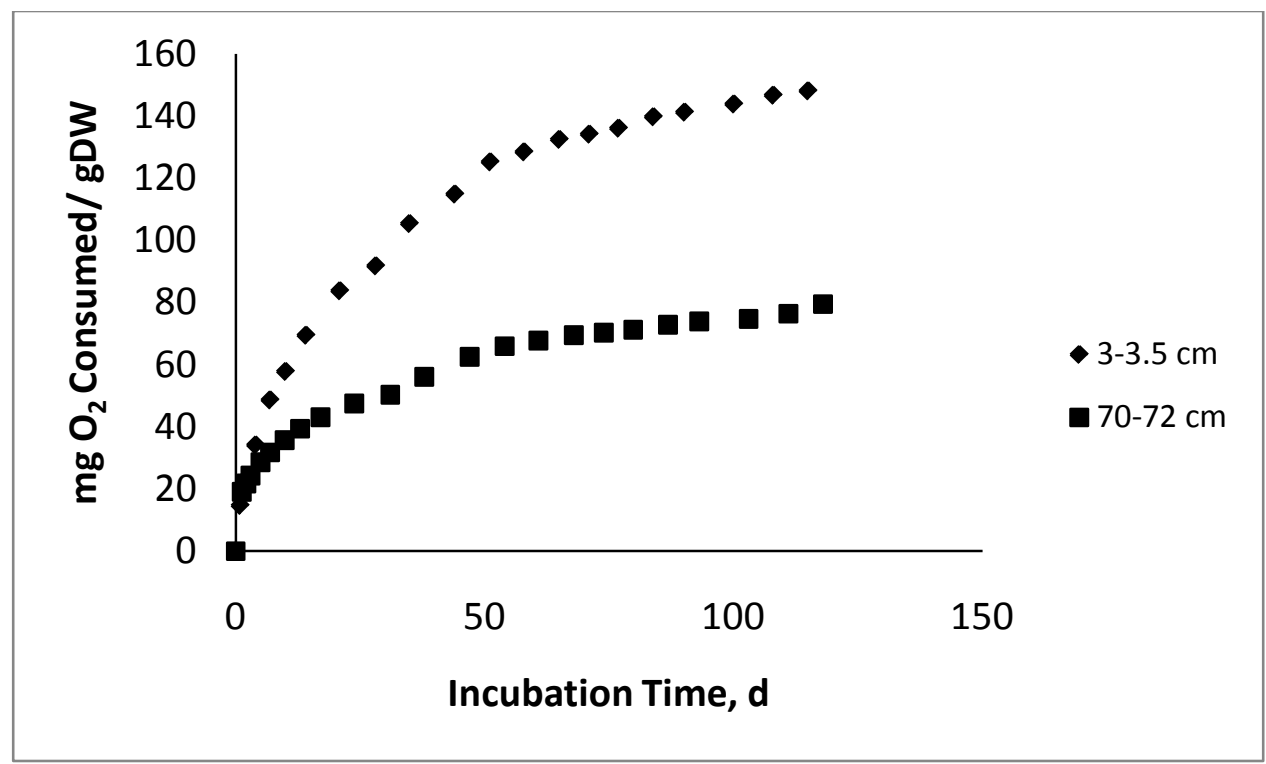

Figure 5: Representative results of oxic bioassays conducted on sediment collected at depths of 3-3.5 and 70-72 cm in the core.

In addition, direct TOC measurements were completed for some of the samples to provide validation that the oxygen consumption method of finding TOC lability was usable. The comparison of the results showed a good match between the two methods at calculating the percent lability, as shown in the figure below. In addition, a statistical analysis was performed to determine significant difference between the direct TOC measurements and oxygen-consumption derived carbon consumption. In nine assays utilizing sediment from identical (4) or proximate (5; average difference $3 \mathrm{~cm}$ ) depths, the two approaches were compared to determine if they yielded comparable estimates of lability. There was no significant differences $(p<0.05)$ between the oxygen and carbon consumption methods for 7 of the 9 assays. 


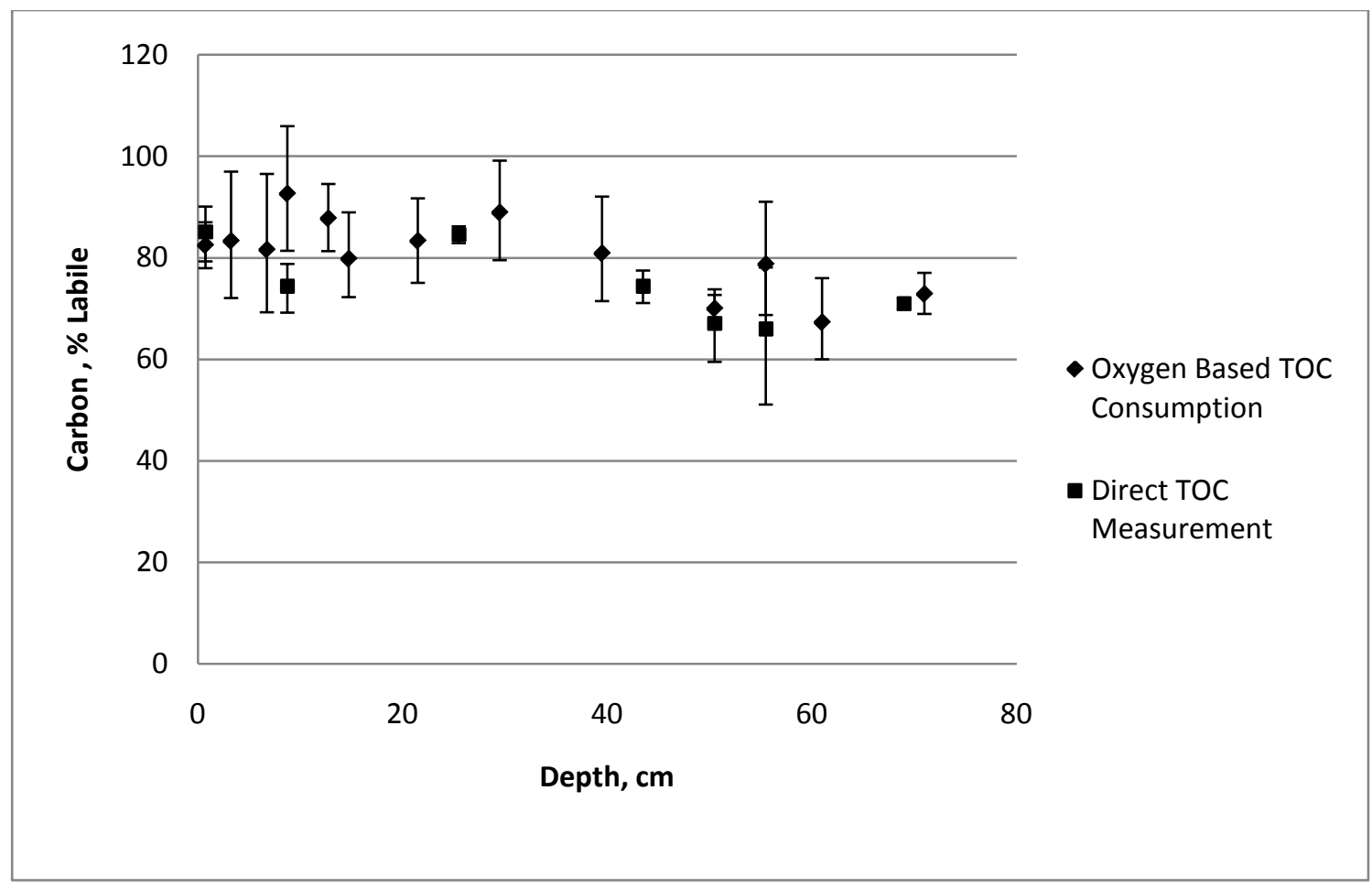

Figure 6: Validation of the oxygen consumption method. The oxygen derived TOC measurements are compared to direct TOC measurements to validate the method used.

For anoxic bioassays, replicate aliquots of sample ( $0.5 \mathrm{~g}$ wet weight sediment) were placed in $40 \mathrm{~mL}$ vials filled with ALW, sealed against oxygen penetration and incubated in a revolving chamber (30-45 revolutions per minute) that provided continuous mixing. The vials were kept at temperatures of $30^{\circ} \mathrm{C}$ and $8^{\circ} \mathrm{C}$. Vials were harvested at intervals of 2.5 days initially and at intervals of 15 days as the reaction rate slowed and subjected to TOC analysis. Once an asymptote was reached, the labile carbon content (\%) was determined by comparison to the initial TOC. Figure 7 shows two representative depths and the corresponding decrease in TOC over the incubation period of the experiment. Methanogenesis was the main anoxic process present in the anoxic bioassays, with the 
potential of sulfate reduction due to the sulfate in the artificial lake water (Appendix D). The artificial lake water was purposely kept free of nitrate to avoid potential denitrification.

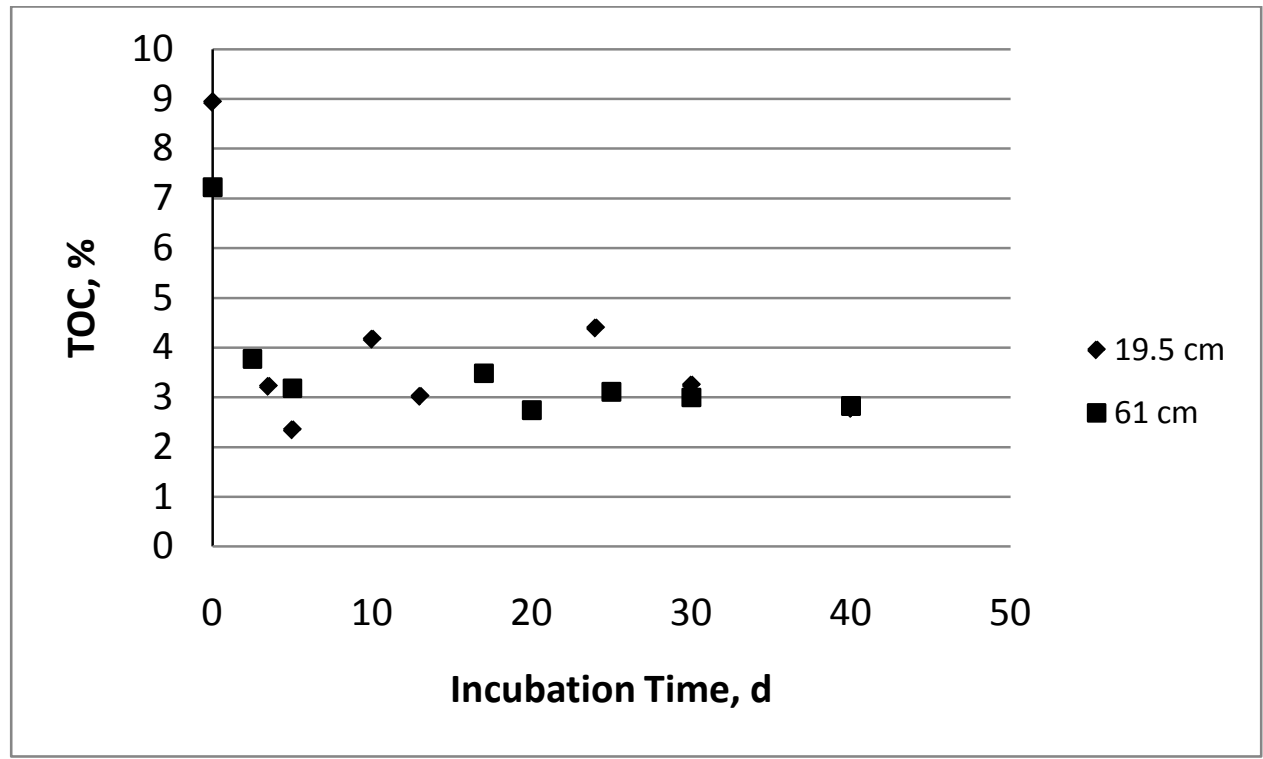

Figure 7: Representative results of anoxic bioassays conducted on sediment collected at depths of 19.5 and $61 \mathrm{~cm}$ in the core.

Sediment trap material was also tested, with the same experimental setup as described above for oxic and anoxic assays. The oxic sediment trap assays were run at a temperature of $35^{\circ} \mathrm{C}$ and the anoxic sediment trap was analyzed at $8^{\circ} \mathrm{C}$. In both cases, direct TOC measurement was used to calculate lability.

\subsection{Analysis Based on Profiles}

Sediment cores collected in 1995 and 2008 were compared to gain insights regarding the fate of labile organic carbon (e.g., the dimensions of an active sediment layer and the rate at which it undergoes diagenesis). TOC profiles were depth adjusted based on 
sedimentation rate and sediment characteristics (Appendix E), with sediment and carbon data providing a window into diagenesis near the surface wabove the depth of the 1995 profile. The area between the profiles represents the carbon consumed over the 14-year interval, and the confluence of the profiles established the active sediment depth. Figure 8 below graphically represents both the carbon consumed between the two profiles over the interval of time between measurement and the edge of the active sediment layer.

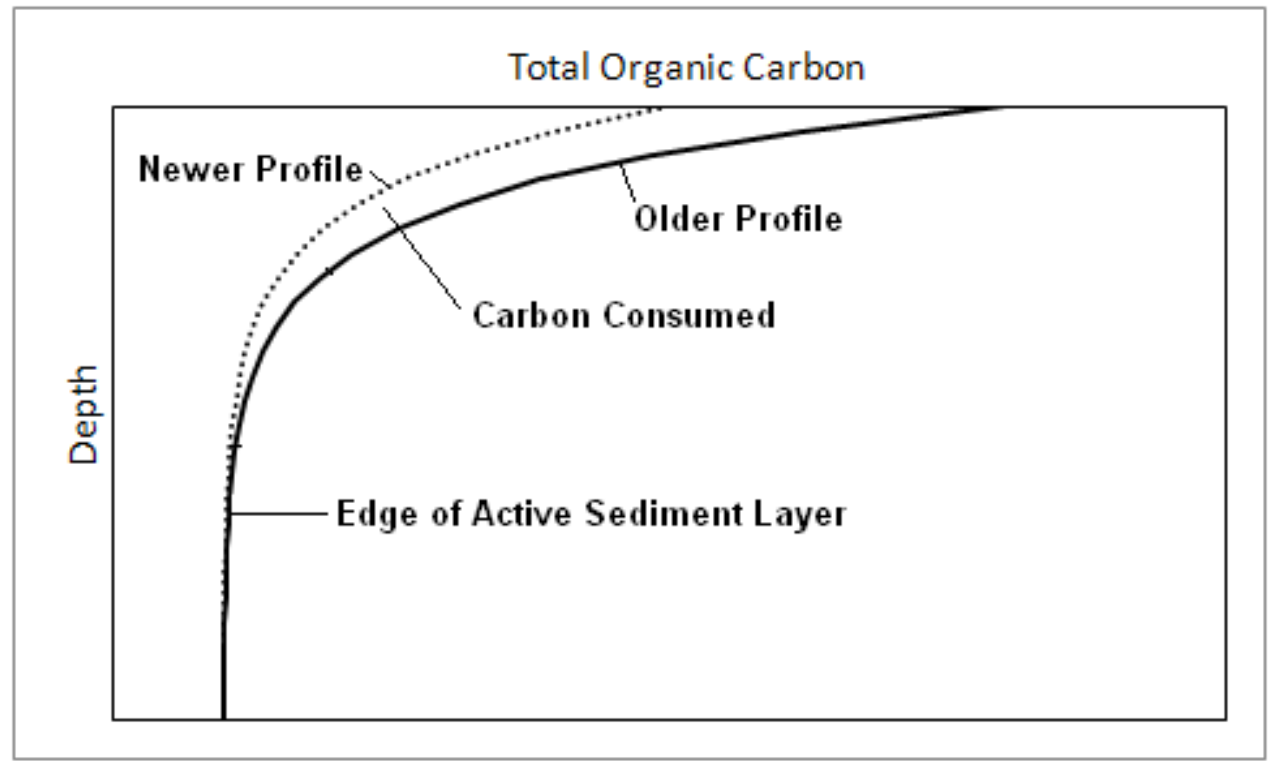

Figure 8: Example of Profile Comparison. Old and New Profiles are overlayed to note the point at which congruence happens. This point is the edge of the active sediment layer. 


\subsection{Results and Discussion}

Characterizing the organic carbon in the sediments of Onondaga Lake requires a combination of laboratory work and analysis of historical data. The starting point for the analysis is the contemporary TOC profile, which provides the standard to which all other measurements were compared. Bioassays open the window into the lability of carbon, both as a freshly deposited material and as aged material in the sediment profile. Finally, carbon residence time and active sediment layer depth evolves from a comparison of contemporary and historical profiles.

\subsection{Contemporary TOC Profile}

As previously noted, the starting point for analysis of carbon fate in the sediments of Onondaga Lake is the contemporary TOC profile. The shape of the profile reflects the history of Onondaga Lake, specifically trends in nutrient loading and attendant primary production. The peak in TOC, occurring at about $30 \mathrm{~cm}$ ( 1970s), represents a period when sediments richest in carbon were deposited (Figure 9). As one can note from the TOC profile, there has been a marked decrease in TOC deposition over the top $20 \mathrm{~cm}$ of the profile, representing approximately 25 years in the history of Onondaga Lake. 
Organic Carbon (\%DW)

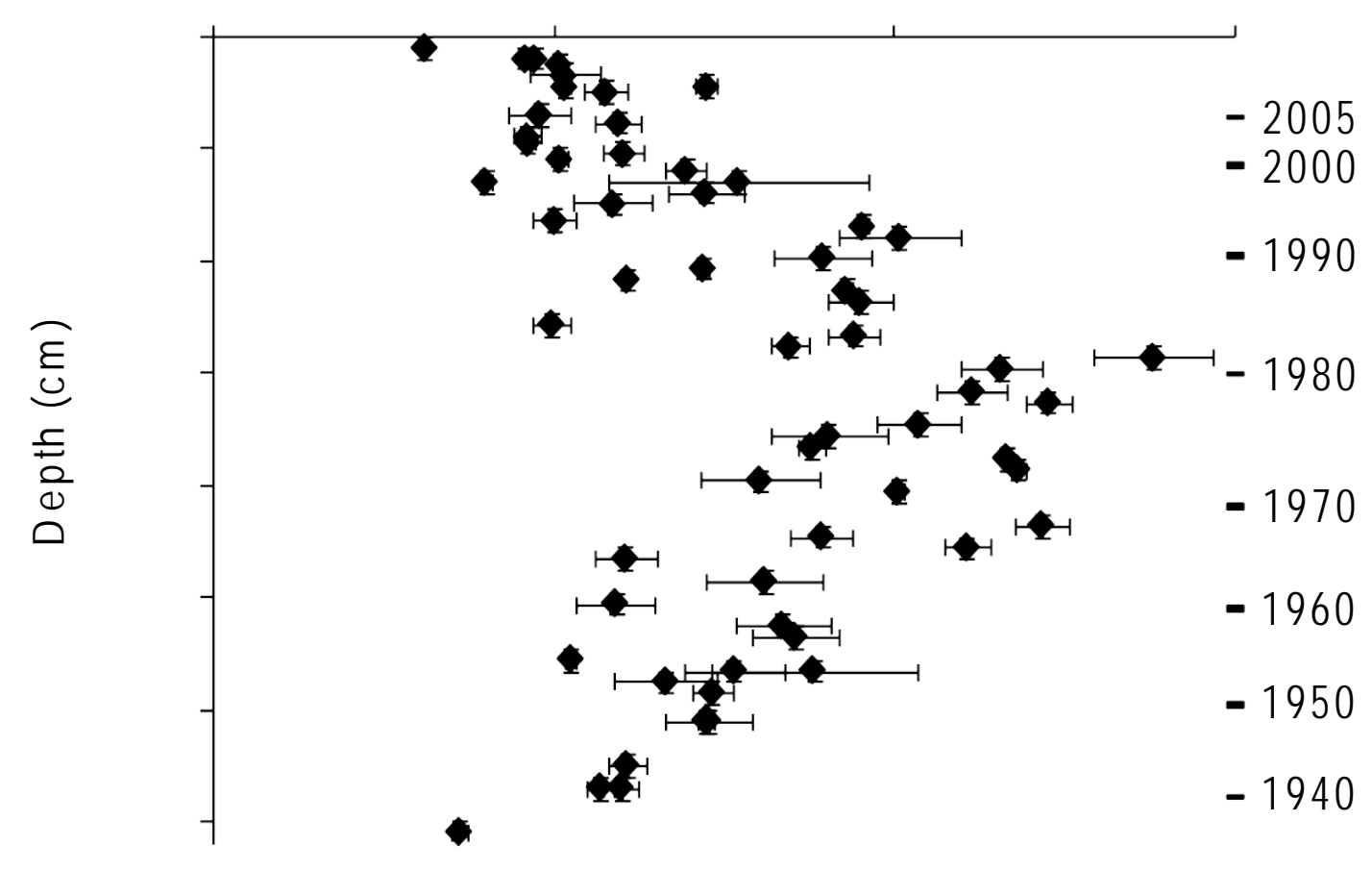

Figure 9: Total organic carbon profile for Onondaga Lake. Core collected at the South Deep Station in May, 2008. Bars represent [standard deviation] of the mean, $n=3$ ].

The association of organic carbon accumulation with nutrient inputs is made clear by comparing the TOC profile (Figure 9) with a total phosphorus profile collected at the same location (Figure 10; Penn et al. 1995). The peak in the phosphorus profile, representing maximum nutrient loads, clearly corresponds with the peak in the TOC profile, representing maximum rates of primary production. 


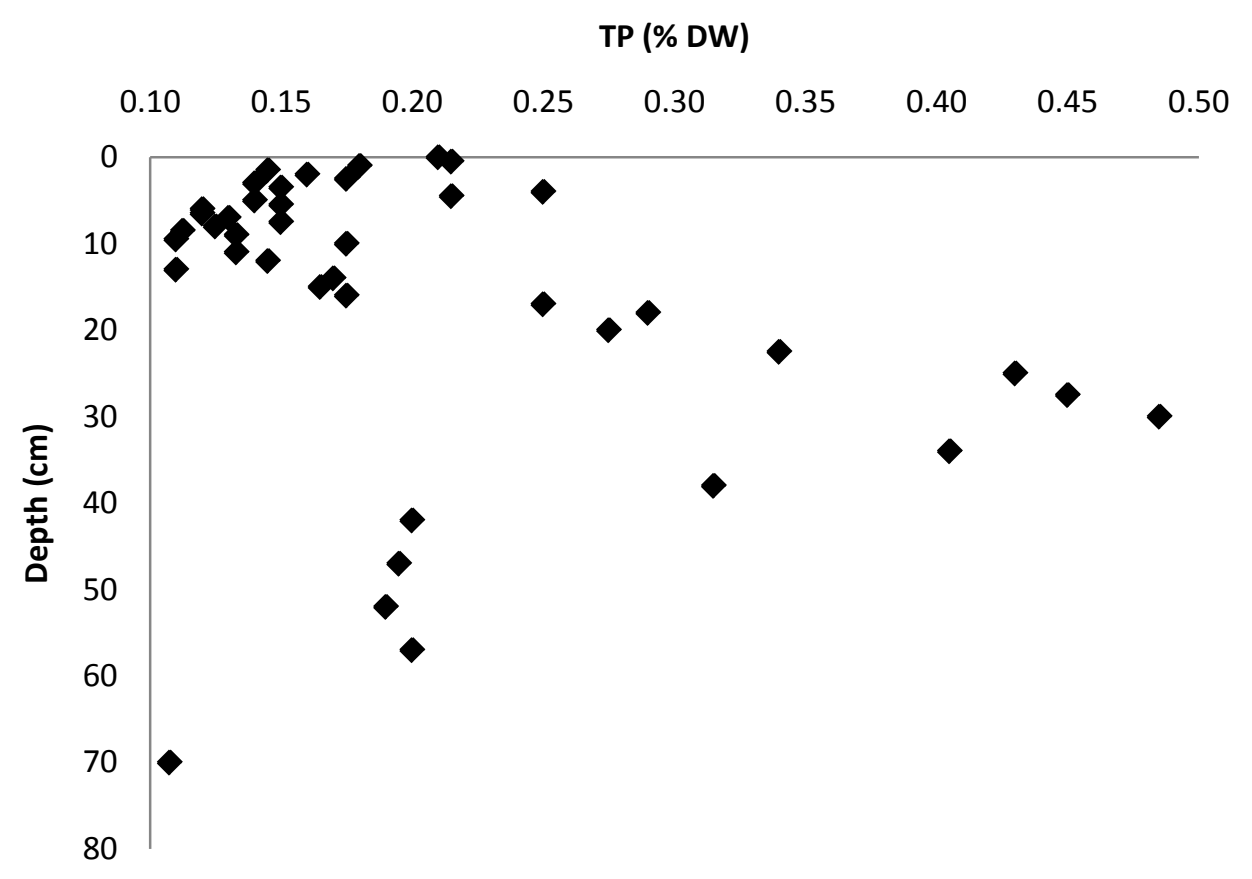

Figure 10: Total phosphorus profile for Onondaga Lake (Penn et al. 1995)

In lakes with short hydraulic residence times (rapid flushing), the sediments control the time course and extent of lake recovery. Here, the magnitude and lability of legacy deposits play a critical role. The design and long-term operation of a remediation plan involving electron acceptor augmentation requires a knowledge of the character of those deposits. The issue of lability in recently-sedimented material and in legacy deposits was addressed using bioassays as discussed subsequently. 


\subsection{Lability at Deposition}

\begin{tabular}{|l|l|}
\hline $\begin{array}{l}\text { Table 5: Lability of Freshly Deposited } \\
\text { Material }\end{array}$ \\
\hline Process & Lability (\% TOC) \\
\hline Oxic Mineralization & $89.0+/-2.2$ (St. Dev.) \\
\hline Anoxic Mineralization & $61.7+/-4.2$ (St. Dev.) \\
\hline
\end{tabular}

A knowledge of lability at deposition is necessary, as it provides the initial condition for modeling and a standard against which the lability of legacy deposits may be compared. Freshly deposited material was collected via sediment traps and tested for lability under both oxic and anoxic conditions. The results of individual assays are presented in Appendix A and labilities summarized in Table 5.

The lability at deposition represents the capacity for degradation before preservation mechanisms occur in the sediment, such as interactions with minerals and biological incorporation. Therefore, it expresses the maximum amount of mineralization possible for the organic carbon fraction. Looked at in another way, the lability at deposition denotes the true refractory carbon. For Onondaga Lake sediments, approximately $11 \%$ of the organic material that is deposited to the sediment-water interface is not subject to diagenesis under any redox condition. This fraction rises to almost $38 \%$ when oxygen is removed from the system, suggesting that nearly $27 \%$ of the material is composed of fractions (i.e. organomacromolecules and degradation resistant compounds) that are 
susceptible to attack from oxic enzymes, but not from weaker anoxic enzymes (Sobek et al. 2009).

The source of organic carbon plays a role in determining the overall lability. Onondaga Lake's organic carbon showed a very high lability in the laboratory, suggesting that the majority of the material is grown within the lake and not transported in via tributaries. Hedges et al. (1988) found organic carbon derived from phytoplankton to be five times more reactive in sediments than carbon from riverine sources. Sobek et al. (2009) found that systems receiving large amounts of autochthonous material (organic carbon produced in-lake) had higher carbon labilities than those lakes receiving the majority of their organic material from allochthonous (terrestrial-based) sources. When adjusted for the oxygen exposure time of the sediment, the observations from Sobek et al. fit right in with our results. For oxygen exposure times of 1 year, the lability was $72.5 \%$, which drops to a lability of $65 \%$ for 0.1 year (Sobek et al. 2009). On average, for the lakes studied (10 sites, 5 lakes), the average lability was $78 \%$, which resides between our oxic and anoxic sediment trap experiments.

There are two reasons presented for the increase in lability for autochthonously dominated lakes versus allochthonously dominated lakes. First, the time of transport ages the allochthonous materials, allowing for mineralization of organic material to occur before the material is deposited to the sediment-water interface (Mollenhauer and Eglington 2007). In addition, terrestrial based organic matter is often composed of 
materials that display higher resistance to degradation (Sobek et al. 2009 and sources referenced therein).

Once deposited at the sediment-water interface, many changes can occur within the organic material as it interacts with the physical and biological components of the sediment matrix, as previously described (see Section 1.4.4). Therefore, it becomes important to look at the lability of the organic material through the depth of the sediment core.

\subsection{Lability of Legacy Deposits}

Oxic (at $30^{\circ} \mathrm{C}$ ) and anoxic (at 8 and $30^{\circ} \mathrm{C}$ ) bioassays were performed to quantify the downcore lability of organic carbon in Onondaga Lake sediments. In the $30{ }^{\circ} \mathrm{C}$ oxic assays, organic carbon lability generally decreased with depth averaging $85 \pm 5 \%$ (Standard Deviation, SD) for the first $10 \mathrm{~cm}$ and $72 \pm 5 \%$ (SD) for the last $20 \mathrm{~cm}$. The data ranged from $67 \%$ to $92 \%$ and averaging $80.4+/-8.0 \%$ (SD, $n=15$, Figure 11 ) for the entire length of the core. This average is not significantly different $(p=0.05)$ from that of the freshly-deposited material $(89.0+/-2.2 \%(S D))$. 


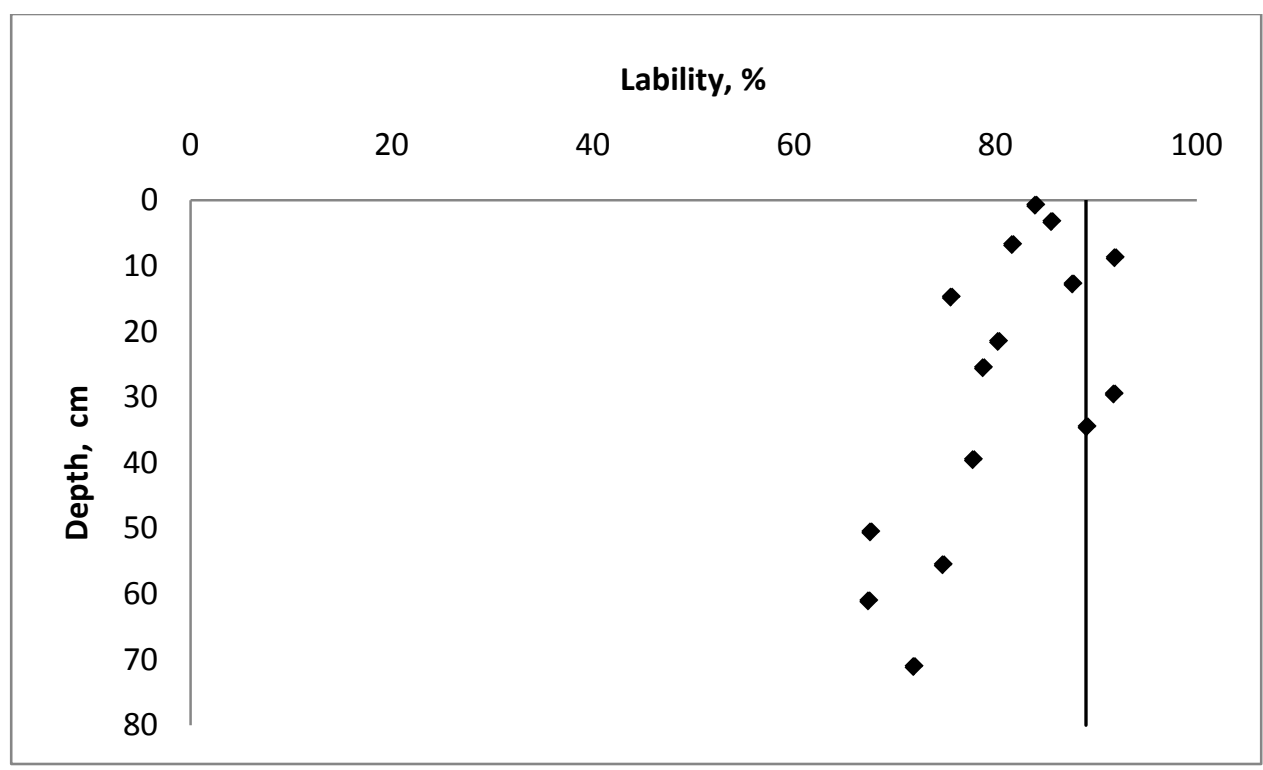

Figure 11: $30{ }^{\circ} \mathrm{C}$ oxic lability bioassay results. The diamonds represent downcore measurements of carbon lability, while the solid line represents the lability of the sediment trap material.

Labilities exceeded $60 \%$ over the entire profile, including sediment that had been maintained under anoxic conditions for decades. It is surprising that so much labile organic carbon remains labile (on exposure to oxic conditions) after so long a time. Sediment labilities were similar to those of sediment trap material, suggesting that preservation mechanisms were operable. As discussed above, limited oxygen exposure time tends to reduce the degree of mineralization and enhance the degree of preservation. In Onondaga Lake, where sedimentation rates are high (2-8 $\mathrm{mm} \cdot \mathrm{yr}^{-1}$; Upstate Freshwater Institute, unpublished) and where oxygen penetrates only 1-2 mm into the sediment (see Section 5.4.1), the oxygen exposure time is on the order of 5-35 days. This period is further attenuated by the periods of anoxia experienced during thermal stratification. Thus, there exists the potential for significant quantities of otherwise labile material to be removed from the pool available for diagenesis and 
become preserved. That availability may be restored by exposing the sediment to oxygen in the laboratory setting as evidenced here and as observed by Keil et al. (1994).

Legacy organic carbon was less labile under anoxic conditions (see discussion below) even when incubations were performed at $30{ }^{\circ} \mathrm{C}$, a near optimal temperature for methanogenesis (Zeikus and Winfrey 1976; Schultz et al. 1997). Here the lability dropped to from $81-89 \%$ for in-place and freshly-deposited sediment incubated under oxic conditions to an average of $50.5+/-8.6 \%$ (SD, $n=9$, range: $39.2 \%-61.6 \%)$ under anoxic conditions (Figure 12). Mechanisms potentially responsible for this reduction include hummified material and sorption to mineral surfaces (see discussion in Section 1.4).

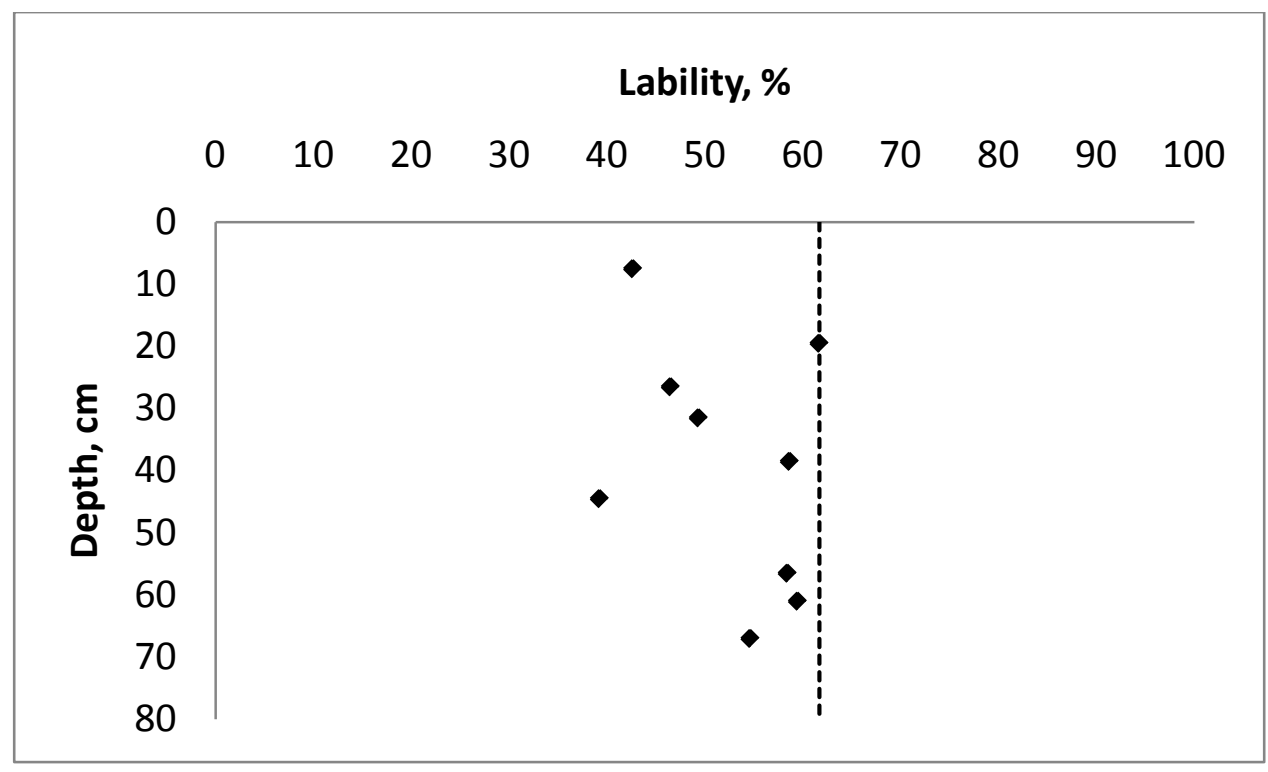

Figure 12: 30 Degree Anoxic Lability Bioassays. The lability of organic carbon is shown as a function of depth (diamonds) for sediment exposed to anoxic conditions at a temperature of 30 degrees. The dashed line shows the lability of the sediment trap with respect to anoxic conditions. 
Reducing the temperature below the optimum for methanogenesis resulted in a further decrease in lability. Incubation at a representative hypolimnetic temperature ( 8 $\left.{ }^{\circ} \mathrm{C}\right)$ yielded an average lability of $29.3+/-10.1 \%(\mathrm{SD}, \mathrm{n}=5$, range: $13.2 \%-37.0 \%)$, well below both the $30{ }^{\circ} \mathrm{C}$ oxic and anoxic labilities for recently-deposited and deep sediment, as shown in Figure 13.

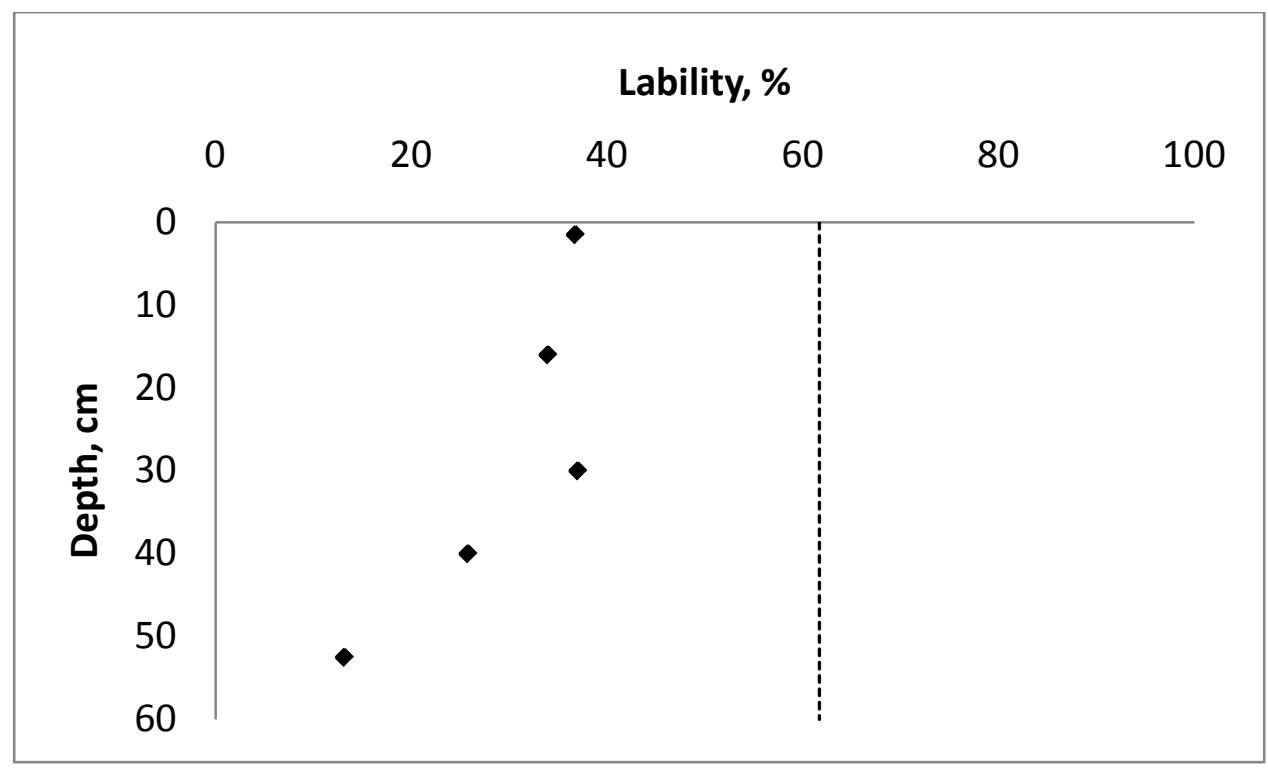

Figure 13: 8 Degree Anoxic Lability Bioassays. The lability of organic carbon is shown as a function of depth (diamonds) for sediment exposed to anoxic conditions at a temperature of 8 degrees. The dashed line shows the lability of the sediment trap with respect to anoxic conditions.

The experiment results bare out a conundrum: how can organic carbon that has been present in the sediment for a period of decades be mineralized in a matter of days within the laboratory? The length of the core studied represents about a century of carbon deposition, and labile carbon was found throughout the depth in the laboratory. 
However, if this labile carbon was to degrade in situ at a rate similar to the trials, the entire labile fraction would be exhausted within the top few millimeters of the column. Reversible preservation by sorption to minerals, as previously discussed, acts to greatly slow down the degradation of carbon, sometimes retarding the rate by up to five orders of magnitude (Keil et al. 1994). Thus, the laboratory setting of the experiments must promote the desorption of organic carbon with such a mechanism that is not present in sedimentary environmental conditions.

The physical mixing of the sediments in the experiments likely played a major role in the rapid and extensive mineralization of organic carbon. The sorbed organic matter can be released in a mixing environment in a dissolved organic carbon form that is readily available to diagenesis and degrades away rapidly (Keil et al. 1994). Arzayus and Canuel (2005) studied two sites of the York River estuary found that physical mixing of sediments promotes degradation of the organic carbon in the in situ environment. Our laboratory trials had physical mixing of the sediment samples that was more vigorous and constant than would be found in such environments; standing to reason that the rotational mixing promoted carbon mineralization in sediments to an extent and at a rate that would be much higher than the in situ conditions.

Experiments of desorbed organic material show this material to have high levels of lability, and very high rates of degradation, similar to those presented earlier in this thesis (see Kristensen and Holmer 2001 and Section 1.4.4). Keil et al. (1994) showed in laboratory trials that the desorbed carbon was mineralized within a period of six days, 57 
even for sediment that had been buried for more than a century. In addition to rapid mineralization, it is also important to note that $60-90 \%$ of the organic material was degraded during that time period, with the higher labilities for fresher material (Keil et al. 1994). This lability is similar to what was measured in our oxic bioassay experiments, both for the length of the core and also for the sediment trap.

The results of our bioassays display a difference in lability between the oxic and anoxic experiments. There is a higher efficiency of preservation when oxygen is not present, suggesting that the mechanisms of organic carbon degradation are dependent on oxic versus anoxic conditions. Literature suggests that the burial efficiency of organic carbon is highly negatively correlated with the exposure time to oxygen, with more carbon being preserved under anoxic conditions (Sobek et al. 2009). The differences in lability have to do with the initial step of carbon degradation, namely the enzymaticallyinduced release of carbon from a bound state (Sun et al. 1991) or the enzymatic breakdown of an organic molecule (Sobek et al. 2009). Aerobes have the capability to produce stronger oxidizing agents (i.e. $\mathrm{H}_{2} \mathrm{O}_{2}$ ) than the enzymes of anaerobes (Hulthe et al. 1998 ; Sobek et al. 2009), in addition to the multi-step mineralization required by anoxic organisms (Fenchel et al. 1998, Kristensen 2000).

Our laboratory results compare favorably to other experiments. For example, it was found by Harvey et al. (1995) that the amount of organic carbon degraded under oxic conditions was significantly different than when oxygen was not present. In these experiments with one species of diatom ( $T$. weissflogii), the lability was found to be $96 \%$ 
in the presence of oxygen, dropping to $78 \%$ under anoxic conditions. For the cyanobacteria Synnechoccus sp. the total degradation of POC was $83 \%$ with oxygen, compared to $64 \%$ under anoxic conditions (Harvey et al. 1995). Lehmann et al. (2003) also found a marked decrease between oxic and anoxic experiments, with around $87 \%$ of organic carbon decaying away under oxic conditions versus only $77.5 \%$ under anoxic conditions for sediments from Lake Lugano.

Other geological and experimental evidence points to the idea of reversible preservation of carbon, and that oxic conditions can enhance the degradation of organic carbon. Moodley et al (2005; as cited in Sobek et al. 2009) exposed ancient Mediterranean sediments to oxygen and mineralization occurred, proving that even sediments deposited millennia previous are still highly reactive and that anoxic conditions contributed a major role in the formation of the carbon deposits. Keil et al. (1994), as previously mentioned, found organic carbon mineralization in sediments that had been buried away from oxygen for a period of decades to centuries. Thus, it becomes clear that anoxic conditions enhance preservation in the sediments, yet adding in oxygen can reverse the majority of the preservation process, even when the anoxic interval extends over an extensive period of time. Therefore, it becomes possible to rapidly mineralize the labile carbon fraction through the addition of oxygen, as noted in our experiments (Keil et al. 1994).

Temperature also plays a role in determining the lability of organic carbon under anoxic conditions. As the temperature was lowered from $30^{\circ} \mathrm{C}$ to $8{ }^{\circ} \mathrm{C}$, the percentage of 
carbon mineralized dropped from an average of $50.5 \%$ to $29.3 \%$, suggesting that the mechanisms of preservation are more efficient under colder anoxic conditions. Kristensen et al. (1992) also found that the particulate organic carbon pool in bioturbated and non-bioturbated laboratory trials was highly dependent on temperature, with the highest lability found at the highest temperature tested. Sobek et al. (2009) also noted a positive relationship between the extent of mineralization and temperature, with enhanced preservation at lower temperatures.

The laboratory results suggest that labile organic carbon is present throughout the length of the core that was examined, and that it can be mineralized rapidly in the laboratory. However, the experimental conditions vary greatly from environmental conditions, and it becomes important to look at the in situ environment in multiple ways to determine the true lability of carbon and how long it remains resident in the sediment column.

\subsection{Porewater Profiles}

Porewater profiles taken in the summer of 2008 showing electron acceptors and the reduced species end product of total sulfide (Figure 14) provide direct evidence of diagenetic activity and its distribution within the sediment. The most favorable terminal electron acceptor, oxygen, is utilized within the first two millimeters, with nitrate being exhausted quickly below that point $(\sim 3 \mathrm{~mm})$. Nitrate is then replaced by sulfate as the terminal electron acceptor, with sulfate reduction extending to a depth of $2 \mathrm{~cm}$. As 
summer stratification progresses, oxygen and nitrate may become completely utilized with net sulfate reduction moving toward the sediment-water interface.

The electron transport system assay (ETSA; see Stromquist 1996) measures the distribution of all diagenetic processes having a thermodynamic favorability greater than methanogenesis. Stromquist (1996) demonstrated that ETSA activity in Onondaga Lake sediments reached an asymptote at $~ 8 \mathrm{~cm}$ in 1995 (Figure 15a) indicating a switch to methanogenesis below that depth. This observation is supported by a companion porewater profile of methane (Figure 15b; Stromquist 1996).

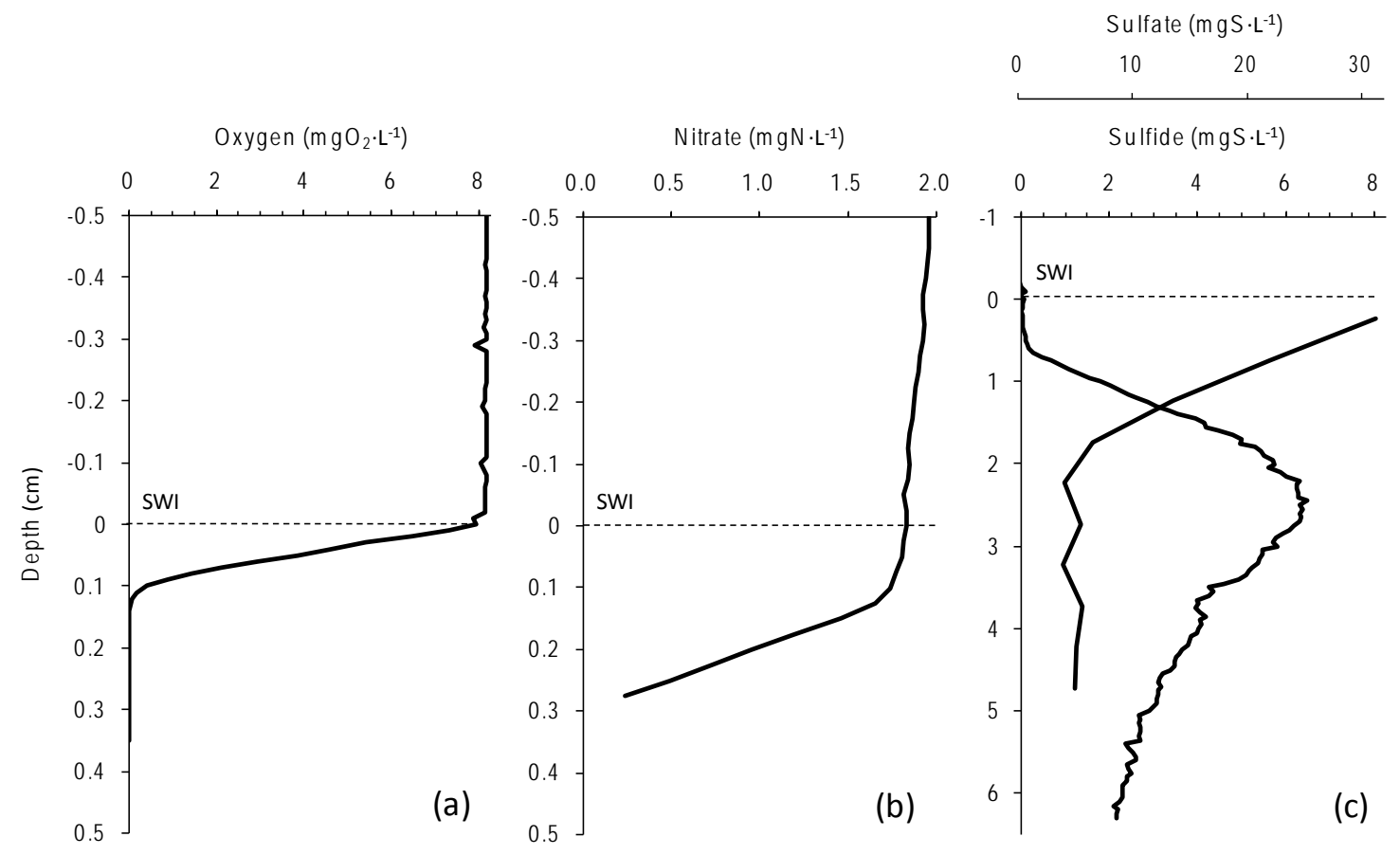

Figure 14. Porewater profiles of selected electron acceptors and reduced species end products: (a) oxygen, (b) nitrate and (c) sulfate- sulfide (source: Auer et al. 2009). The notation 'swi' identifies the sediment-water interface. 

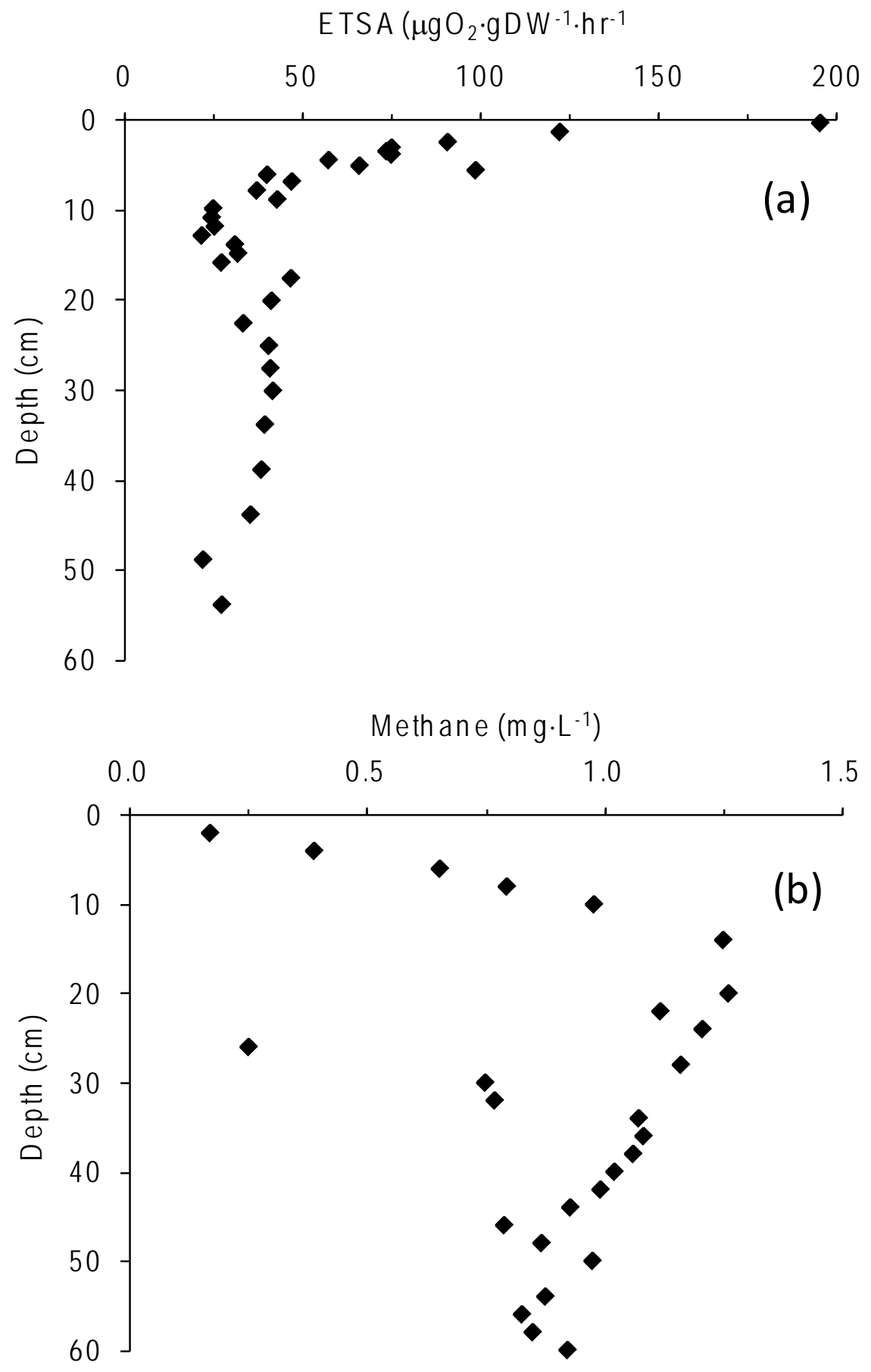

Figure 15. Porewater profiles of (a) electron transport system activity and (b) methane concentration (Stromquist (1996). 
The edge of methane production represents the end of early carbon diagenesis. In order to find the point at which this occurs on the profile, one must look at the slopes of the limbs of the graph. Places where the slope is linear, the top few points for example, represent areas of diffusive transport. In areas where the slope is not linear, hence the second derivative is not equal to zero, it can be inferred that there is a source or a sink. In this case, a non-zero second derivative represents the area of methane production. Figure 16 shows the two linear slope areas of the methane profile. The production of methane occurs in the area between the linear regions, namely between $10-20 \mathrm{~cm}$.

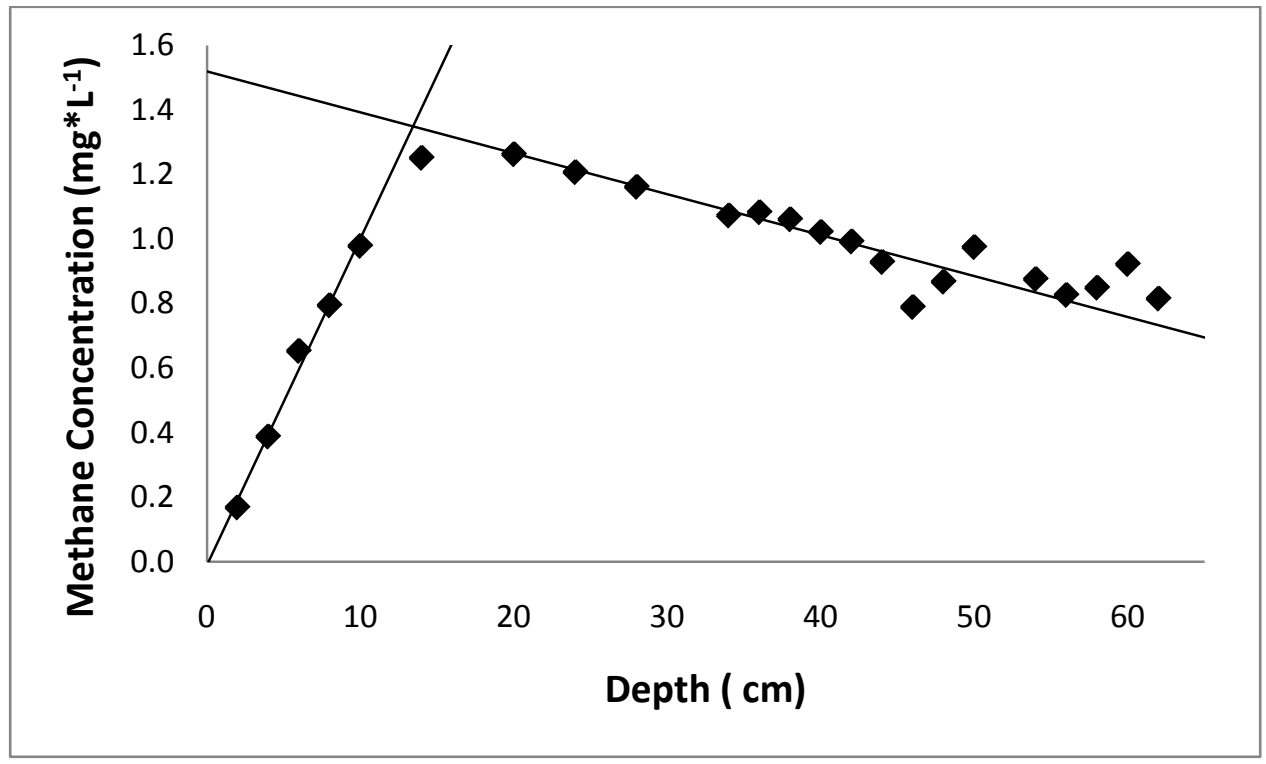

Figure 16: Methane Production Zone. The region of methane production is found as the non-linear region around $10-20 \mathrm{~cm}$, where the second derivative is not equal to zero. This provides evidence that the active region of the sediment ended around 10-20 $\mathrm{cm}$ of sediment depth in the year the profile was taken, 1995.

Based on this first line of evidence, electron acceptor and reduced species end product profiles, it may be concluded that diagenesis largely ceased below of sediment depth of 
$20 \mathrm{~cm}$ in 1995 and that organic carbon below that is protected from mineralization by preservation mechanisms. Methane present below this depth reflects mass transport and not production.

\subsection{Decade-Scale Changes in TOC Profiles}

The hypothesis that preservation mechanisms are active over the sediment profile implies that, below a certain depth, there should be little change in TOC concentrations with time. To test this theory, the contemporary TOC profile is tested against historical TOC and depositional conditions. The initial condition provided for the analysis included a 1995 TOC profile (Stromquist 1996) and historical carbon and sediment deposition rate (Upstate Freshwater Institute, unpublished data). These conditions were set with a kinetic rate coefficient of zero and run with Sed2K (see Appendix E), resulting in a profile that would result from a 2008 TOC profile with no diagenesis occurring. Where measured 2009 TOC values fall below the simulated profile, diagenesis has been active; locations where the measurements and simulation largely overlie one another have not supported significant diagenesis over the 13-year interval. The results indicate that diagenesis in Onondaga Lake is limited to the top $15 \mathrm{~cm}$ of the sediment. This provides the second line of evidence that an active sediment layer exists for Onondaga Lake. 


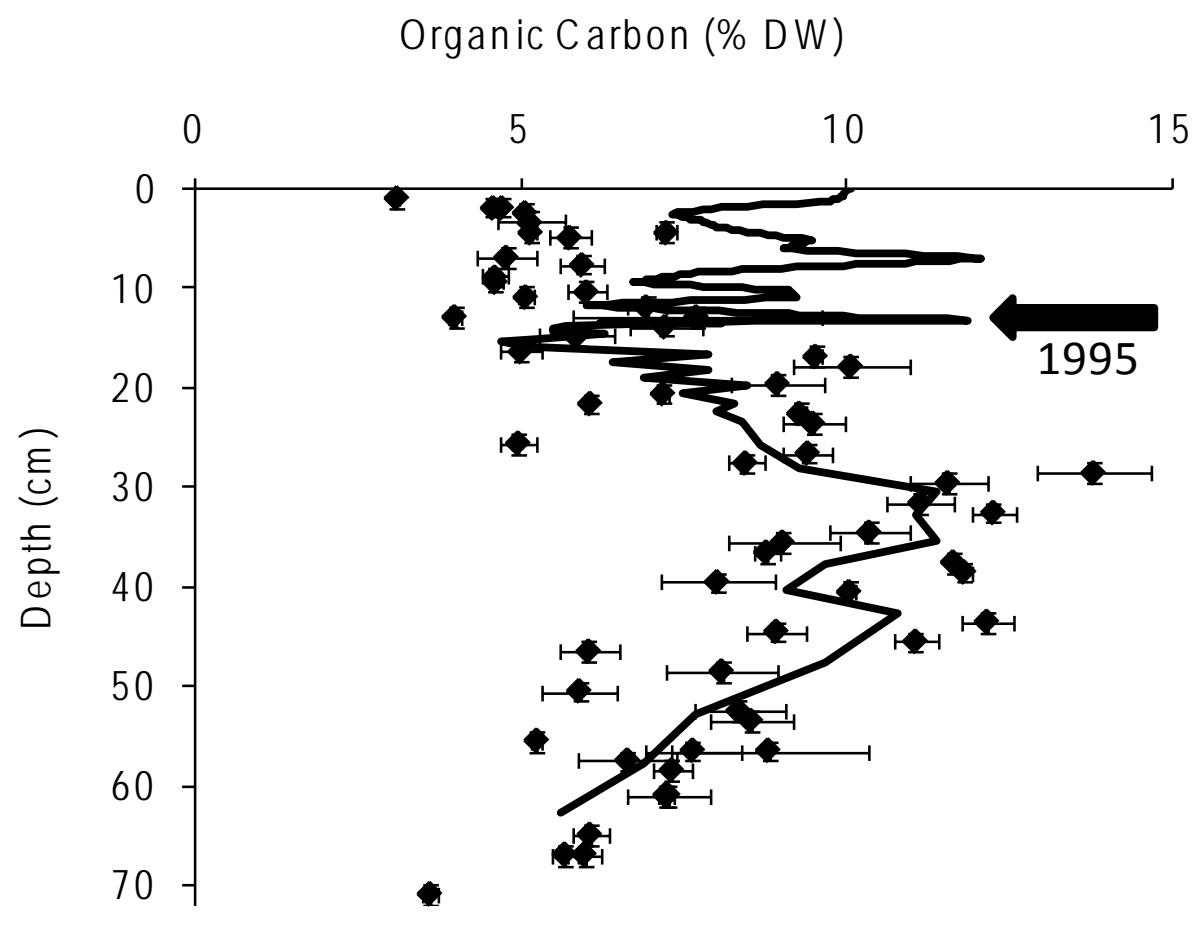

Figure 17: Comparison of the measured contemporary TOC profile (2008) with a simulation of that profile assuming that no diagenesis occurs. Differences between the two profiles over the first $12 \mathrm{~cm}$ of the core suggest that diagenetic activity is largely confined to that region.

\subsection{The Active Sediment Layer and Kinetic Rate Coefficients}

A third line of evidence regarding the role of preservation can be found in the rate coefficients presented from the literature. Using the slow $\mathrm{k}$ value of $0.134 \mathrm{yr}^{-1}$ presented by Gälman et al. (2008) in a first-order diagenesis equation for an in situ temperature, it is found that $t_{99}$, or the time it takes for $99 \%$ of the material to be mineralized, is equal to about 34 years, or what would be equal to approximately $\sim 30 \mathrm{~cm}$ in the Onondaga Lake sediment. Add in the fact that the organic material present is not all organic material present is of the slow-decaying nature, suggesting that the time to 
$99 \%$ mineralization is likely less than this and that the edge of diagenesis resides higher in the core.

Another way to examine this line of evidence is to calculate the kinetic rate coefficient necessary to account for $99 \%$ mineralization of the slow-reacting organic matter for the length of the core examined. For the $72 \mathrm{~cm}$ of the sediment column examined, a period of just over 70 years is required. Using the same first-order diagenesis equation, it was found that it would take a rate coefficient of approximately $0.0655 \mathrm{yr}^{-1}$ for tg9 $_{99}$ to occur at $72 \mathrm{~cm}$. This is approximately half the value of what is given in the literature (Gälman et al. 2008).

Thus, based on the literature, it is evident that it would be unlikely for labile organic carbon to be present deep in the sediment. It is notable, using the previously mentioned rate coefficient, that the time it takes for the majority of the labile carbon pool to become mineralized in this analysis is slightly higher, but still in line with, the porewater profiles and the profile overlay matching. Therefore, the third line of evidence presented here further strengthens the argument for an active sediment layer of about $20 \mathrm{~cm}$.

\subsection{Management Implications under a Preservation Scenario}

The multiple lines of evidence presented above pointing to the operation of preservation mechanisms further suggest that there exists a depth below which relatively little or no diagenesis occurs. Above that depth, coincident with the limits of 
diagenetic activity, there exists an active sediment layer mediating the 'when and to what extent' of the restoration response. Adopting the $15-20 \mathrm{~cm}$ depth as the lower boundary for the active sediment layer indicates that that the majority of the legacy deposits of organic carbon in Onondaga Lake has become preserved, i.e. removed from the active sediment layer. The true legacy deposit, i.e. historical deposition that continues to impact the water column, is much less than would be predicted based on the TOC profile alone (Figure 7) or on the downcore lability experiments.

The establishment of an active sediment layer facilitates estimation of a residence time for labile organic carbon in the sediment. Here, residence time is defined as the time for the organic material to react completely or be transported by burial out of the active sediment layer. The residence time for Onondaga Lake is equal to approximately $15-20$ years. This residence time is slightly less than that determined by Gälman et al. (2008) in modeling exercises which indicated that it would require 25-30 years for organic carbon to reach steady-state following a change in the rate of deposition. The organic-carbonbased residence time calculated here for Onondaga Lake sediments is also quite similar to that reported for nitrogen (20 years; Wickman 1996) and phosphorus (19-26 years; Lewis et al. 2007) .

\subsection{Modeling Diagenesis Under a Preservation Scenario}

The presence of a preservation mechanism for labile organic carbon in the sediments requires that traditional carbon diagenesis models be modified to accommodate the 
phenomenon. Whereas traditional models (e.g. Westrich and Berner 1984) permanently partition particulate organic carbon into labile and refractory fractions, the results presented here suggest that the organic carbon is more appropriately considered conditionally labile. Traditional frameworks make no provision for conditional lability, i.e. the transformation of organic matter from a labile to a refractory form as the sediment passes through regions of the profile where different diagenesis processes occur.

Hedges and Keil (1995) proposed a 36 framework consisting of a pool that is unconditionally labile (i.e. degradable by any pathway), a pool that is conditionally labile (i.e. degradable only with oxygen as the electron acceptor) and a refractory pool, $C_{t}=\sum_{i}\left(C_{l, i} \cdot e^{-k_{i} \cdot t}\right)+\sum_{j}\left(C_{l, j} \cdot e^{-k_{j} \cdot O E T}\right)+C_{r e f r a c t o r y}$

where: $\quad \mathrm{OET}=$ the time the sediment is exposed to oxygen, $\mathrm{yr}$

$\mathrm{I}, \mathrm{j}=\quad$ subscripts denoting the unconditionally and conditionally labile fractions, respectively

This treatment makes the decay of the conditionally labile carbon fraction a function of the oxygen exposure time, with diagenesis of this fraction stopping once the oxygen exposure time has been reached. This approach does not treat preservation explicitly, but does move in that direction by incorporating the oxygen dependence of carbon diagenesis. Further, the treatment does not ease the burden of application as it remains necessary to partition the total organic carbon pool into fractions. 


\subsection{Conclusions}

The processes that occur within the sediments, specifically the diagenesis of organic carbon, are potentially the driving force that determines the water quality of an aquatic system. The sum total of carbon diagenetic processes is directly proportional to the total demand on terminal electron acceptors. Two of these terminal electron acceptors, oxygen and nitrate, act as gatekeepers, preventing the release of toxic methyl-mercury from the sediment. In addition, oxygen acts as a gatekeeper to prevent other detrimental effects. If the demand for electron acceptors is high enough that the gatekeeper is exhausted, nutrient phosphorus, sulfide, methane, and methyl mercury are released from the sediment. Thus, being able to characterize the organic carbon in the sediments and predicting the associated demand of oxygen and nitrate is vital to a lake management plan.

There exists a large quantity of carbon in the sediments of Onondaga Lake, representing the cultural eutrophication of past generations and the degradation of water quality over the past century. Finding the lability of this carbon and the length of time the carbon remains active in the sediments are vital to finding the time period and extent of recovery for the water column.

The results of the experimental trials bear out the fact that there is labile organic carbon that is protected from mineralization by redox conditions and temperature. There are a number of mechanisms for this preservation, some of which are reversible depending on the prevailing conditions in the sediment. The cold temperature of the sediments, 
due to the higher density of cold water and protection from mixing during stratification of the water column, slows the kinetics of degradation and enhances preservation. This is especially true in the anoxic sediment region, which exists very close to the sedimentwater interface.

Thus, there exists a large fraction of conditionally-labile carbon in the sediments of Onondaga Lake, representing the cultural eutrophication of past generations and the degradation of water quality over the past century. However, this carbon has been preserved to burial by advection away from the sediment-water interface and the electron acceptor, oxygen, that would allow for mineralization. Given that oxygen only penetrates the sediments of Onondaga Lake to a depth of a few millimeters, this portion of the organic material is only labile for a period of days. This fact is exacerbated by the conditions of anoxia that are present during periods of stratification, further decreasing the oxygen exposure time for this form of carbon. Thus, this fraction varies between labile and refractory, exhibiting degradation in oxic sediments and presenting as a part of the non-reactive pool under anoxic conditions.

The absence of labile organic carbon below a depth of $15-20 \mathrm{~cm}$ presented through multiple lines of evidence, implies that the historical nutrient enrichment and enhanced primary production will not permanently degrade the water quality of Onondaga Lake. There comes a point where only refractory carbon remains, and interactions with the water column are halted. In the case of Onondaga Lake, this occurs after a period of approximately 15-20 years from deposition. Thus, the time course of lake recovery is 
defined by this residence time of labile organic material, which is controlled by the conditions present within the sediment column. 


\subsection{Future Work}

Further laboratory work is needed to expand on the relationship between organic carbon lability and temperature under anoxic conditions. For the two temperatures that were tested, marked differences in preservation efficiency were noted. It would be beneficial to know more about this coupling. In addition, it would be of importance to identify the mechanisms involved in the lability/temperature relationship, rather than the empirical observations noted in this thesis. Similarly, tests to determine if there is a relationship between lability and anaerobic mineralization process would also be helpful.

The factors influencing the time course of lake recovery are laid out in this research. By understanding the lability and residence time of organic carbon in the sediment column, one can pinpoint the time in the future in which historical eutrophication no longer has an impact on the water column. Ultimately, the sins of the past become buried and preserved in the sediment and no longer impact the lake, and knowledge of the time required allows lake managers to plan for recovery and potential intervention in the interim.

This research also provides a partial framework for an early sediment diagenesis model. This predictive model will use insights on carbon diagenesis to forecast the terminal electron acceptor demand and subsequent methyl-mercury flux from the sediment. The model allows for the quantification of the extent of lake recovery, which is certain 
to occur with reduced nutrient loadings. Management of the aquatic system relies on the model to better grasp the success or failure of loading control practices once the lake sediments reach balance with the new loading regime.

In the end, the economics of lake recovery come into play. The lost beneficial uses that are reclaimed through lake rehabilitation must be measured against the physical cost of treatment. The model uses the metrics of eutrophication, sediment terminal electron acceptor demand, as well as reduced and toxic species flux from the sediment to provide the information necessary to understand how the water quality improves as lake recovery efforts are implemented. A strength of modeling in this regard is the ability to load many different nutrient loading scenarios and to determine the extent of lake recovery for each. 


\subsection{References}

Addess, J.M., and Effler, S.W. 1996. Summer methane fluxes and fall oxygen resources of Onondaga Lake. Lake Reserv. Manage. 12 (1): 91-101.

Arnarson, T.S., and Keil, R.G. 2005. Influence of organic-mineral aggregates on microbial degradation of the dinoflagellate Scrippsiella trochoidea. Geochim. Cosmochim. Acta. 69(8): 2111-2117.

Arnarson, T.S. and Keil, R.G. 2007 Changes in organic material-mineral interactions for marine sediments with varying oxygen exposure times. Geochim. Cosmochim. Acta. 71 (14):3545-3556.

Arzayus, K.M., and Canuel, E.A. 2005. Organic matter degradation in sediments of the York River estuary: Effects of biological versus physical mixing. Geochim. Cosmochim. Acta. 69 (2): 455-463.

Baldock J. A., Masiello C. A., Ge'linas Y., and Hedges J. I. 2004. Cycling and composition of organic matter in terrestrial and marine ecosystems. Mar. Chem. 92: 39-64.

Berner, R.A. 1980. Early Diagenesis- A Theoretical Approach. Princeton University Press. Princeton, N.J. 241pg.

Beutel, M.W., Leonard, T.M, Dent, S.R., and Moore, B.C. 2008. Effects of aerobic and anaerobic conditions on $\mathrm{P}, \mathrm{N}, \mathrm{Fe}, \mathrm{Mn}$ and $\mathrm{Hg}$ accumulation in waters overlying profundal sediments of an oligo-mesotrophic lake. Water Res. 42: 1953-1962.

Boudreau, B. 1996. A method-of-lines code for carbon and nutrient diagenesis in aquatic sediments. Computers and Geosciences. 22: 479-496.

Canale, R.P., Gelda, R.K., and Effler, S.W. 1996. Development and testing of a nitrogen model for Onondaga Lake. Lake Reserv. Manage. 12 (1): 151-164.

Canavan, R.W., Slomp, C.P., Jourabchi, P. Van Cappellen, P., Laverman, A.M.,and ven den Berg, G.A. Organic matter mineralization in sediment of a coastal freshwater lake in response to salinization. Geochim. Cosmochim. Acta.70: 2836-2855.

Canfield, D.E., Jorgensen, B.B., Fossing, H., Glud, R., Gunderson, J., Ramsing, N.B., Thamdrup, B., Hansen, J.W., Nielsen, L.P., and Hall, P.O.J. 1993. Pathways of organic carbon oxidation in three continental margin sediments. Mar. Geol. 113: 27-40. 
Capone, D.G., and Kiene, R.P. 1988. Comparison of microbial dynamics in marine and freshwater sediments: Contrasts in anaerobic catabolism. Limnol. Oceanogr. 33: 725749.

Carpenter, S.R., Bolgrien, D., Lathrop, R.C., Stowe, C.A., Reed, T., and Wilson, M.A., 1997. Ecological and economic analysis of lake eutrophication by nonpoint pollution. Australian J. of Eco. 23, 68-79.

Carpenter, S.R., Ludwig, D., and Brock, W.A., 1999. Management of eutrophication for lakes subject to potentially irreversible change. Ecol. App. 9: 751-771.

Carignan, R., and Lean, D.R.S. 1991. Regeneration of dissolved substances in a seasonally anoxic lake: The relative importance of processes occurring in the sediments. Limnol. Oceanogr. 36(43): 683-707.

Chapra, S.C. 1997. Surface Water-Quality Modeling. McGraw-Hill, NY. 844pp.

Chapra, S.C. and K.H. Reckhow. 1983. Engineering Approaches for Lake Management: Volume 2: Mechanistic Modeling. Butterworth Publishers, Woburn, Massachusetts, $492 \mathrm{pp}$.

Clark, A. 1974. The Chemosorptive Bond: Basic Concepts. Academic, New York, NY. 207pp.

Collins, M.J., Bishop, A.N, and Farrimond, P. Sorption by mineral surfaces: Rebirth of the classical condensation pathway for kerogen formation. Geochim. Cosmochim. Acta. 59(11): 2387-2391.

Compeau, G., and Bartha, R. 1984. Methylation and demethylation of mercury under controlled redox, pH, and salinity conditions. App. Enviro. Micro.. 48: 1203-1207.

Compeau, G., and Bartha, R. 1985. Sulfate-Reducing Bacteria: Principal Methylators of Mercury in Anoxic Estuarine Sediment. App. Enviro. Micro. 50: 498-502.

Conrad, R. 1999. Contribution of hydrogen to methane production and control of hydrogen concentrations in methanogenic soils and sediments. FEMS Micro. Eco.. 28: 193-202.

Cooke, G.D., Welch, E.B., Peterson, S.A., and Nichols, S.A. 2005. Restoration and Management of Lakes and Reservoirs. Taylor and Francis. 
Correll, D.L. 1998. The Role of Phosphorus in the Eutrophication of Receiving Waters: A Review. J. of Enviro. Qual. 27: 261.

Curry, K.J., Bennet, R.H., Mayer, L.M., Curry, A., Abril, M., Biesiot,P.M., and Hulbert, M.H. 2007. Direct visualization of clay microfabric signatures driving organic matter preservation in fine-grained sediment. Geochim. Cosmochim. Acta. 71: 1709-1720.

Desauziers, V., Castre, N., and LeCloirec, P. 1997. Sorption of methymercury by clays and mineral oxides. Enviro. Tech. 18: 1009-1018.

DiToro, D.M. 2001. Sediment Flux Modeling. Wiley.

Dodds, W.K., Bouska, W.W., Eitzmann, J.L., Pilger, T.J., Pitts, K.L., Riley, A.J., Schloesser, J.T., and Thornbrugh, D.J. 2009. Eutrophication of U.S. Freshwaters: Analysis of Potential Economic Damages. Enviro. Sci. Tech. 43: 12-19.

Effler, A.J.P., Gelda, R.K., Effler, S.W., Matthews, D.A., Field, S.D., and Hassett, J.M. 2008. Decreases in primary production in Onondaga Lake from reductions in point source inputs of phosphorous. Archiv für Hydrobiologie. 172: 239-253.

Effler, S.W. 1996. Limnological and engineering analysis of a polluted urban lake. Prelude to environmental management of Onondaga Lake. New York: SpringerVerlag.

Effler, S.W., Matthews, C.M., and Driscoll, C.T. 2001. Changes in deposition of phytoplankton constituents in a $\mathrm{Ca}^{2+}$ polluted lake. Env. Sci. Tech. 35: 3082-3088.

Effler, S.W., O’Donnell, S.M., Matthews, D.A., Matthews, C.M., O’Donnell, D.M., Auer, M.T., and Owens, E.M. 2002 Limnological and loading information and a phosphorous total maximum daily load analysis for Onondaga Lake. Lake Reser. Manage. 18: 87108.

Effler, S.W., and Matthews, D.A. 2003. Impacts of a soda ash facility on Onondaga Lake and the Seneca River, NY. Lake Reser. Manage. 19: 285-306.

Effler, S.W., and Matthews, D.A. 2008. Implications of redox processes for the rehabilitation of an urban polluted lake. Lake Reser. Manage. 24: 122-133.

Effler, S.W., Owens, E.M., Matthews, D.A., O'Donnell, S.M., and Hassett, J.M. 2009. Effects of Discharge of Spent Coolant Water from an Oligotrophic Lake to a Polluted Eutrophic Lake. J. Water Resour. PIng. and Mgmt. 135: 96-106 
Fenchel, T., King, G.M., and Blackburn, T.H. 1998. Bacterial Biogeochemistry: the Ecophysiology of Mineral Cycling. Academic Press, San Diego. 307.

Froelich, P.N., Klinkhammer, G.P., Bender, M.L., Luedtke, N.A., Heath, G.R., Cullen, D., Dauphin, P. Hammond, D., Hartman, and B., Maynard, V. 1979. Early oxidation of organic matter in pelagic sediments of the eastern equatorial Atlantic: Suboxic diagenesis. Geochim. Cosmochim. Acta. 43: 1075-1090.

Gälman, V. , Rydberg, J., de-Luna, S.S., Bindler, R., and Renberg, I. 2008. Carbon and nitrogen loss rates during aging of lake sediment: Changes over 27 years studied in a varved lake sediment. Limnol. Oceanogr. 53: 1076-1082.

Garber, J.H. 1984 Laboratory study of nitrogen and phosphorus remineralization during the decomposition of coastal plankton and seston. Estuarine Coastal Shelf Sci. 18: 685702.

Gelda, R.K., Auer, M.T., and Effler, S.W. 1995.Determination of sediment oxygen demand by direct measurements and by inference from reduced species accumulation. Mar. Freshwat. Res. 46: 81-88.

Gelda, R.K., and Auer, M.T. 1996. Development and testing of a dissolved oxygen model for a hypereutrophic lake. Lake Reser. Manage. 12: 165-179.

Gupta, B.K.S., Turner, R.E., and Rabalais, N.N. 1996. Seasonal oxygen depletion in continental shelf waters of Louisiana: historical record of benthic foraminifers. Geo. 24: 227-230.

Harvey, R.H., Tuttle, J.H., and Bell, J.T. 1995. Kinetics of phytoplankton decay during simulated sedimentation: Changes in biochemical composition and microbial activity under oxic and anoxic conditions. Geochim. Cosmochim. Acta. 59(16): 3367-3377.

Hedges, J.I. 1988. Polymerization of humic substances in natural environments. In Humic Substances and Their Role in the Environment. (Editors: Frimmel, F.H., Christman, R.F.). Wiley, New York, NY. 45-58.

Hedges, J.I., Clark, W.A., and Cowie, G.L. 1988. Fluxes and reactivities of organic matter in a coastal marine bay. Limnol. Oceanogr. 33: 1137-1152.

Hedges, J.I., and Keil, R.G. 1995. Sedimentary organic matter preservation: an assessment and speculative synthesis. Mar. Chem. 49: 81-115. 
Hedges J. I., and Oades J. M. 1997. Comparative organic geochemistries of soils and marine sediments. Org. Geochem. 27: 319-361.

Hedges, J.I., Hu, F.S., Devol, A.H., Hartnett, H.E., Tsamakis, E., and Kiel, R.G. 1999. Sedimentary Organic Matter Preservation: A Test for Selective Degradation Under Oxic Conditions. Am. J. of Sci. 299: 529-555.

Henrichs, S.M., and Doyle, A.P. 1986. Decomposition of ${ }^{14} \mathrm{C}$-labeled organic substances in marine sediments. Limnol. Oceanogr. 31(4): 765-778.

Hulthe, G., Hulth, S., and Hall, P.O.J. 1998. Effect of oxygen on degradation rate of refractory and labile organic matter in continental margin sediments. Geochim. Cosmochim. Acta. 62(8): 1319-1328.

Hutchinson, G.E. 1973. Eutrophication: the scientific background of a contemporary practical problem. Am. Sci. 61: 269-279.

Ingall, E., and Jahnke, R. 1997. Influence of water-column anoxia on the elemental fractionation of carbon and phosphorous during sediment diagenesis. Mar. Geo. 139: 219-229.

Jackson, G.A., and Lochmann, S.E. 1992. Effect of coagulation on nutrient and light limitation of an algal bloom. Limnol. Oceanogr. 37: 77-89.

Keil, R.G., Hu, F.S., Tsamakis, E.C., and Hedges, J.I. 1994. Pollen in marine sediments as an indicator of oxidation of organic matter, Nat. 369: 639-641.

Keil, R.G., Montlucon, D.B., Prahl, F.G., and Hedges, J.I. 1994. Sorptive preservation of labile organic matter in marine sediments. Nat. 370: 549-552.

Kennedy M., Droser M., Mayer L. M., Pevear D., and Mrofka, D. 2006. Late Precambrian oxygenation: inception of the clay mineral factory. Sci. 311: 1446-1449.

Klump, J.V., Paddock, R., Remsen, C.C., Fitzgerald, S., Boraas, M., and Anderson, P. 1989. Variations in sediment accumulation rates and the flux of labile organic matter in eastern Lake Superior. J. Great Lakes Res. 15(1): 104-122.

Kristensen, E., Andersen, F.O., and Blackburn, T.H. 1992. Effects of benthic macrofauna and temperature on macroalgal detritus: The fate of organic carbon. Limno. Oceanogr. 37(7): 1404-1419. 
Kristensen, E., Ahmed, S.I., and Devol, A.H. 1995. Aerobic and anaerobic decomposition of organic matter in marine sediment: which is fastest? Limnol. Oceanogr. 40 (8): 1430-1437.

Kristensen, E., and Hansen, K. 1995. Decay of plant detritus in organic-poor marine sediment: Production rates and Stoichiometry of dissolved $\mathrm{C}$ and $\mathrm{N}$ compounds. J. of Mar. Res. 53: 675-702.

Kristensen, E. 2000. Organic matter diagenesis at the oxic/anoxic interface in coastal marine sediments, with emphasis on the role of burrowing animals. Hydrobiologia. 426: 1-24.

Kristensen, E., and Holmer, M. 2001. Decomposition of plant materials in marine sediment exposed to different electron acceptors $\left(\mathrm{O}_{2}, \mathrm{NO}_{3}{ }^{-}\right.$, and $\left.\mathrm{SO}_{4}{ }^{2-}\right)$ with emphasis on substrate origin, degradation kinetics, and the role of bioturbation. Geochim. Cosmochim. Acta. 65(3): 419-433.

Ladd, J.N., and Paul, E.A., 1973. Changes in enzymic activity and distribution of acid soluble, amino acid-nitrogen in soil during nitrogen immobilization and mineralization. Soil Biol. Biochem. 5: 825-840.

Lambertsson, L., and Nilsson, M. 2006. Organic Material: The Primary Control on Mercury Methylation and Ambient Methyl Mercury Concentrations in Estuarine Sediments. Env. Sci. Tech. 40: 1822-1829.

Larsen, D.P., Van Sickle, J., Maleug, K., and Smith, P. 1979. The Effect of Wastewater Phosphorous Removal on Shagawa Lake, Minnesota: Phosphorous Supplies, Lake Phosphorous, and Chlorophyll a. Water Res. 13: 1259-1272.

Lehmann, M.F., Bernasconi, S.M., Barbieri, A., and McKenzie, J.A. 2002. Preservation of organic matter and alteration of its carbon and nitrogen isotope composition during simulated and in situ early sedimentary diagenesis. Geochim. Cosmochim. Acta. 66 (20): 3573-3583.

Lewis, G.N., Auer, M.T., Xiang, X., and Penn, M.R. 2007. Modeling phosphorous flux in the sediments of Onondaga Lake: Insights on the timing of lake response and recovery. Eco. Modeling. 209 (2-4): 121-135. 
Likkanen, A. Huttunen, J.T., Valli, K., and Martikainen, P.J. 2002. Methane cycling in the sediment and water column of mid-boreal hyper-eutrophic Lake Kevaton, Findland. Finland. Arch. Hydrobiol. 154: 585-603.

Mason, R.P., Kim, E-H, Cornwell, J., and Heyes, D. 2006. An examination of the factors influencing the flux of mercury, methylmercury and other constituents from estuarine sediment. Mar. Chem.. 102: 96-110.

Matthews, D.A., and Effler, S.W. 2006. Long-term changes in the areal hypolimnetic oxygen demand (AHOD) of Onondaga Lake: Evidence of sediment feedback. Limnol. Oceanogr. 51: 702-714.

Matthews, D.A., Effler, S.W., Driscoll, C.T., O'Donnell, S.M., and Matthews, C. M. 2008. Electron budgets for the hypolimnion of a recovering urban lake, 1989-2004: Response to changes in organic carbon deposition and availability of electron acceptors. Limnol. Oceanogr. 53(2): 743-759.

Mayer, L.M. 1994a. Surface area control of organic matter accumulation in continental shelf sediments. Geochim. Cosmochim. Acta. 58: 1271-1284.

Mayer, L.M. 1994b. Relationships between mineral surfaces and organic carbon concentrations in soils and sediments. Chem. Geol. 114: 347-363.

Mayer, L.M. 2004. The inertness of being organic. Mar. Chem. 94: 135-140.

Mayer L. M., Schick L. L., Hardy K. R., Wagal R., and MacCarthy J. 2004. Organic matter in small mesopores in sediments and soils. Geochim. Cosmochim. Acta. 68, 3863-3872.

Middelburg, J.J., Klaver, G., Nieuwenhuize, J., Wielemaker, A., de Haas, W., Vlug, T., and van der Nat, J. 1996. Organic matter mineralization in intertidal sediments along an estuarine gradient. Mar. Ecol. Prog. Ser. 132: 157-168.

Moodley, L., Middelburg, J., Herman, P., Soetaert, K., and Lange, G. 2005. Oxygenation and organic matter preservation in marine sediments: Direct experimental evidence from ancient organic carbon-rich deposits. Geo. 33 (11): 889-892.

Mollenhauer, G., and Eglington, T. 2007 Diagenetic and sedimentological controls on the composition of organic matter preserved in California Borderland Basin sediments. Limnol. Oceanogr. 52 (2): 558-576.

Morel, F.M., Kraepiel, A.M., and Amyot, M. 1998. The chemical cycle and bioaccumulation of mercury. Annu. Rev. Ecol. Syst. 29: 543-566. 
Naidja A., Huang P. M., and Bollag J.-M. 2000. Enzyme-clay interactions and their impact on transformations of natural and anthropogenic organic compounds in soil. $J$. Env. Qual. 29: 677-691.

Nguyen, R.T., Harvey, H.R., Zang, X., van Heemst, J.D.H., Hetenyi, M. and Hatcher, P.G. R.T. 2003. Preservation of algaenan and proteinaceaous material during the oxic decay of Botryococcus braunii as revealed by pyrolysis-gas chromatography/mass spectrometry and 13C NMR spectroscopy. Org. Geochem. 34: 483-497.

Packard, T.T. 1971. The measurement of respiratory electron-transport-system activity of marine phytoplankton. J. Mar. Res. 29: 235-244.

Penn, M.R., Auer, M.T., VanOrman, E.L., and J.J. Korienek. 1995. Phosphorus diagenesis in lake sediments: Investigations using fractionation techniques. Mar. Freshwater Res. 46: 89-99.

Prepas, E. E., and Burke, J. M. 1997. "Effects of hypolimnetic oxygenation on water quality in Amisk Lake, Alberta, a deep eutrophic lake with high internal phosphorus loading rates." Can. J. Fish. Aquat. Sci. 54(9): 2111-2120.

Riedel, G.F., Sanders, J.G., and Osman, R.W. 1999. Biogeochemical control on the flux of trace elements from estuarine sediments: effects of seasonal and short-term hypoxia. Mar. Env. Res. 47: 349-372.

Rowell, H.C. 1992. Paleolimnological indications of water quality in Onondaga Lake, New York. PhD. Dissertation, State University of New York, College of Environmental Science and Forestry, Syracuse, NY.

Rowell, C. 1996. Paleolimnology of Onondaga Lake: The history of anthropogenic impacts on lake water quality. Lake Res. Manage.. 12: 35-45.

Schultz, P., and Urban, N.R. 2008. Effects of bacterial dynamics on organic matter decomposition and nutrient release from sediments: A modeling study. Eco. Modeling. 210: 1-14.

Schultz, S. Matsuyama, H, and Conrad, R. 1997. Temperature dependence of methane production from different precursors in a profundal sediment (Lake Constance). FEMS Microbio. Eco.. 22: 207-213.

Smith, V.H., Tilman, G.D., and Nekola, J.C. 1999. Eutrophication: impacts of excess nutrient inputs on freshwater, marine, and terrestrial ecosystems. Env. Poll. 100: 179196. 
Sobek, S., Durisch-Kaiser, E., Zurbrügg, R, Wongfun, N., Wessels, M., Pasche, N., and Wehril, B. 2009. Organic carbon burial efficiency in lake sediments controlled by oxygen exposure time and sediment source. Limnol. Oceanogr. 54: 2243-2254.

Soetaert, K., Herman, P.M.J., and Middelburg, J.J. 1996. A model of early diagenetic processes from the shelf to abyssal depths. Geochim. Cosmochim. Acta. 60: 10191040.

Strayer, R.F., and Tiedje, J.M. 1978. Kinetic parameters of the conversion of methane precursors to methane in a hypereutrophic lake sediment. Appl. Env. Microbio. 36 (2): 330-340.

Stromquist, V.K. 1996. Sediment oxygen demand as a manifestation of organic carbon diagenesis in the sediments of Onondaga Lake, Syracuse, NY. Master's Thesis, Michigan Technological University.

Stumm, W., and Morgan, J.J. 1996. Aqua. Chem., $3^{\text {rd }}$ Ed. Wiley, NY.

Sun, M-Y., Aller, R.C., and Lee, C. 1991. Early diagenesis of Chlorophyll-a in Long Island Sound sediments: A measure of carbon flux and particle reworking. J. of Mar. Res. 49: 379-401.

Sun, M-Y., Lee, C., and Aller, R.C. 1993. Laboratory studies of oxic and anoxic degradation of chlorophyll-a in Long Island Sound sediments. Geochim. Cosmochim. Acta. 57(1): 147-157.

Todorova, S.G., Driscoll, C.T., Matthews, D.A., Effler, S.W., Hines, M.E., and Henry, E.A. 2009. Evidence for regulation of monomethyl mercury by nitrate in a seasonally stratified, eutrophic lake. Env. Sci. Tech. 43: 6572-6578.

Thomsen, L. , vanWeering, T., and Gust, G. 2002. Processes in the benthic boundary layer at the Iberian continental margin and their implication for carbon mineralization. Prog. Oceanogr. 52: 315-329

Tromp, T.K., Van Cappellen, P., and Key, R.M. 1995. A global model for the early diagenesis of organic carbon and organic phosphorous in marine sediments. Geochim. Cosmochim. Acta. 59 (7): 1259-1284.

United States District Court. 2007. Consent Decree Onondaga Lake Bottom Subsite of the Onondaga Lake Superfund Site, Syracuse, NY. Northern District of New York. 
US EPA. 1996. Environmental Indicators of Water Quality in the United States (US EPA 841-R-96-02). Office of Water (4503F), US Government Printing Office, Washington, D.C.

Van Cappellen, P., and Wang, Y. 1996. Cycling of Iron and Manganese in surface sediments: A general theory for the coupled transport and reaction of carbon, oxygen, nitrate, sulfur, iron, and manganese. Amer. J. of Sci. 296: 197-243.

Wakeham, S.G., and Canuel, E.A. 2006. Degradation and Preservation of Organic Matter in Marine Sediments. Marine Organic Matter: Biomarkers, Isotopes, and DNA. Springer Berlin/ Heidelberg. 295-231.

Wang, W., and Driscoll, C.T. 1995 Patterns of total mercury concentration in Onondaga Lake, New York. Env. Sci. Tech. 29: 2261-2266.

Weilenmann, U., O'Melia, C.R., and Stumm, W. 1989. Particle transport in lakes: Models and measurements. Limnol. Oceanogr. 34: 1-18.

Westrich, J.T., and Berner, R.A. 1984. The role of sedimentary organic matter in bacterial sulfate reduction: The G model tested. Limnol. Oceanogr. 29 (2): 236-249

Wickman, T.W. 1996. Modeling and measurement of nitrogen diagenesis and ammonia release from the sediment of a hypereutrophic lake. M.S. Thesis, Michigan Technological University.

Winfrey, M.R., Nelson, D.R., Klevickis, S.C., and Zeikus, J.G. 1977. Association of hydrogen metabolism with methanogenesis in Lake Mendota sediments. App. Env. Microbio. 33 (2): 312-318.

Winfrey, M.R., and Zeikus, J.G. 1979. Anaerobic metabolism of immediate methane precursors in Lake Mendota. App. Env. Microbio. 37(2): 244-253.

Wijsman, J.W.M., Herman, P.M.J., Middelburg, J.J., and Soetaert, K. 2002. A model for early diagenetic processes in the continental shelf of the Black Sea. Estuarine Costal Shelf Sci. 54: 403-421.

Zeikus, J.G., and Winfrey, M.R. 1976. Temperature limitations of methanogenesis in aquatic sediments. App. Env. Microbio. 31: 99-107.

Zimmerman A. R., Chorover J., Goyne K. W., and Brantley, S. 2004. Protection of mesopore adsorbed organic matter from enzymatic degradation. Env. Sci. Tech. 38: 4542-4548 
Zinder, S.H. 1993 Physiological ecology of methanogens. In Methanogenesis: ecology, physiology, biochemistry, and genetics. Chapman \& Hall. New York, NY. P. 128-206. 


\section{Appendix A: Raw Data}

30 Degree Oxygen

Method synopsis: sediment sample was placed in $300 \mathrm{~mL}$ of artificial lake water, aerated to remove easily oxidizable reduced species and incubated with mixing at $30{ }^{\circ} \mathrm{C}$ for $\sim 100$ days. Dissolved oxygen and nitrate were measured daily and samples were re-aerated following daily measurements. Monitoring continued until an asymptote in cumulative oxygen consumption was reached.

\section{Lability calculation:}

(1) Final cumulative oxygen consumption $\left(\mathrm{mgO}_{2} \cdot \mathrm{gDW}^{-1}\right)$ is measured.

(2) Final cumulative nitrate production $\left(\mathrm{mgN} \cdot \mathrm{gDW}^{-1}\right)$ is measured.

(3) Nitrate production is expressed as a nitrogenous oxygen demand $\left(\mathrm{mgO}_{2} \cdot \mathrm{gDW}^{-1}\right)$ by applying a conversion factor of $4.57 \mathrm{mgO}_{2} \cdot \mathrm{mgNO}_{3}-\mathrm{N}^{-1}$.

(4) Carbonaceous demand $\left(\mathrm{mgO}_{2} \cdot \mathrm{gDW}^{-1}\right)$ is calculated as $(1-3)$.

(5) Carbonaceous demand is expressed as a \%DW by applying a conversion factor of $2.67 \mathrm{mgO}_{2} \cdot \mathrm{mgC}$ and dividing by 100 to yield a percent.

(6) The initial organic carbon content (\%DW) of the sample was measured.

(7) Lability, expressed as a \% of the organic carbon content is calculated as [(6 - 5) / 6 * 100]. 
Result summary:

Table A.1 30 Degree Oxygen Summary of Results

\begin{tabular}{|c|c|c|c|c|}
\hline Top of & Bottom of & Midpoint of & Mean & S.D. \\
\hline Slice $(\mathrm{cm})$ & Slice $(\mathrm{cm})$ & Slice $(\mathrm{cm})$ & Lability (\%) & Lability (\%) \\
\hline 0.50 & 1.00 & 0.75 & 84.0 & 2.80 \\
\hline 3.00 & 3.50 & 3.25 & 85.6 & 5.46 \\
\hline 6.50 & 7.00 & 6.75 & 81.7 & 5.79 \\
\hline 8.50 & 9.00 & 8.75 & 91.9 & 0.7 \\
\hline 12.50 & 13.00 & 12.75 & 87.7 & 4.14 \\
\hline 14.50 & 15.00 & 14.75 & 75.6 & 2.68 \\
\hline 21.00 & 22.00 & 21.50 & 80.3 & 7.43 \\
\hline 25.00 & 26.00 & 25.50 & 78.8 & 2.26 \\
\hline 29.00 & 30.00 & 29.50 & 91.8 & 2.23 \\
\hline 34.00 & 35.00 & 34.50 & 89.1 & 8.58 \\
\hline 39.00 & 40.00 & 39.50 & 77.8 & 2.65 \\
\hline 50.00 & 51.00 & 50.50 & 67.6 & 2.15 \\
\hline 55.00 & 56.00 & 55.50 & 74.8 & 1.10 \\
\hline 60.00 & 62.00 & 61.00 & 67.4 & 1.86 \\
\hline 70.00 & 72.00 & 71.00 & 71.9 & 2.40 \\
\hline
\end{tabular}




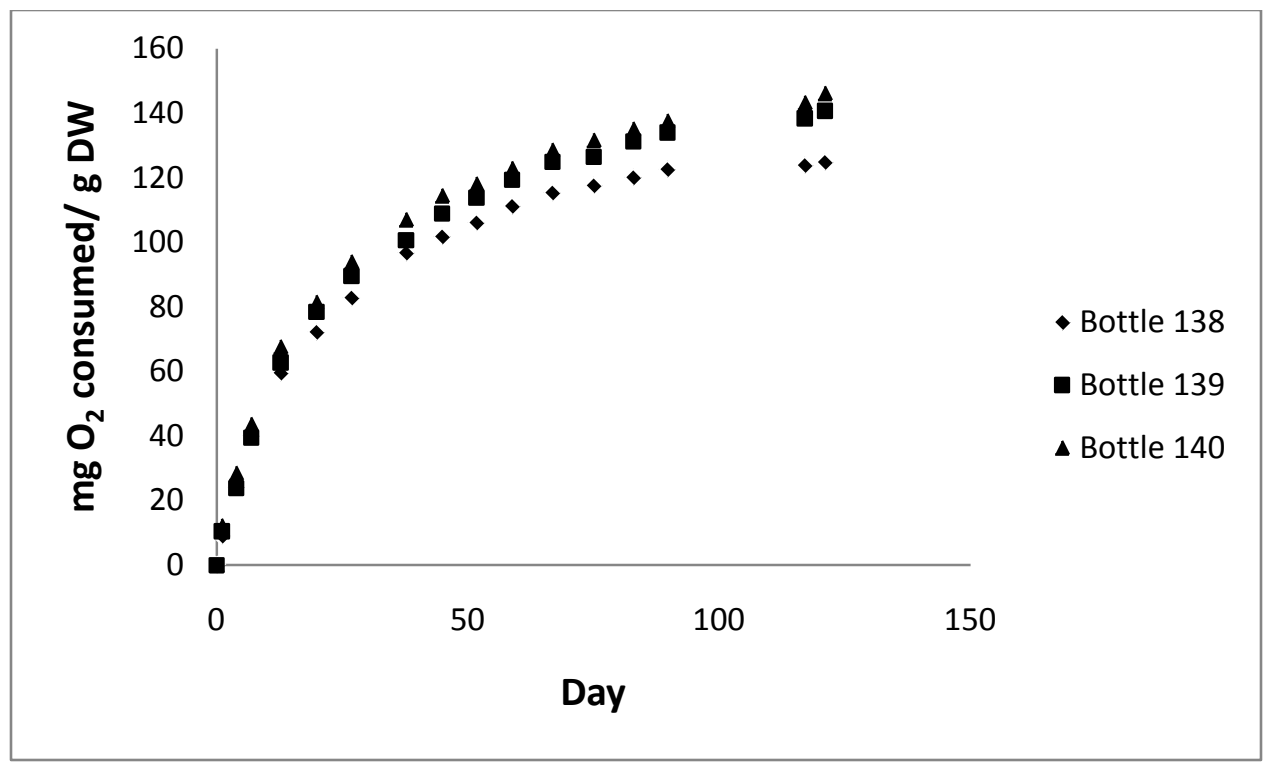

Figure A.1 Oxygen consumed from the $0.5-1 \mathrm{~cm}$ slice.

\begin{tabular}{|c|c|c|c|c|c|c|c|}
\hline \multicolumn{8}{|c|}{ Table A.2: 0.5-1 cm Sediment Slice Lability } \\
\hline Bottle & $\begin{array}{l}\text { Oxygen } \\
\text { Consumed } \\
\mathrm{mgO}_{2} \cdot \mathrm{gDW}^{-1}\end{array}$ & $\begin{array}{l}\text { Nitrate } \\
\text { Produced } \\
\mathrm{mgN} \cdot \mathrm{gDW}^{-1}\end{array}$ & $\begin{array}{l}\text { Nitrogenous } \\
\text { Demand } \\
\mathrm{mgO}_{2} \cdot \mathrm{gDW}^{-1}\end{array}$ & $\begin{array}{l}\text { Carbonaceous } \\
\text { Demand } \\
\mathrm{mgO}_{2} \cdot \mathrm{gDW}^{-1}\end{array}$ & $\begin{array}{l}\text { Carbonaceous } \\
\text { Demand } \\
\text { C, \%DW }\end{array}$ & $\begin{array}{l}\text { Initial } \\
\text { Carbon } \\
\text { C, \%DW }\end{array}$ & $\begin{array}{l}\text { Carbon } \\
\text { Lability } \\
\%\end{array}$ \\
\hline 138 & 122.6 & 4.5 & 20.6 & 102.1 & 3.8 & 4.7 & 81.3 \\
\hline 139 & 134.0 & 6.3 & 28.8 & 105.2 & 4.0 & 4.7 & 83.8 \\
\hline 140 & 137.6 & 6.2 & 28.5 & 109.1 & 4.1 & 4.7 & 86.8 \\
\hline & & & & & & Mean & 84.0 \\
\hline & & & & & & S.D. & 2.8 \\
\hline
\end{tabular}




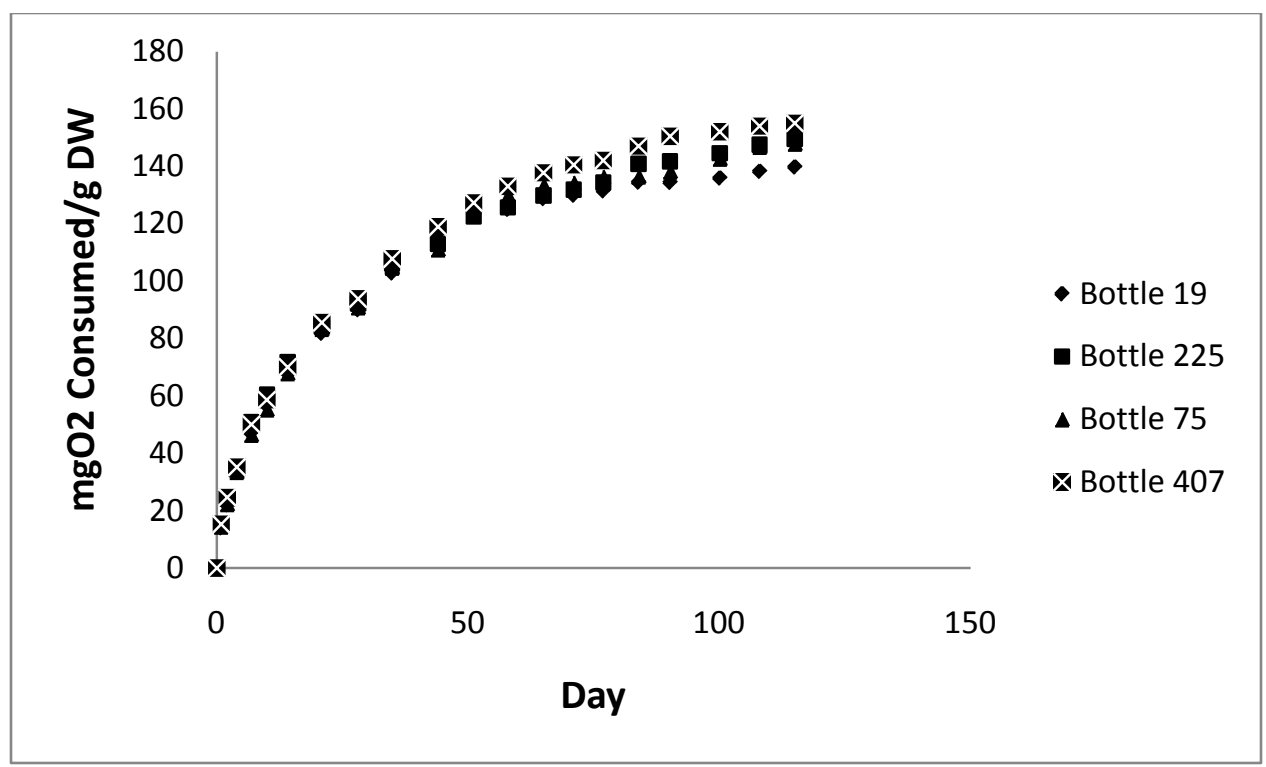

Figure A.2: Oxygen consumed from the $3-3.5 \mathrm{~cm}$ slice.

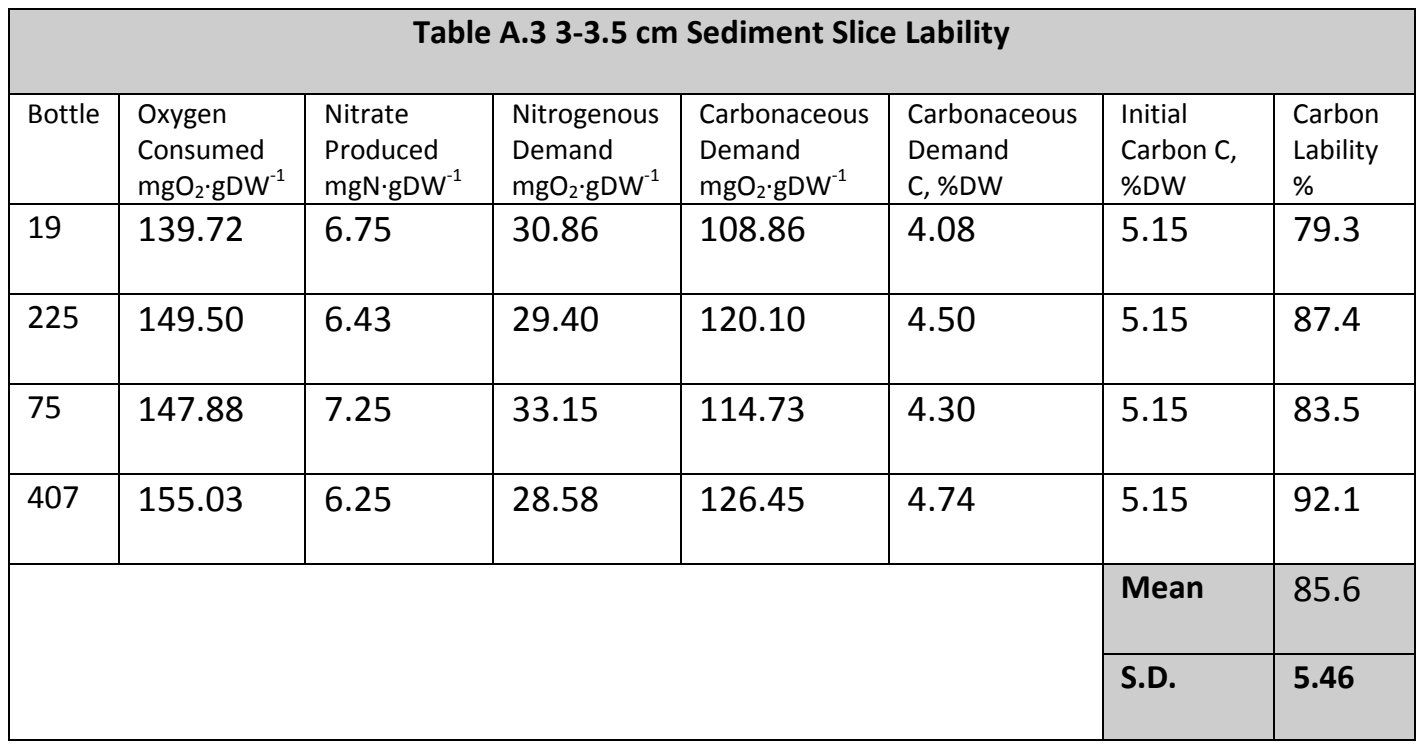




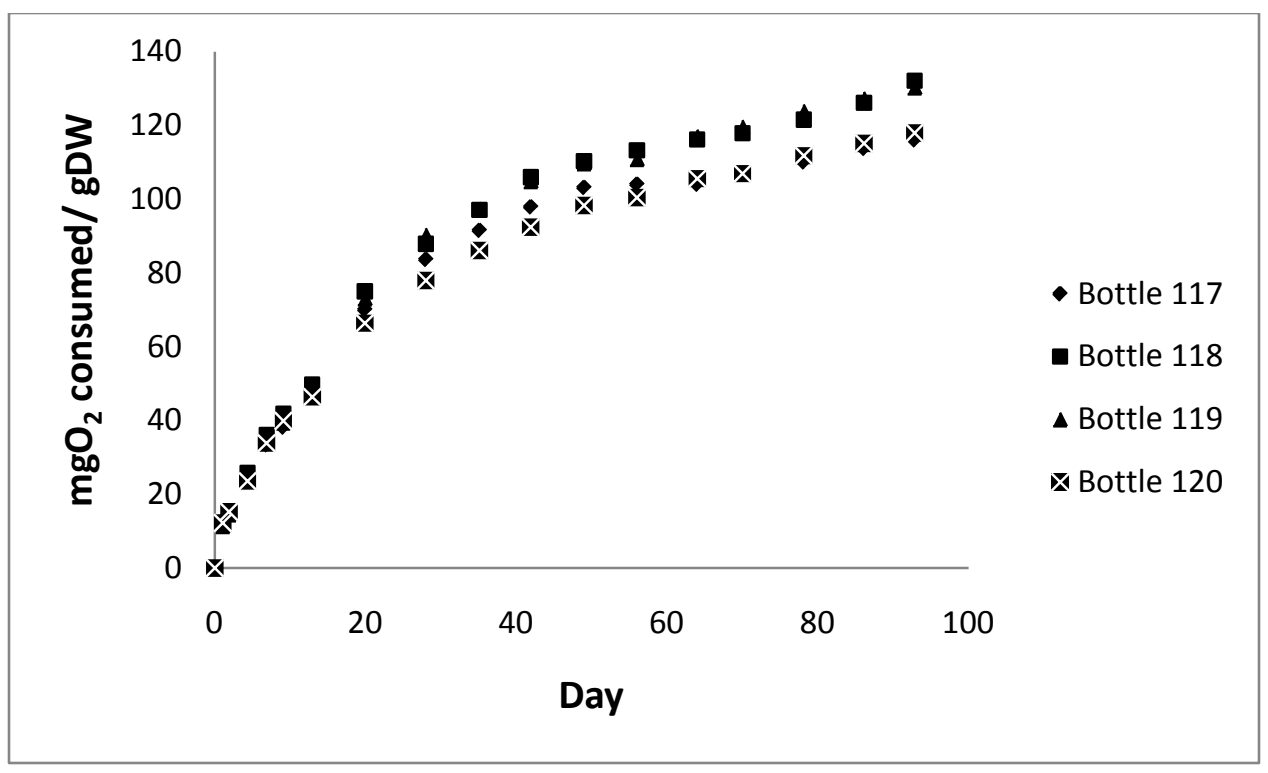

Figure A.3 Oxygen consumed from the $6.5-7 \mathrm{~cm}$ slice.

\begin{tabular}{|l|l|l|l|l|l|l|l|}
\hline \multicolumn{7}{|c|}{ Table A.4 6.5-7 cm Sediment Slice Lability } \\
\hline Bottle & $\begin{array}{l}\text { Oxygen } \\
\text { Consumed } \\
\mathrm{mgO}_{2} \cdot \mathrm{gDW}^{-1}\end{array}$ & $\begin{array}{l}\text { Nitrate } \\
\text { Produced } \\
\mathrm{mgN} \cdot \mathrm{gDW}^{-1}\end{array}$ & $\begin{array}{l}\text { Nitrogenous } \\
\text { Demand } \\
\mathrm{mgO}_{2} \cdot \mathrm{gDW}^{-1}\end{array}$ & $\begin{array}{l}\text { Carbonaceous } \\
\text { Demand } \\
\mathrm{mgO}_{2} \cdot \mathrm{gDW}^{-1}\end{array}$ & $\begin{array}{l}\text { Carbonaceous } \\
\text { Demand } \\
\text { C, \%DW }\end{array}$ & $\begin{array}{l}\text { Initial } \\
\text { Carbon C, } \\
\% \mathrm{DW}\end{array}$ & $\begin{array}{l}\text { Carbon } \\
\text { Lability } \\
\%\end{array}$ \\
\hline 117 & 115.99 & 3.85 & 17.61 & 98.38 & 3.69 & 4.78 & 77.2 \\
\hline 118 & 132.07 & 4.52 & 20.65 & 111.42 & 4.18 & 4.78 & 87.4 \\
\hline 119 & 130.22 & 4.54 & 20.75 & 109.47 & 4.11 & 4.78 & 85.9 \\
\hline 120 & 117.94 & 4.55 & 20.79 & 97.15 & 3.64 & 4.78 & 76.2 \\
\hline & & & & & & Mean & 81.7 \\
\cline { 4 - 8 } & & & & & S.D. & 5.79 \\
\end{tabular}




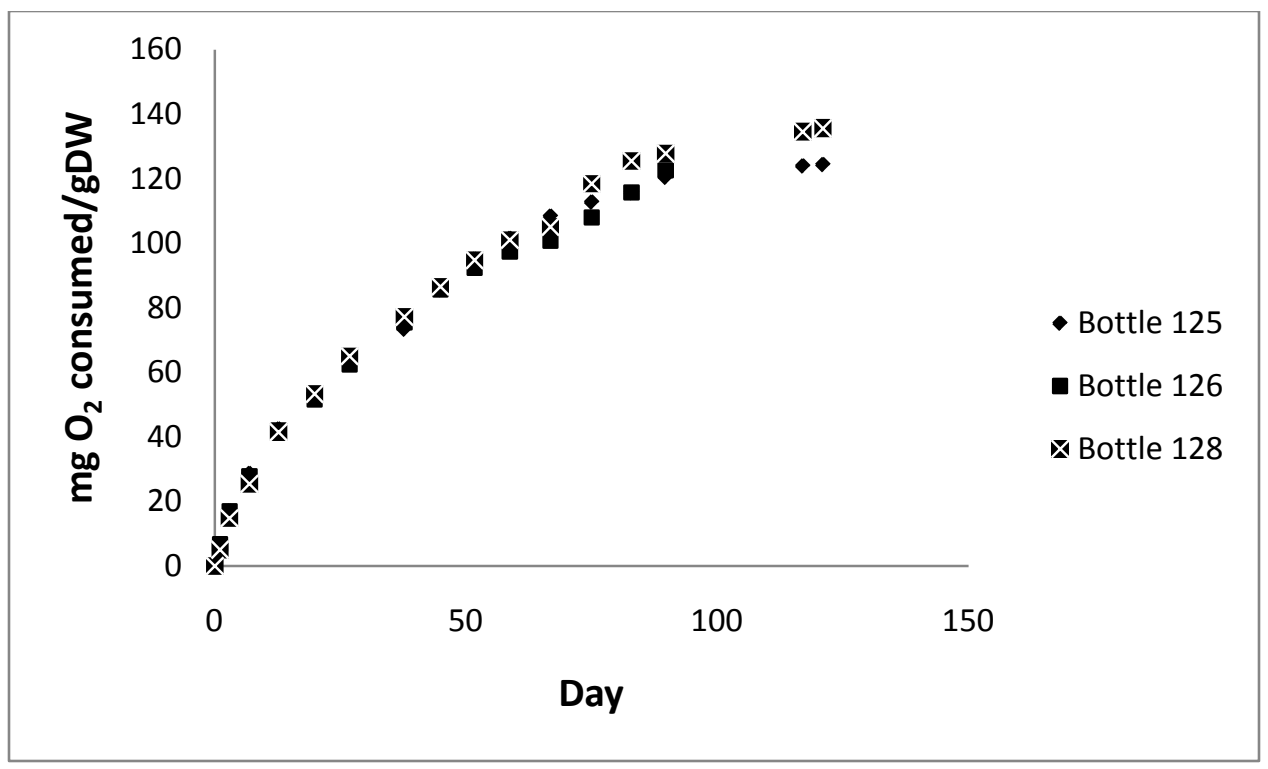

Figure A.4 Oxygen consumed from the $8.5-9 \mathrm{~cm}$ slice.

\begin{tabular}{|l|l|l|l|l|l|l|l|}
\hline \multicolumn{7}{|c|}{ Table A.5 8.5-9 cm Sediment Slice Lability } \\
\hline Bottle & $\begin{array}{l}\text { Oxygen } \\
\text { Consumed } \\
\mathrm{mgO}_{2} \cdot \mathrm{gDW}^{-1}\end{array}$ & $\begin{array}{l}\text { Nitrate } \\
\text { Produced } \\
\mathrm{mgN} \cdot \mathrm{gDW}^{-1}\end{array}$ & $\begin{array}{l}\text { Nitrogenous } \\
\text { Demand } \\
\mathrm{mgO}_{2} \cdot \mathrm{gDW}^{-1}\end{array}$ & $\begin{array}{l}\text { Carbonaceous } \\
\text { Demand } \\
\mathrm{mgO}_{2} \cdot \mathrm{gDW}^{-1}\end{array}$ & $\begin{array}{l}\text { Carbonaceous } \\
\text { Demand } \\
\mathrm{C}, \% \mathrm{WW}\end{array}$ & $\begin{array}{l}\text { Initial } \\
\text { Carbon C, } \\
\% \mathrm{WW}\end{array}$ & $\begin{array}{l}\text { Carbon } \\
\text { Lability } \\
\%\end{array}$ \\
\hline 125 & 120.41 & 3.21 & 14.66 & 105.75 & 3.97 & 4.34 & 91.4 \\
\hline 126 & 122.55 & 3.61 & 16.50 & 106.05 & 3.98 & 4.34 & 91.6 \\
\hline 128 & 127.77 & 4.48 & 20.47 & 107.30 & 4.02 & 4.34 & 92.7 \\
\hline
\end{tabular}




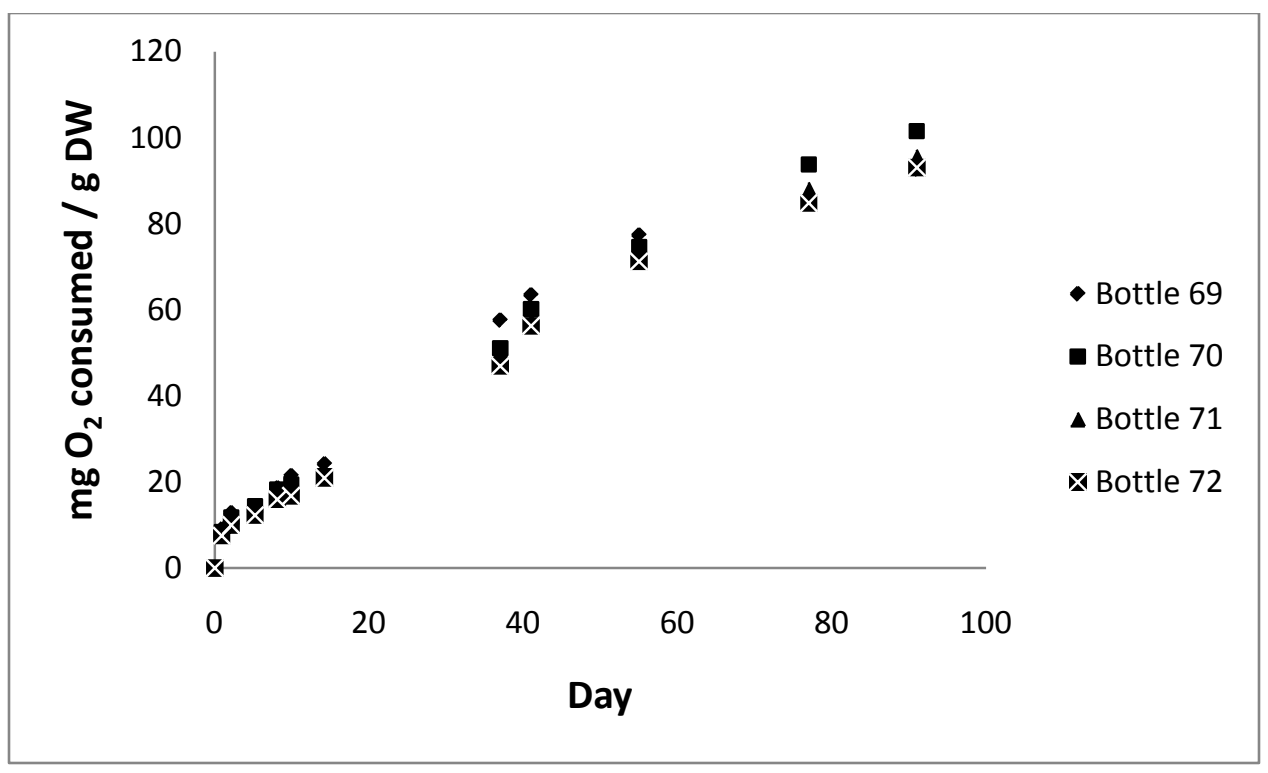

Figure A.5 Oxygen consumed from the $12.5-13 \mathrm{~cm}$ slice.

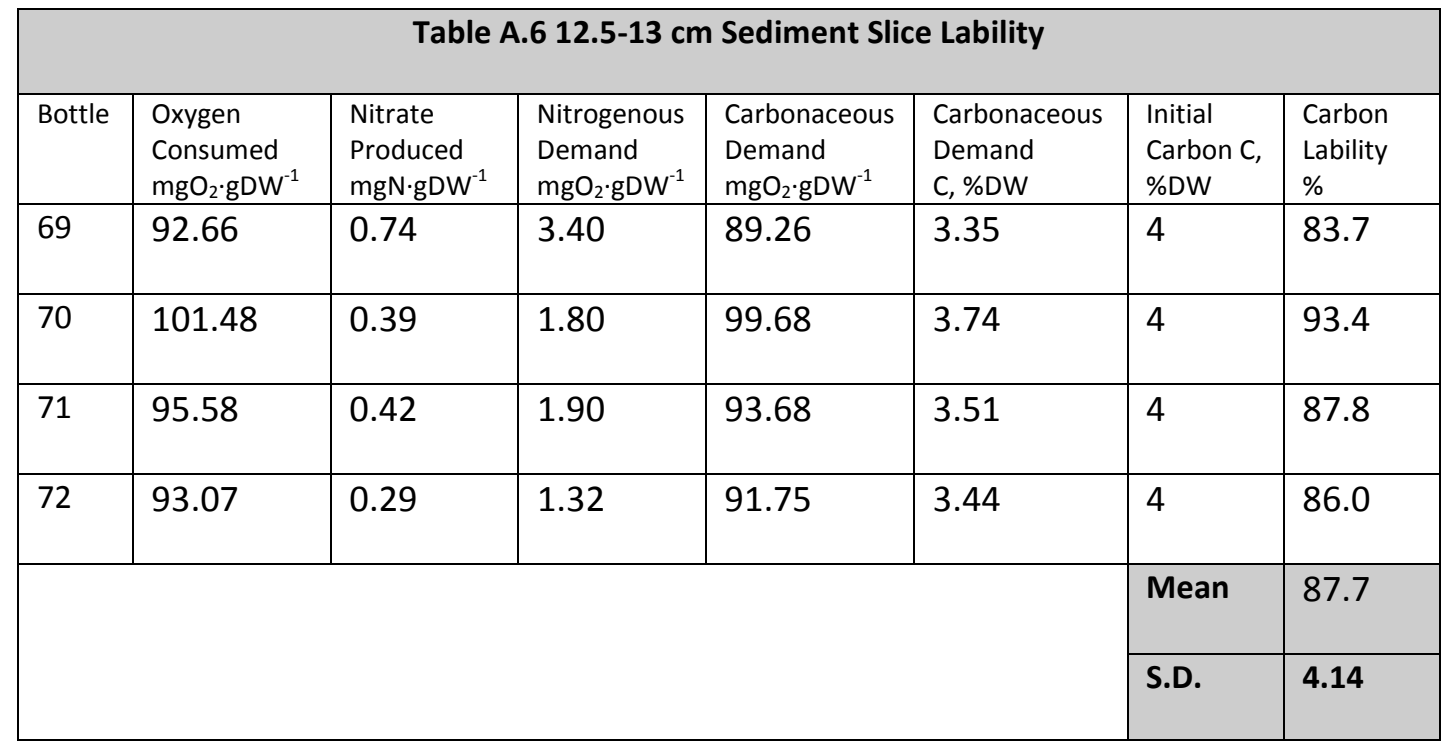




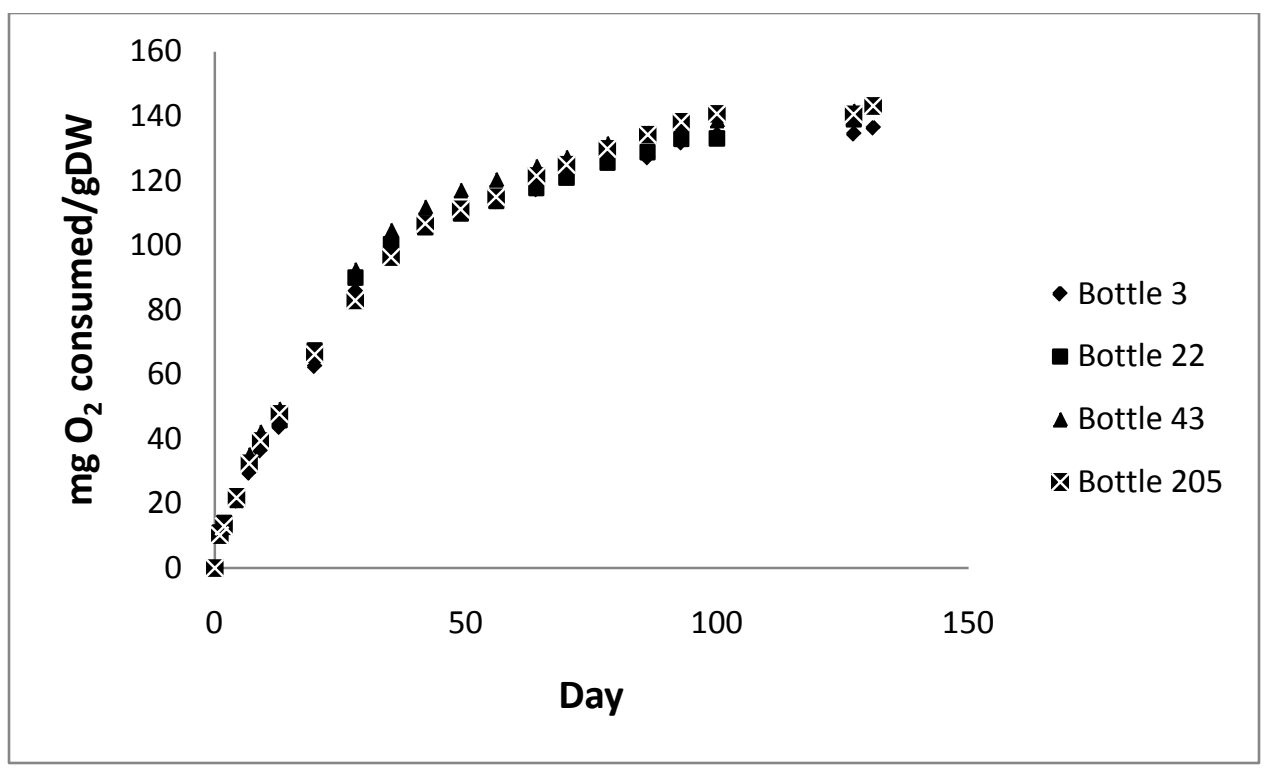

Figure A.6 Oxygen consumed from the $14.5-15 \mathrm{~cm}$ slice.

\begin{tabular}{|l|l|l|l|l|l|l|l|}
\hline \multicolumn{7}{|c|}{ Table A.7 14.5-15 cm Sediment Slice Lability } \\
\hline Bottle & $\begin{array}{l}\text { Oxygen } \\
\text { Consumed } \\
\mathrm{mgO}_{2} \cdot \mathrm{gDW}^{-1}\end{array}$ & $\begin{array}{l}\text { Nitrate } \\
\text { Produced } \\
\mathrm{mgN} \cdot \mathrm{gDW}^{-1}\end{array}$ & $\begin{array}{l}\text { Nitrogenous } \\
\text { Demand } \\
\mathrm{mgO}_{2} \cdot \mathrm{gDW}^{-1}\end{array}$ & $\begin{array}{l}\text { Carbonaceous } \\
\text { Demand } \\
\mathrm{mgO}_{2} \cdot \mathrm{gDW}^{-1}\end{array}$ & $\begin{array}{l}\text { Carbonaceous } \\
\text { Demand } \\
\text { C, \%DW }\end{array}$ & $\begin{array}{l}\text { Initial } \\
\text { Carbon C, } \\
\% \mathrm{DW}\end{array}$ & $\begin{array}{l}\text { Carbon } \\
\text { Lability } \\
\%\end{array}$ \\
\hline 3 & 134.22 & 4.29 & 19.62 & 114.60 & 4.30 & 5.86 & 73.3 \\
\hline 22 & 133.11 & 4.06 & 18.55 & 114.57 & 4.30 & 5.86 & 73.3 \\
\hline 43 & 138.76 & 3.97 & 18.14 & 120.62 & 4.52 & 5.86 & 77.2 \\
\hline 205 & 140.73 & 3.96 & 18.08 & 122.65 & 4.60 & 5.86 & 78.5 \\
\hline
\end{tabular}




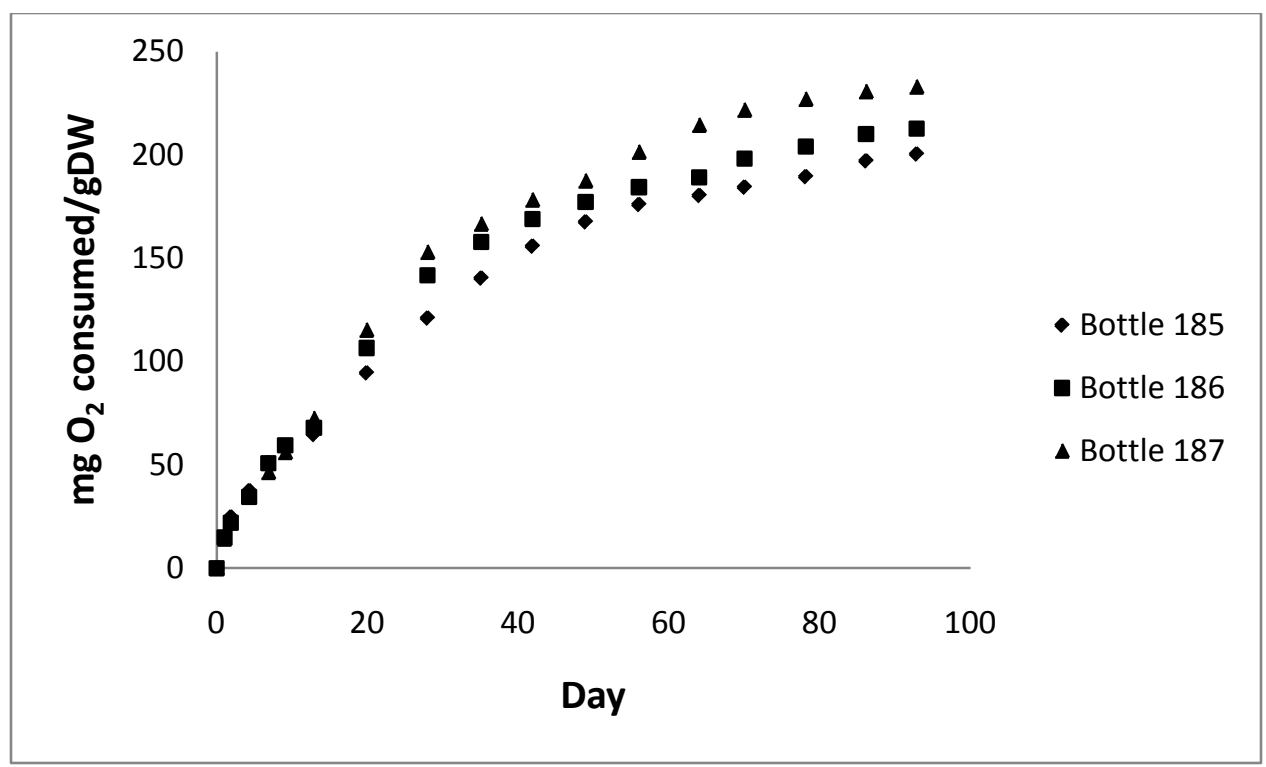

Figure A.7 Oxygen consumed from the $21-22 \mathrm{~cm}$ slice.

\begin{tabular}{|l|l|l|l|l|l|l|l|}
\hline \multicolumn{7}{|c|}{ Table A.8 21-22 cm Sediment Slice Lability } \\
\hline Bottle & $\begin{array}{l}\text { Oxygen } \\
\text { Consumed } \\
\mathrm{mgO}_{2} \cdot \mathrm{gDW}^{-1}\end{array}$ & $\begin{array}{l}\text { Nitrate } \\
\text { Produced } \\
\mathrm{mgN} \cdot \mathrm{gDW}^{-1}\end{array}$ & $\begin{array}{l}\text { Nitrogenous } \\
\text { Demand } \\
\mathrm{mgO}_{2} \cdot \mathrm{gDW}^{-1}\end{array}$ & $\begin{array}{l}\text { Carbonaceous } \\
\text { Demand } \\
\mathrm{mgO}_{2} \cdot \mathrm{gDW}^{-1}\end{array}$ & $\begin{array}{l}\text { Carbonaceous } \\
\text { Demand } \\
\mathrm{C}, \% \mathrm{DW}\end{array}$ & $\begin{array}{l}\text { Initial } \\
\text { Carbon } \\
\mathrm{C}, \% \mathrm{DW}\end{array}$ & $\begin{array}{l}\text { Carbon } \\
\text { Lability } \\
\%\end{array}$ \\
\hline 185 & 200.43 & 3.89 & 17.77 & 182.66 & 6.85 & 9.28 & 73.8 \\
\hline 186 & 212.71 & 3.92 & 17.91 & 194.80 & 7.30 & 9.28 & 78.7 \\
\hline 187 & 233.02 & 3.14 & 14.36 & 218.66 & 8.20 & 9.28 & 88.4 \\
\hline & & & & & & Mean & 80.3 \\
\cline { 3 - 7 } & & & & & S.D. & 7.43 \\
\hline
\end{tabular}




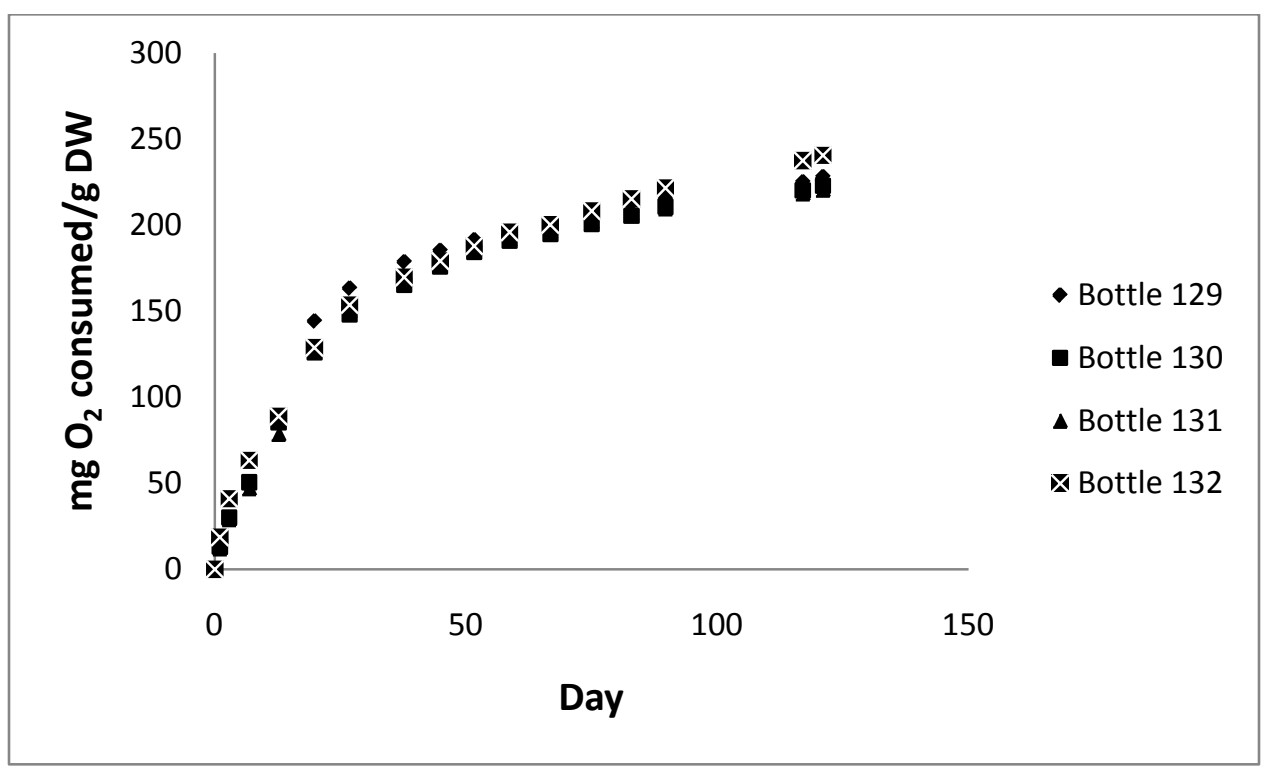

Figure A.8 Oxygen consumed from the $25-26 \mathrm{~cm}$ slice.

\begin{tabular}{|l|l|l|l|l|l|l|l|}
\hline \multicolumn{7}{|c|}{ Table A.9 25-26 cm Sediment Slice Lability } \\
\hline Bottle & $\begin{array}{l}\text { Oxygen } \\
\text { Consumed } \\
\mathrm{mgO}_{2} \cdot \mathrm{gDW}^{-1}\end{array}$ & $\begin{array}{l}\text { Nitrate } \\
\text { Produced } \\
\mathrm{mgN} \cdot \mathrm{gDW}^{-1}\end{array}$ & $\begin{array}{l}\text { Nitrogenous } \\
\text { Demand } \\
\mathrm{mgO}_{2} \cdot \mathrm{gDW}^{-1}\end{array}$ & $\begin{array}{l}\text { Carbonaceous } \\
\text { Demand } \\
\mathrm{mgO}_{2} \cdot \mathrm{gDW}^{-1}\end{array}$ & $\begin{array}{l}\text { Carbonaceous } \\
\text { Demand } \\
\mathrm{C}, \% \mathrm{DW}\end{array}$ & $\begin{array}{l}\text { Initial } \\
\text { Carbon } \\
\text { C, \%DW }\end{array}$ & $\begin{array}{l}\text { Carbon } \\
\text { Lability } \\
\%\end{array}$ \\
\hline 129 & 215.11 & 3.85 & 17.60 & 197.51 & 7.41 & 9.41 & 78.7 \\
\hline 130 & 210.70 & 3.05 & 13.93 & 196.77 & 7.38 & 9.41 & 78.4 \\
\hline 131 & 209.65 & 3.99 & 18.22 & 191.42 & 7.18 & 9.41 & 76.3 \\
\hline 132 & 221.45 & 3.55 & 16.24 & 205.21 & 7.70 & 9.41 & 81.8 \\
\hline & & & & & & Mean & 78.8 \\
& & & & & & S.D. & $\mathbf{2 . 2 6}$ \\
\hline
\end{tabular}




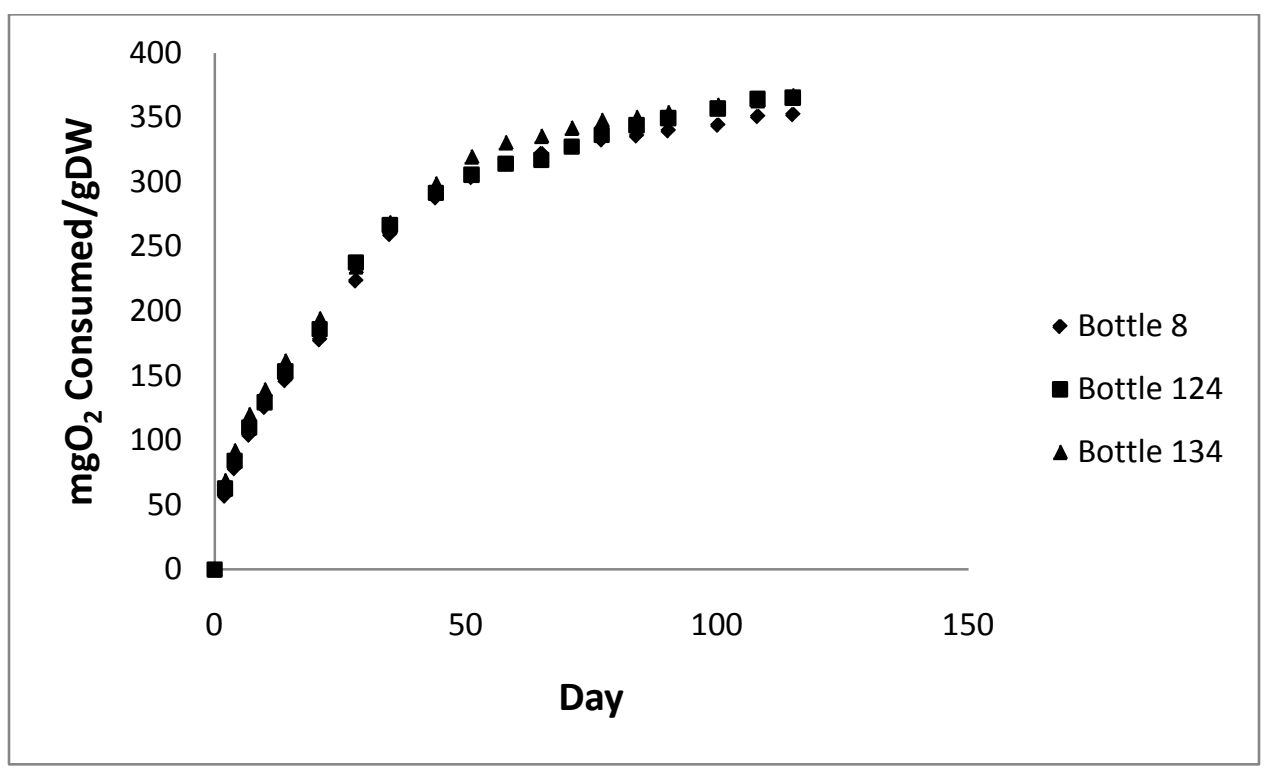

Figure A.9 Oxygen consumed from the $29-30 \mathrm{~cm}$ slice.

\begin{tabular}{|l|l|l|l|l|l|l|l|}
\hline \multicolumn{7}{|c|}{ Table A.10 29-30 cm Sediment Slice Lability } \\
\hline Bottle & $\begin{array}{l}\text { Oxygen } \\
\text { Consumed } \\
\mathrm{mgO}_{2} \cdot \mathrm{gDW}^{-1}\end{array}$ & $\begin{array}{l}\text { Nitrate } \\
\text { Produced } \\
\mathrm{mgN} \cdot \mathrm{gDW}^{-1}\end{array}$ & $\begin{array}{l}\text { Nitrogenous } \\
\text { Demand } \\
\mathrm{mgO}_{2} \cdot \mathrm{gDW}^{-1}\end{array}$ & $\begin{array}{l}\text { Carbonaceous } \\
\text { Demand } \\
\mathrm{mgO}_{2} \cdot \mathrm{gDW}^{-1}\end{array}$ & $\begin{array}{l}\text { Carbonaceous } \\
\text { Demand } \\
\mathrm{C}, \% \mathrm{DW}\end{array}$ & $\begin{array}{l}\text { Initial } \\
\text { Carbon } \\
\mathrm{C}, \% \mathrm{DW}\end{array}$ & $\begin{array}{l}\text { Carbon } \\
\text { Lability } \\
\%\end{array}$ \\
\hline 8 & 352.17 & 5.26 & 24.02 & 328.16 & 12.31 & 13.8 & 89.2 \\
\hline 124 & 365.37 & 5.14 & 23.47 & 341.90 & 12.82 & 13.8 & 92.9 \\
\hline 134 & 367.17 & 5.28 & 24.11 & 343.06 & 12.86 & 13.8 & 93.2 \\
\hline & & & & & & Mean & $\mathbf{9 1 . 8}$ \\
\end{tabular}




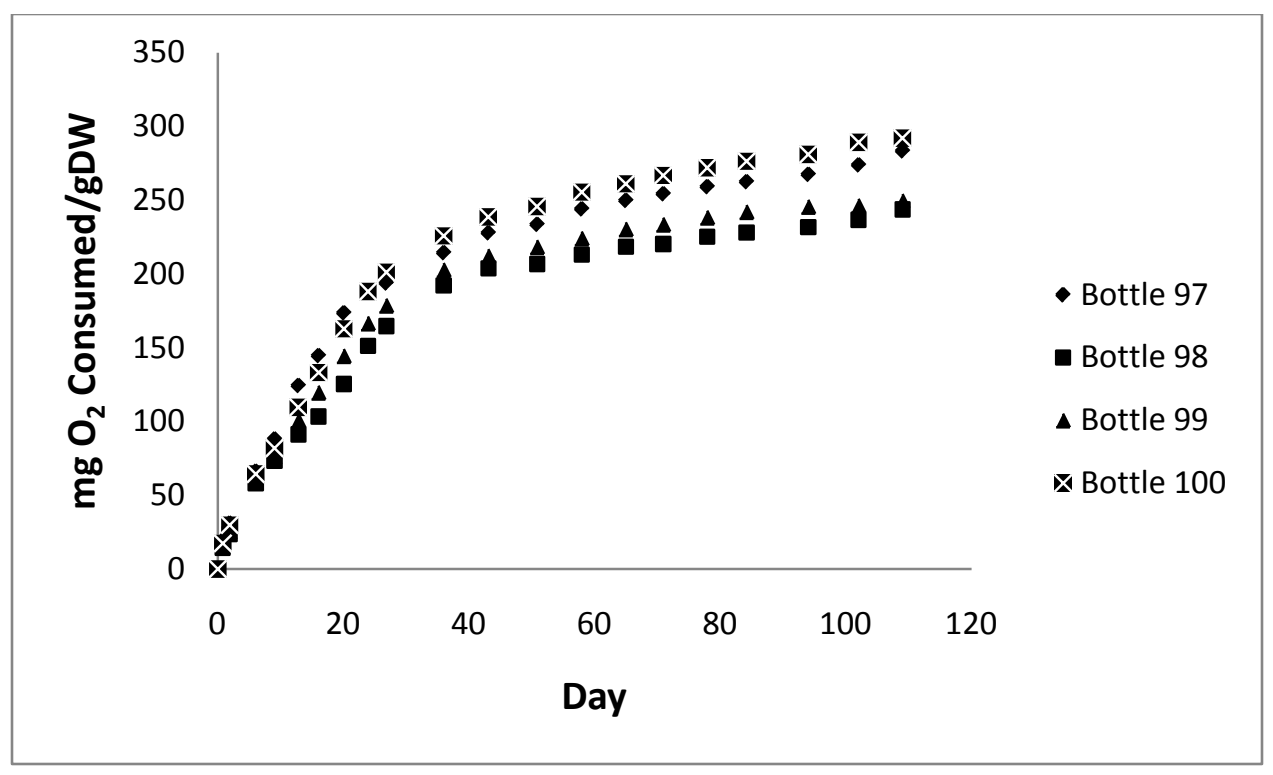

Figure A.10 Oxygen consumed from the $34-35 \mathrm{~cm}$ slice.

\begin{tabular}{|l|l|l|l|l|l|l|l|}
\hline \multicolumn{7}{|c|}{ Table A.11 34-35 cm Sediment Slice Lability } \\
\hline Bottle & $\begin{array}{l}\text { Oxygen } \\
\text { Consumed } \\
\mathrm{mgO}_{2} \cdot \mathrm{gDW}^{-1}\end{array}$ & $\begin{array}{l}\text { Nitrate } \\
\text { Produced } \\
\mathrm{mgN} \cdot \mathrm{gDW}^{-1}\end{array}$ & $\begin{array}{l}\text { Nitrogenous } \\
\text { Demand } \\
\mathrm{mgO}_{2} \cdot \mathrm{gDW}^{-1}\end{array}$ & $\begin{array}{l}\text { Carbonaceous } \\
\text { Demand } \\
\mathrm{mgO}_{2} \cdot \mathrm{gDW}^{-1}\end{array}$ & $\begin{array}{l}\text { Carbonaceous } \\
\text { Demand } \\
\mathrm{C}, \% \mathrm{DW}\end{array}$ & $\begin{array}{l}\text { Initial } \\
\text { Carbon } \\
\mathrm{C}, \% \mathrm{DW}\end{array}$ & $\begin{array}{l}\text { Carbon } \\
\text { Lability } \\
\%\end{array}$ \\
\hline 97 & 283.22 & 4.40 & 20.11 & 263.11 & 9.87 & 10.35 & 95.3 \\
\hline 98 & 243.74 & 4.35 & 19.90 & 223.85 & 8.39 & 10.35 & 81.1 \\
\hline 99 & 249.35 & 4.88 & 22.31 & 227.03 & 8.51 & 10.35 & 82.3 \\
\hline 100 & 292.07 & 4.99 & 22.81 & 269.26 & 10.10 & 10.35 & 97.6 \\
\hline & & & & & & Mean & $\mathbf{8 9 . 1}$ \\
\cline { 5 - 8 } & & & & & & S.D. & $\mathbf{8 . 5 8}$ \\
\hline
\end{tabular}




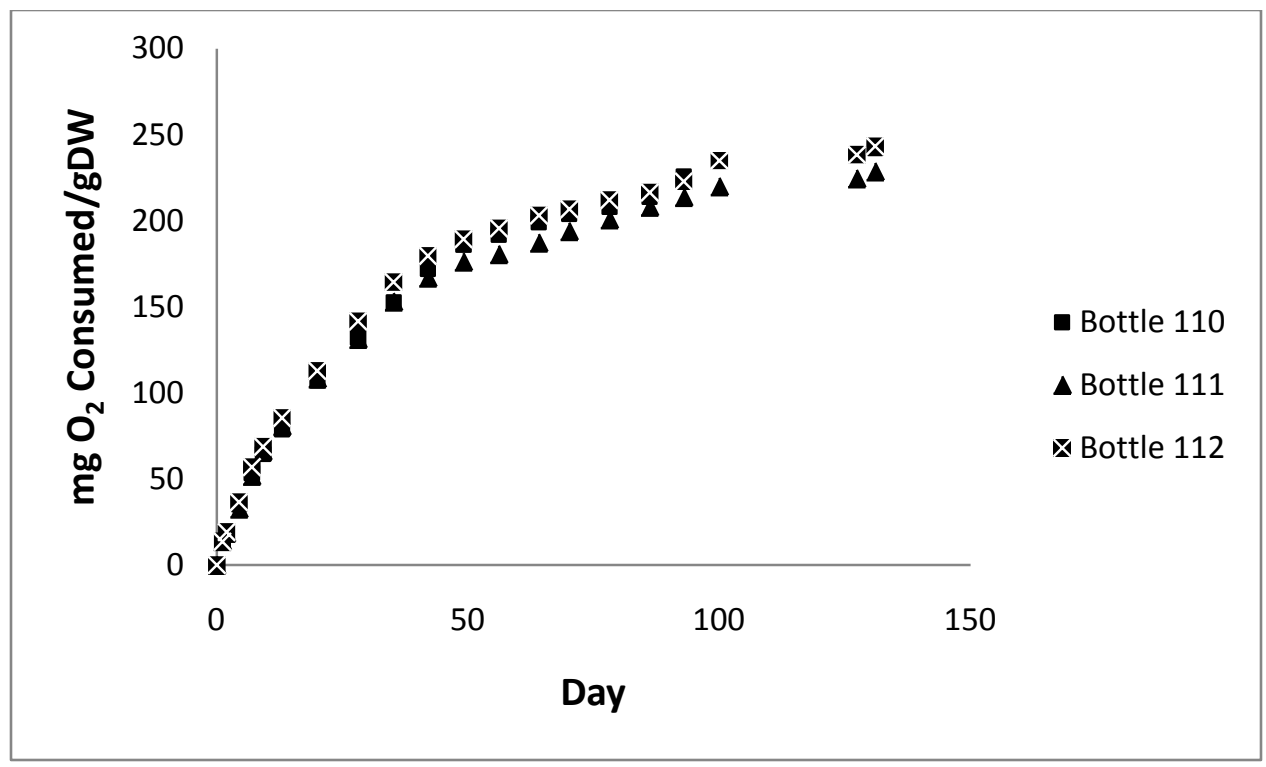

Figure A.11 Oxygen consumed from the $39-40 \mathrm{~cm}$ slice.

\begin{tabular}{|l|l|l|l|l|l|l|l|}
\hline \multicolumn{7}{|c|}{ Table A. 12 39-40 cm Sediment Slice Lability } \\
\hline Bottle & $\begin{array}{l}\text { Oxygen } \\
\text { Consumed } \\
\mathrm{mgO}_{2} \cdot \mathrm{gDW}^{-1}\end{array}$ & $\begin{array}{l}\text { Nitrate } \\
\text { Produced } \\
\mathrm{mgN} \cdot \mathrm{gDW}^{-1}\end{array}$ & $\begin{array}{l}\text { Nitrogenous } \\
\text { Demand } \\
\mathrm{mgO}_{2} \cdot \mathrm{gDW}^{-1}\end{array}$ & $\begin{array}{l}\text { Carbonaceous } \\
\text { Demand } \\
\mathrm{mgO}_{2} \cdot \mathrm{gDW}^{-1}\end{array}$ & $\begin{array}{l}\text { Carbonaceous } \\
\text { Demand } \\
\mathrm{C}, \% \mathrm{DW}\end{array}$ & $\begin{array}{l}\text { Initial } \\
\text { Carbon } \\
\mathrm{C}, \% \mathrm{DW}\end{array}$ & $\begin{array}{l}\text { Carbon } \\
\text { Lability } \\
\%\end{array}$ \\
\hline 110 & 235.08 & 5.50 & 25.15 & 209.93 & 7.87 & 10.04 & 78.4 \\
\hline 111 & 219.89 & 4.21 & 19.26 & 200.63 & 7.52 & 10.04 & 74.9 \\
\hline 112 & 234.94 & 4.51 & 20.60 & 214.34 & 8.04 & 10.04 & 80.1 \\
\hline
\end{tabular}




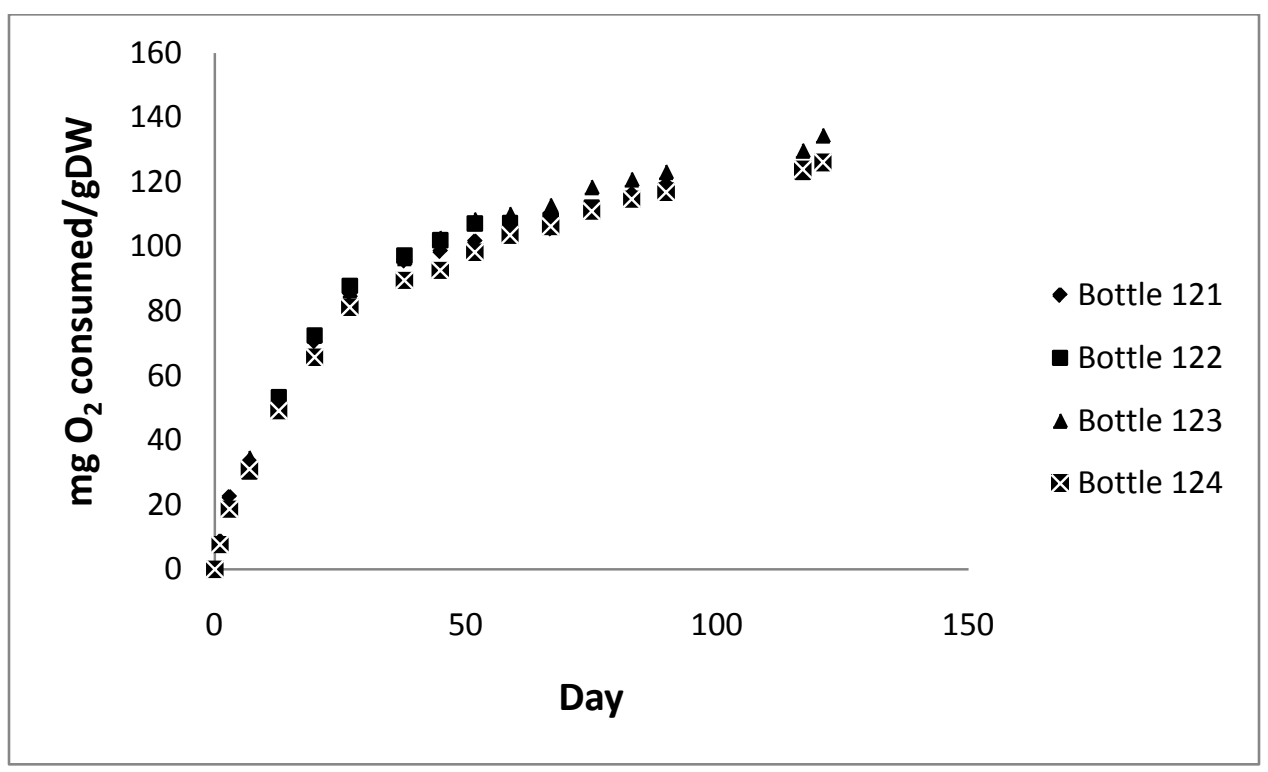

Figure A.12 Oxygen consumed from the $50-51 \mathrm{~cm}$ slice.

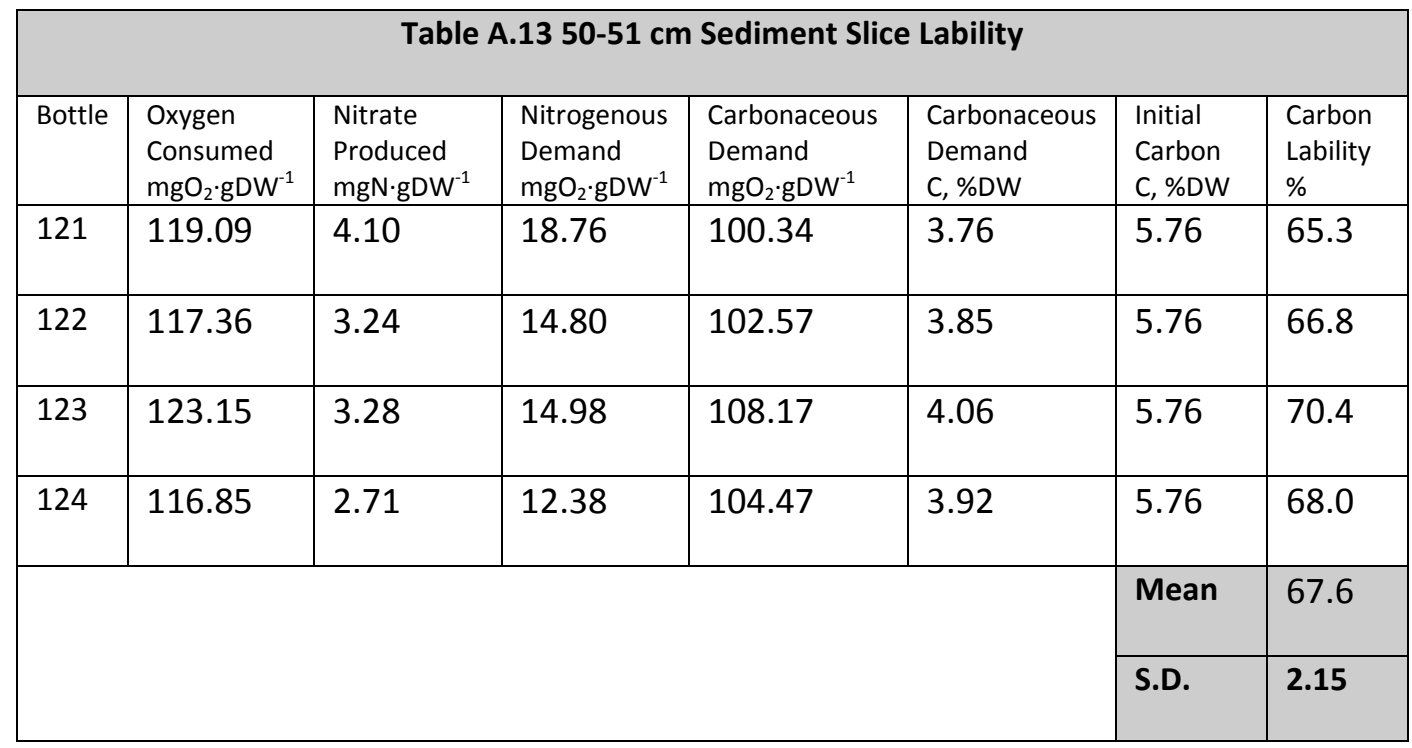




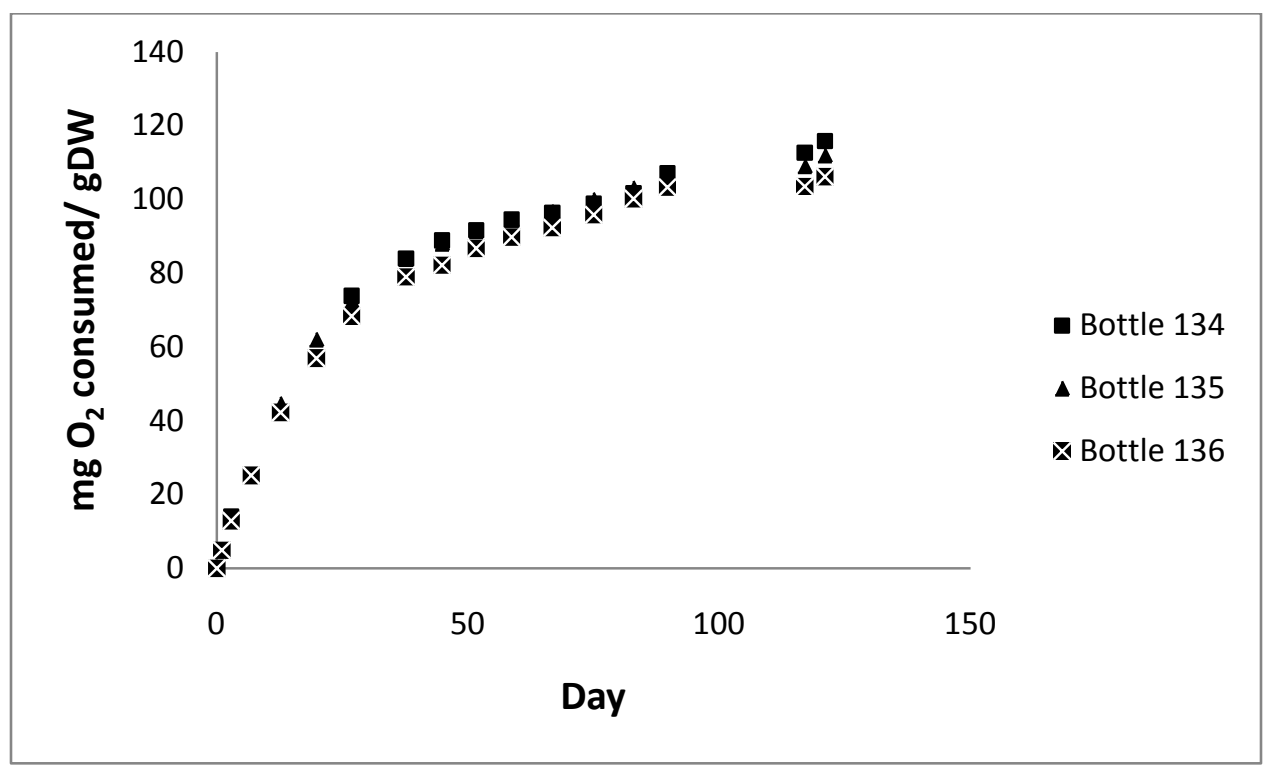

Figure A. 13 Oxygen consumed from the $55-56 \mathrm{~cm}$ slice.

\begin{tabular}{|l|l|l|l|l|l|l|l|}
\hline \multicolumn{7}{|c|}{ Table A.14 55-56 cm Sediment Slice Lability } \\
\hline Bottle & $\begin{array}{l}\text { Oxygen } \\
\text { Consumed } \\
\mathrm{mgO}_{2} \cdot \mathrm{gDW}^{-1}\end{array}$ & $\begin{array}{l}\text { Nitrate } \\
\text { Produced } \\
\mathrm{mgN} \cdot \mathrm{gDW}^{-1}\end{array}$ & $\begin{array}{l}\text { Nitrogenous } \\
\text { Demand } \\
\mathrm{mgO}_{2} \cdot \mathrm{gDW}^{-1}\end{array}$ & $\begin{array}{l}\text { Carbonaceous } \\
\text { Demand } \\
\mathrm{mgO}_{2} \cdot \mathrm{gDW}^{-1}\end{array}$ & $\begin{array}{l}\text { Carbonaceous } \\
\text { Demand } \\
\mathrm{C}, \% \mathrm{DW}\end{array}$ & $\begin{array}{l}\text { Initial } \\
\text { Carbon } \\
\mathrm{C}, \% \mathrm{DW}\end{array}$ & $\begin{array}{l}\text { Carbon } \\
\text { Lability } \\
\%\end{array}$ \\
\hline 134 & 107.14 & 3.43 & 15.67 & 91.46 & 3.43 & 4.52 & 75.9 \\
\hline 135 & 105.10 & 3.56 & 16.26 & 88.84 & 3.33 & 4.52 & 73.7 \\
\hline 136 & 103.30 & 2.88 & 13.14 & 90.16 & 3.38 & 4.52 & 74.8 \\
\hline
\end{tabular}




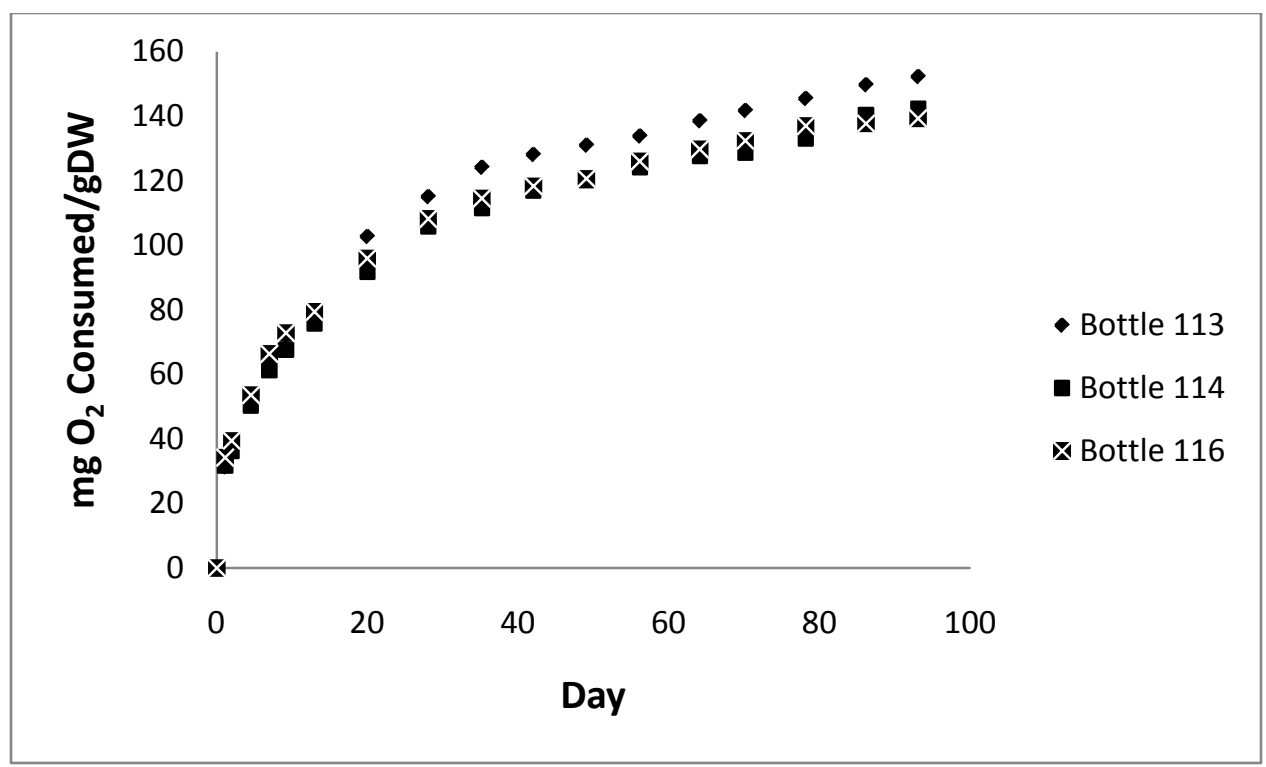

Figure A.14 Oxygen consumed from the $60-62 \mathrm{~cm}$ slice.

\begin{tabular}{|l|l|l|l|l|l|l|l|}
\hline \multicolumn{7}{|c|}{ Table A.15 60-62 cm Sediment Slice Lability } \\
\hline Bottle & $\begin{array}{l}\text { Oxygen } \\
\text { Consumed } \\
\mathrm{mgO}_{2} \cdot \mathrm{gDW}^{-1}\end{array}$ & $\begin{array}{l}\text { Nitrate } \\
\text { Produced } \\
\mathrm{mgN} \cdot \mathrm{gDW}^{-1}\end{array}$ & $\begin{array}{l}\text { Nitrogenous } \\
\text { Demand } \\
\mathrm{mgO}_{2} \cdot \mathrm{gDW}^{-1}\end{array}$ & $\begin{array}{l}\text { Carbonaceous } \\
\text { Demand } \\
\mathrm{mgO}_{2} \cdot \mathrm{gDW}^{-1}\end{array}$ & $\begin{array}{l}\text { Carbonaceous } \\
\text { Demand } \\
\mathrm{C}, \% \mathrm{DW}\end{array}$ & $\begin{array}{l}\text { Initial } \\
\text { Carbon C, } \\
\% \mathrm{DW}\end{array}$ & $\begin{array}{l}\text { Carbon } \\
\text { Lability } \\
\%\end{array}$ \\
\hline 113 & 152.29 & 3.83 & 17.48 & 134.81 & 5.06 & 7.27 & 69.5 \\
\hline 114 & 142.36 & 3.13 & 14.28 & 128.08 & 4.80 & 7.27 & 66.1 \\
\hline 116 & 139.31 & 2.28 & 10.44 & 128.88 & 4.83 & 7.27 & 66.5 \\
\hline
\end{tabular}




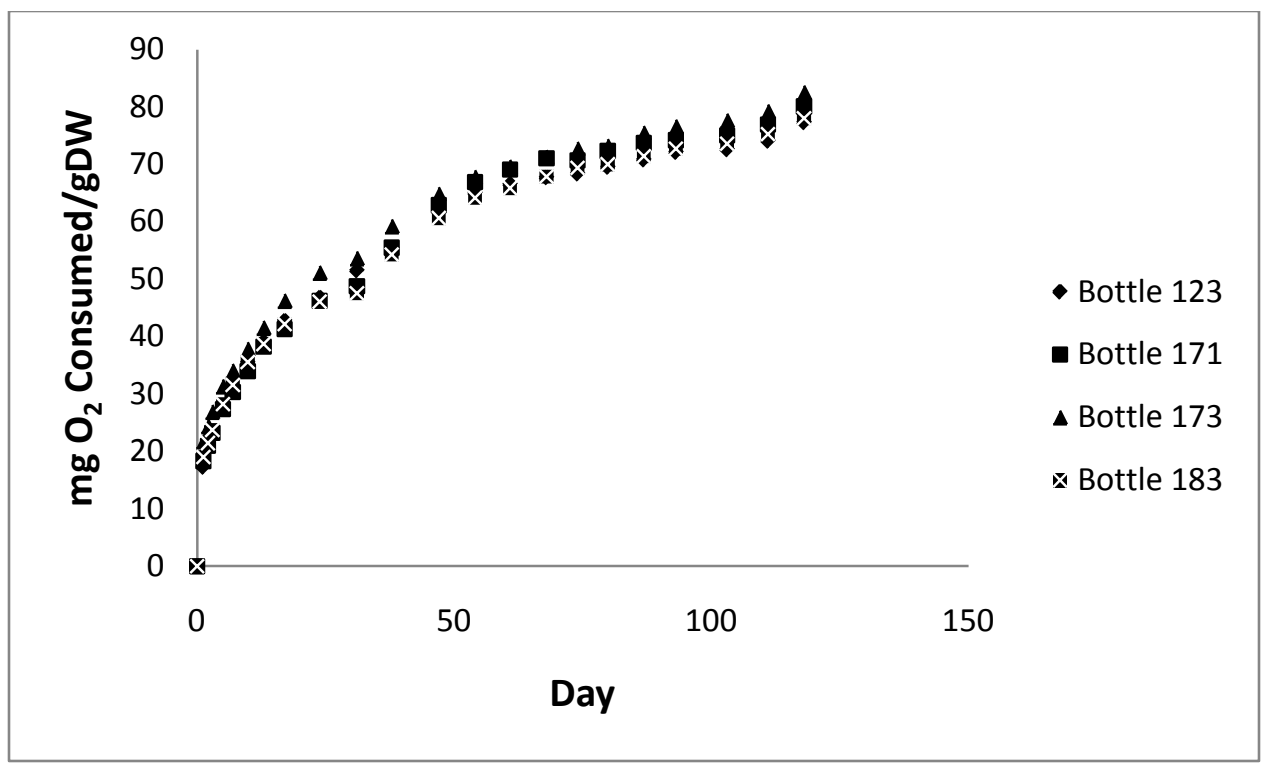

Figure A.15 Oxygen consumed from the $70-72 \mathrm{~cm}$ slice.

\begin{tabular}{|l|l|l|l|l|l|l|l|}
\hline \multicolumn{7}{|c|}{ Table A.16 70-72 cm Sediment Slice Lability } \\
\hline Bottle & $\begin{array}{l}\text { Oxygen } \\
\text { Consumed } \\
\mathrm{mgO}_{2} \cdot \mathrm{gDW}^{-1}\end{array}$ & $\begin{array}{l}\text { Nitrate } \\
\text { Produced } \\
\mathrm{mgN} \cdot \mathrm{gDW}^{-1}\end{array}$ & $\begin{array}{l}\text { Nitrogenous } \\
\text { Demand } \\
\mathrm{mgO}_{2} \cdot \mathrm{gDW}^{-1}\end{array}$ & $\begin{array}{l}\text { Carbonaceous } \\
\text { Demand } \\
\mathrm{mgO}_{2} \cdot \mathrm{gDW}^{-1}\end{array}$ & $\begin{array}{l}\text { Carbonaceous } \\
\text { Demand } \\
\text { C, \%DW }\end{array}$ & $\begin{array}{l}\text { Initial } \\
\text { Carbon } \\
\text { C, \%DW }\end{array}$ & $\begin{array}{l}\text { Carbon } \\
\text { Lability } \\
\%\end{array}$ \\
\hline 123 & 77.28 & 1.81 & 8.26 & 69.02 & 2.59 & 3.61 & 71.7 \\
\hline 171 & 80.08 & 2.26 & 10.31 & 69.77 & 2.62 & 3.61 & 72.5 \\
\hline 173 & 82.50 & 2.33 & 10.66 & 71.84 & 2.69 & 3.61 & 74.6 \\
\hline 183 & 78.00 & 2.58 & 11.80 & 66.20 & 2.48 & 3.61 & 68.8 \\
\hline
\end{tabular}


$30{ }^{\circ} \mathrm{C}$ anoxic lability assays.

Method synopsis: a sediment sample was placed in $40 \mathrm{~mL}$ of artificial lake water, sealed against penetration by oxygen and incubated at $30{ }^{\circ} \mathrm{C}$ in a revolving chamber that provided continuous mixing for $\sim 50$ days. Measurements of particulate organic carbon were made at intervals of 2.5 to 15 days until the concentration approached an asymptote.

Lability calculation:

(1) Initial particulate organic carbon content is measured (C, \%DW).

(2) Final particulate organic carbon content is measured (C, \%DW).

(3) Lability, expressed as a \% of the organic carbon content is calculated as [(2-1)/ 2 * 100]. 
Table A.17 30 Degree Anoxic Summary of Results

\begin{tabular}{|c|c|c|c|}
\hline $\begin{array}{l}\text { Top of } \\
\text { Slice }(\mathrm{cm})\end{array}$ & $\begin{array}{l}\text { Bottom of } \\
\text { Slice }(\mathrm{cm})\end{array}$ & $\begin{array}{l}\text { Midpoint of } \\
\text { Slice }(\mathrm{cm})\end{array}$ & $\begin{array}{l}\text { Lability } \\
\text { (\%) }\end{array}$ \\
\hline 7.50 & 8.00 & 7.75 & 43 \\
\hline 19.50 & 20.00 & 19.75 & 62 \\
\hline 26.00 & 27.00 & 26.50 & 47 \\
\hline 31.00 & 32.00 & 31.50 & 49 \\
\hline 38.00 & 39.00 & 38.50 & 59 \\
\hline 44.00 & 45.00 & 44.50 & 39 \\
\hline 56.00 & 57.00 & 56.50 & 58 \\
\hline 60.00 & 62.00 & 61.00 & 60 \\
\hline 66.00 & 68.00 & 67.00 & 56 \\
\hline
\end{tabular}




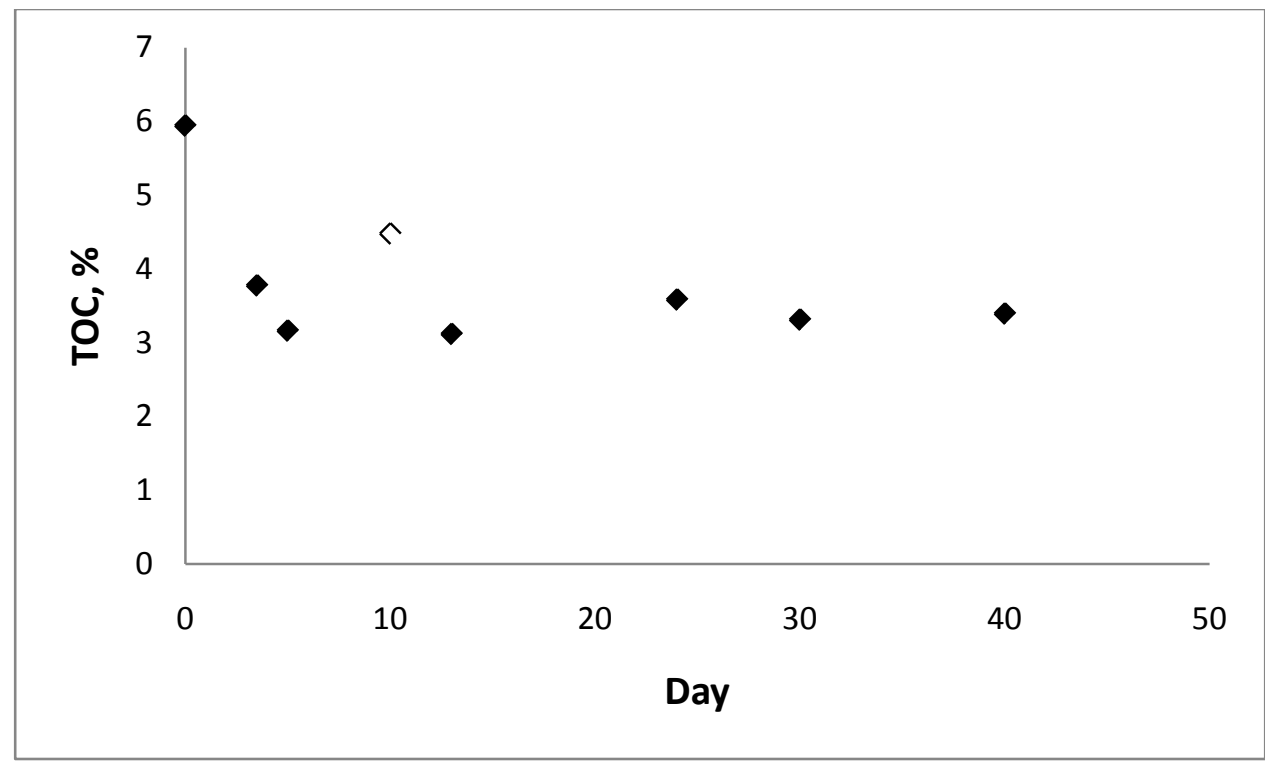

Figure A.16. TOC measurements for the $7.5-8.0 \mathrm{~cm}$ slice

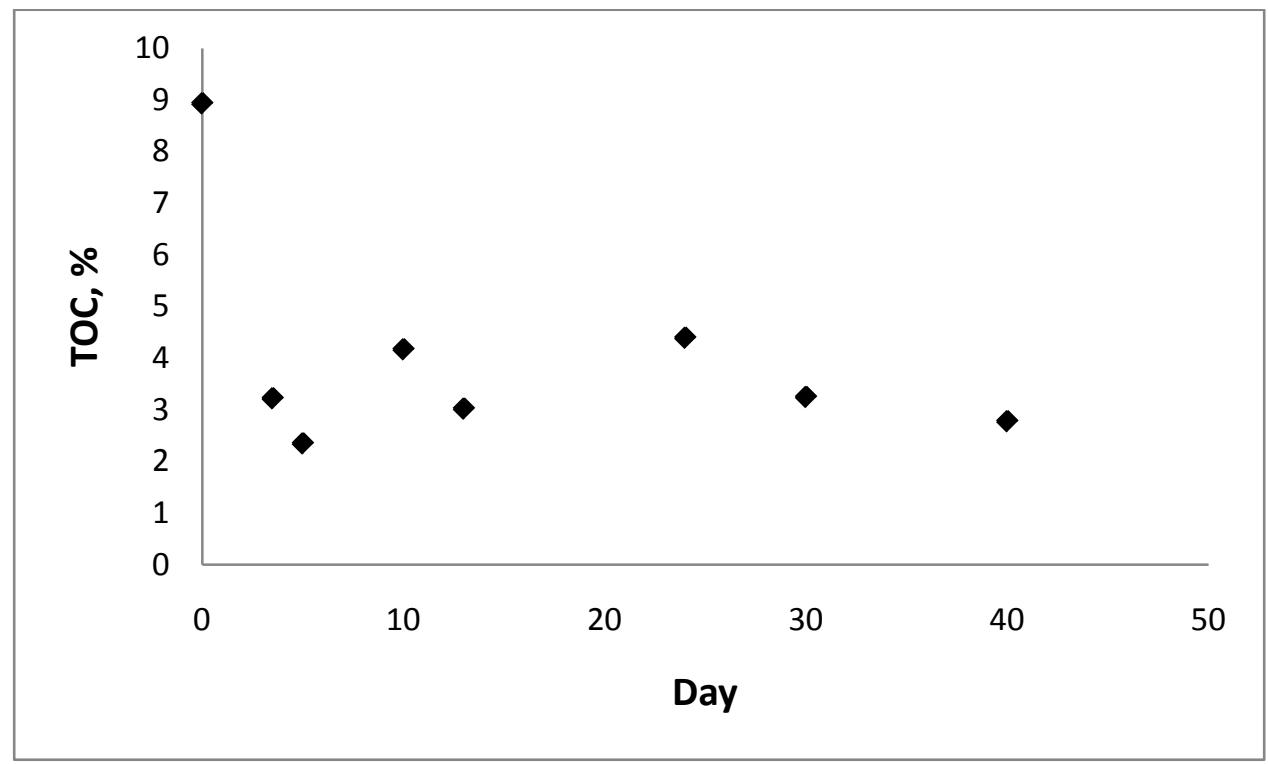

Figure A.17 TOC measurements for the $19.5-20.0 \mathrm{~cm}$ slice 


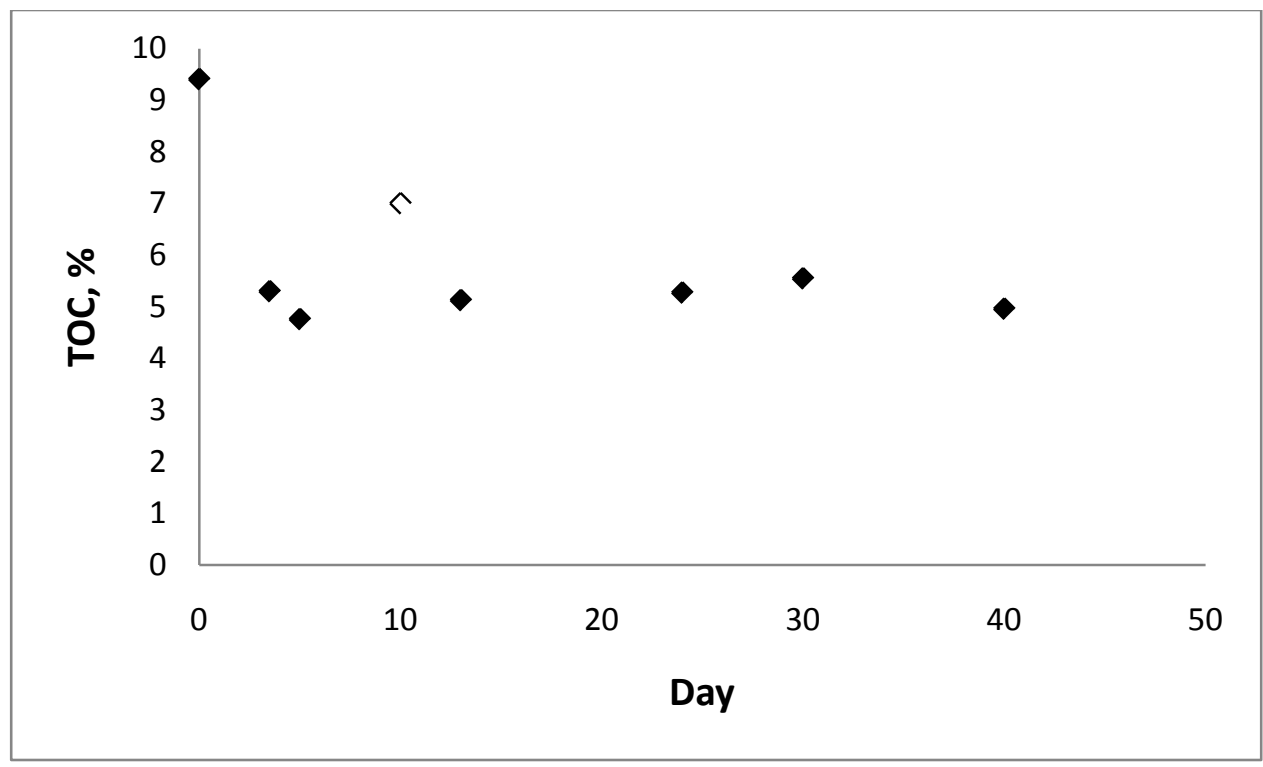

Figure A.18 TOC measurements for the $26.0-27.0 \mathrm{~cm}$ slice

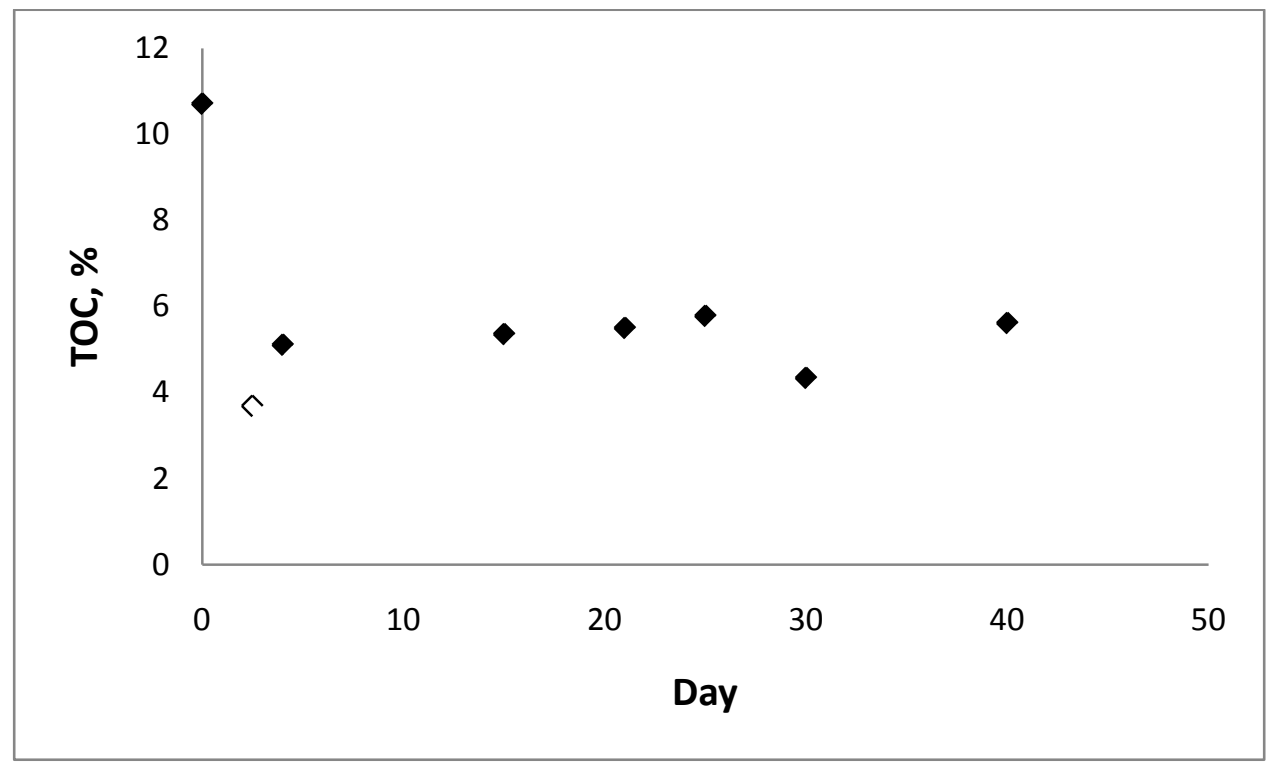

Figure A.19 TOC measurements for the $31.0-32.0 \mathrm{~cm}$ slice 


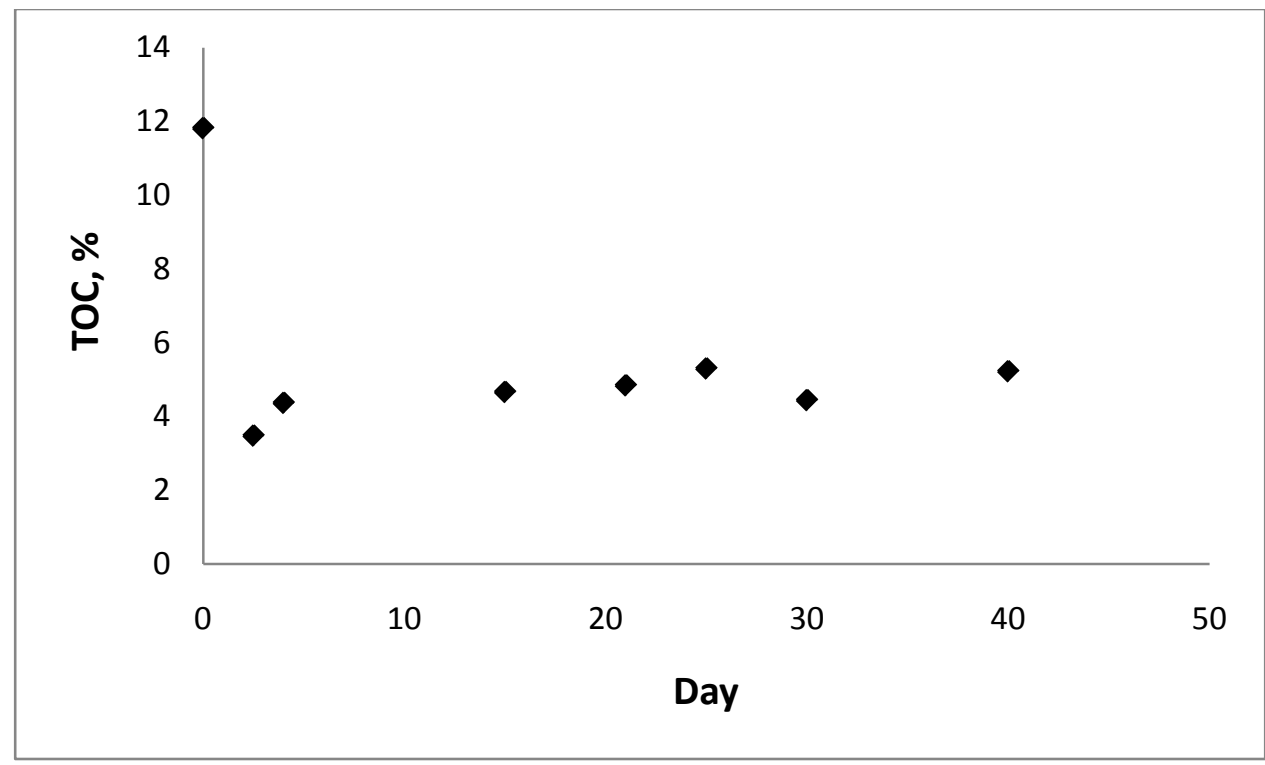

Figure A.20 TOC measurements for the $38.0-39.0 \mathrm{~cm}$ slice

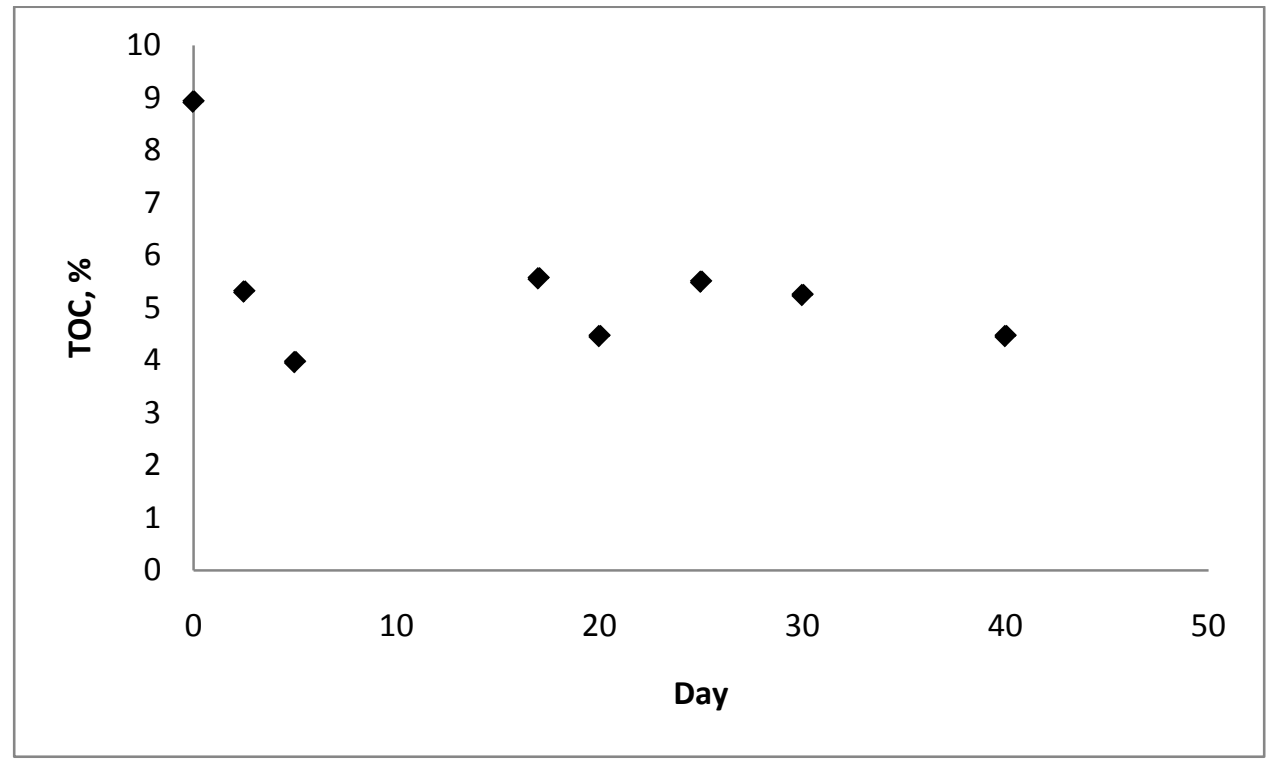

Figure A.21 TOC measurements for the $44.0-45.0 \mathrm{~cm}$ slice 


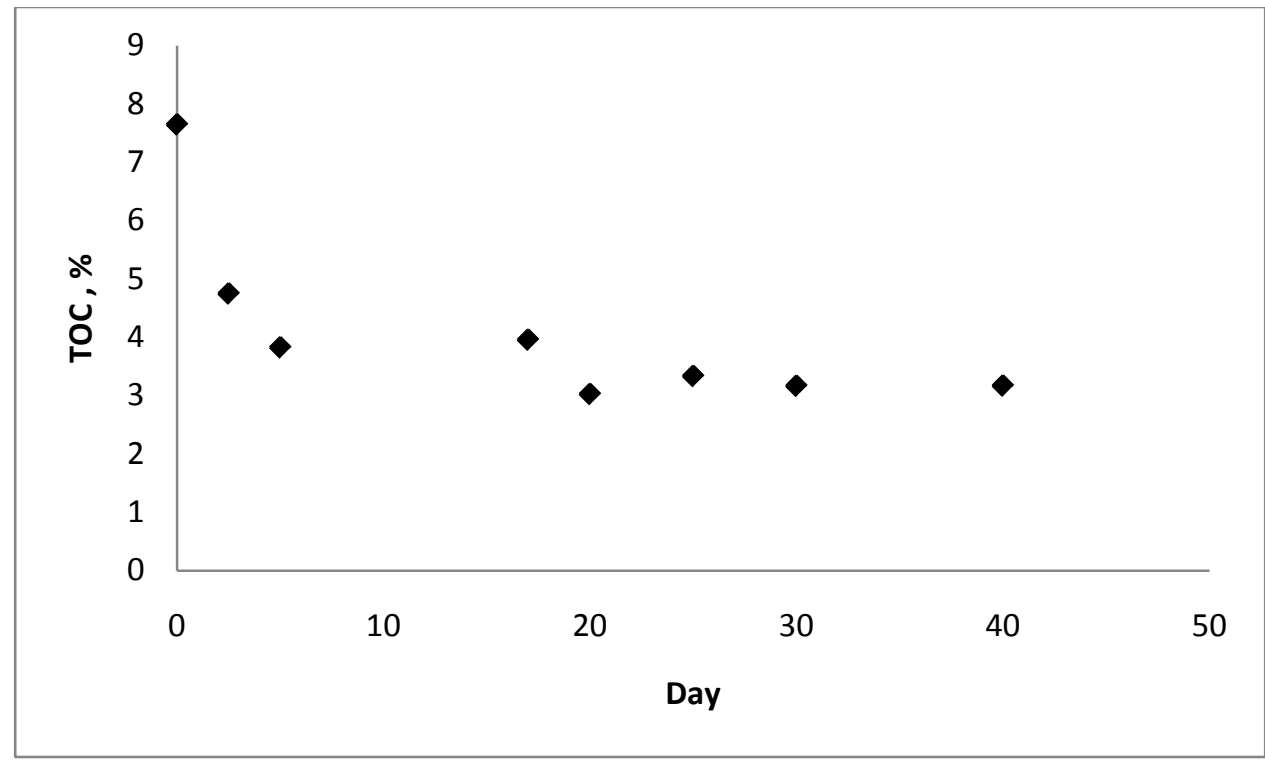

Figure A.22 TOC measurements from the $56.0-57.0 \mathrm{~cm}$ slice

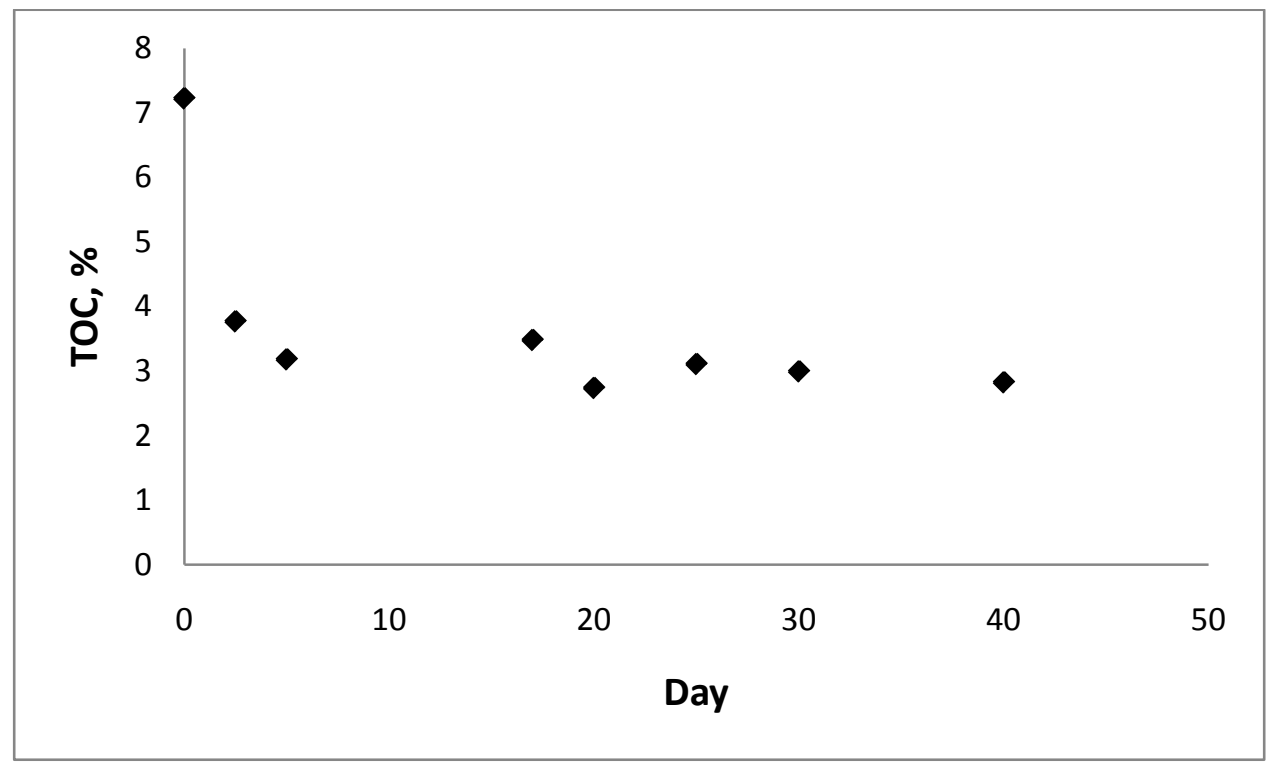

Figure A.23 TOC measurements from the $60.0-62.0 \mathrm{~cm}$ slice 


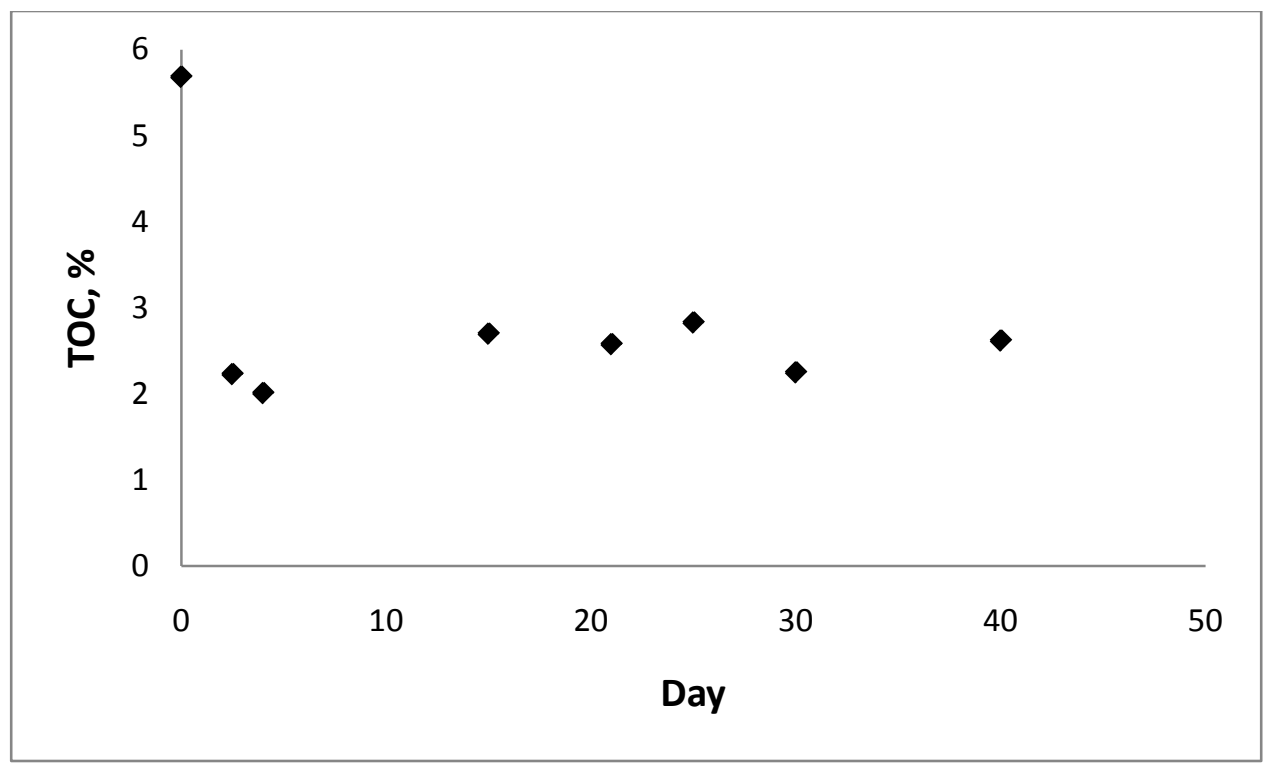

Figure A.24 TOC measurements from the 66.0-68.0 cm slice 
$8^{\circ} \mathrm{C}$ anoxic lability assays.

Method synopsis: as for the $30^{\circ} \mathrm{C}$ anoxic lability assays, but incubated at $8{ }^{\circ} \mathrm{C}$.

Lability calculation: as for the $30^{\circ} \mathrm{C}$ anoxic lability assays

Table A.18 8 Degree Anoxic Summary of Results

\begin{tabular}{|c|c|c|c|}
\hline $\begin{array}{l}\text { Top of } \\
\text { Slice }(\mathrm{cm})\end{array}$ & $\begin{array}{l}\text { Bottom of } \\
\text { Slice }(\mathrm{cm})\end{array}$ & $\begin{array}{l}\text { Midpoint of } \\
\text { Slice }(\mathrm{cm})\end{array}$ & $\begin{array}{l}\text { Lability } \\
\text { (\%) }\end{array}$ \\
\hline 1.00 & 2.00 & 1.50 & 37 \\
\hline 15.00 & 17.00 & 16.00 & 34 \\
\hline 29.00 & 31.00 & 30.00 & 37 \\
\hline 39.00 & 41.00 & 40.00 & 26 \\
\hline 52.00 & 53.00 & 52.50 & 13 \\
\hline
\end{tabular}




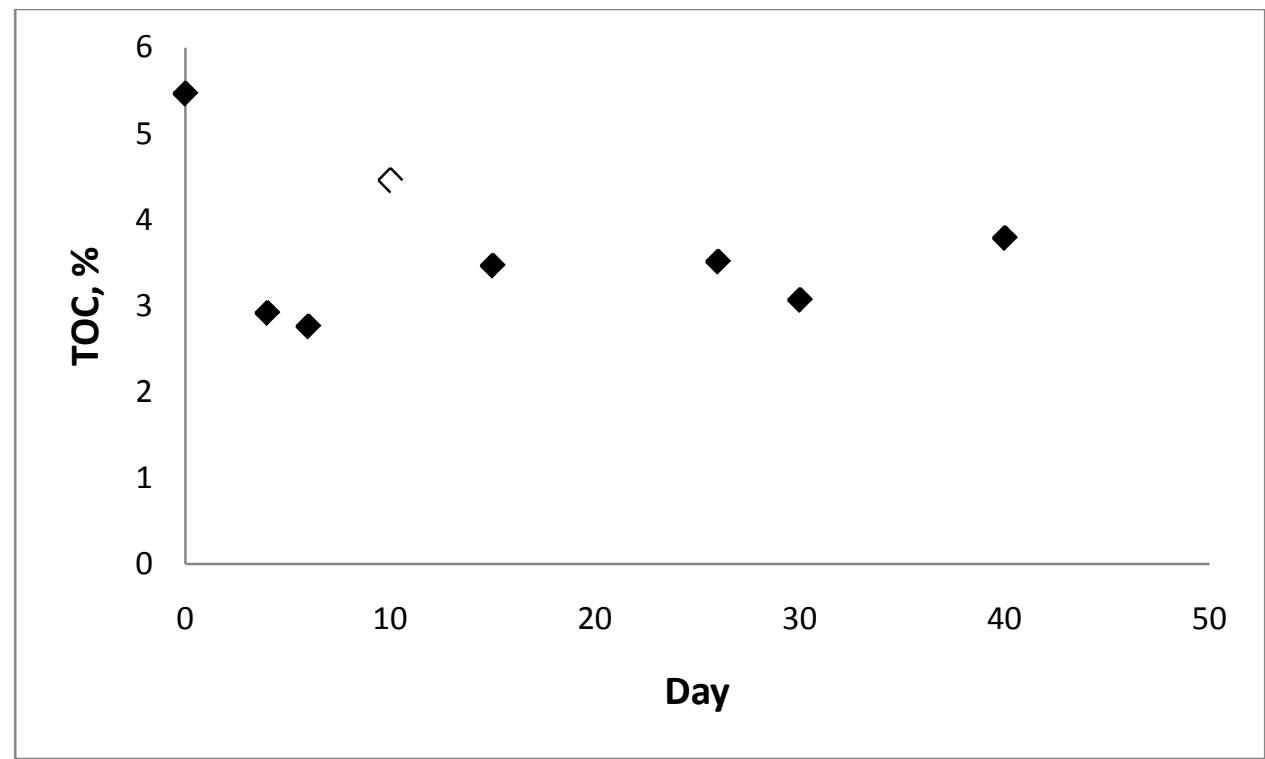

Figure A.25 TOC measurements from the $1.0-2.0 \mathrm{~cm}$ slice

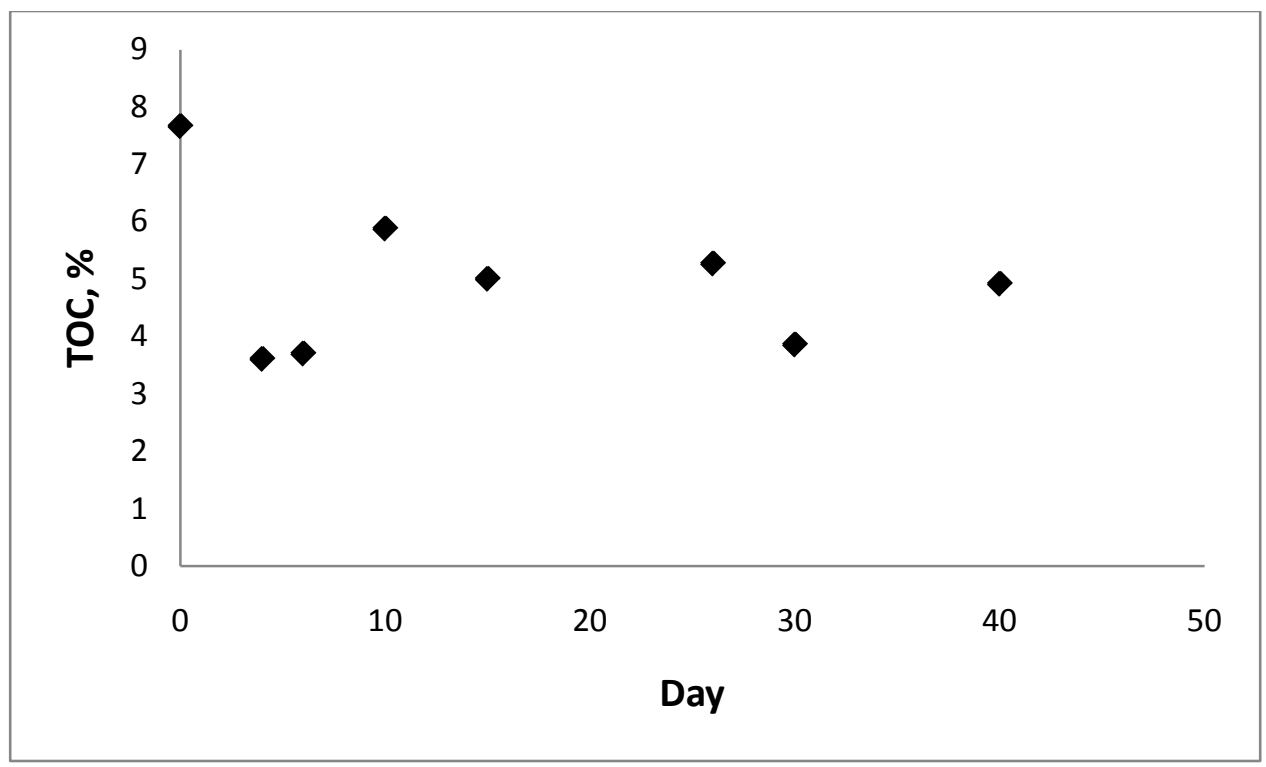

Figure A.26 TOC measurements from the $15.0-17.0 \mathrm{~cm}$ slice 


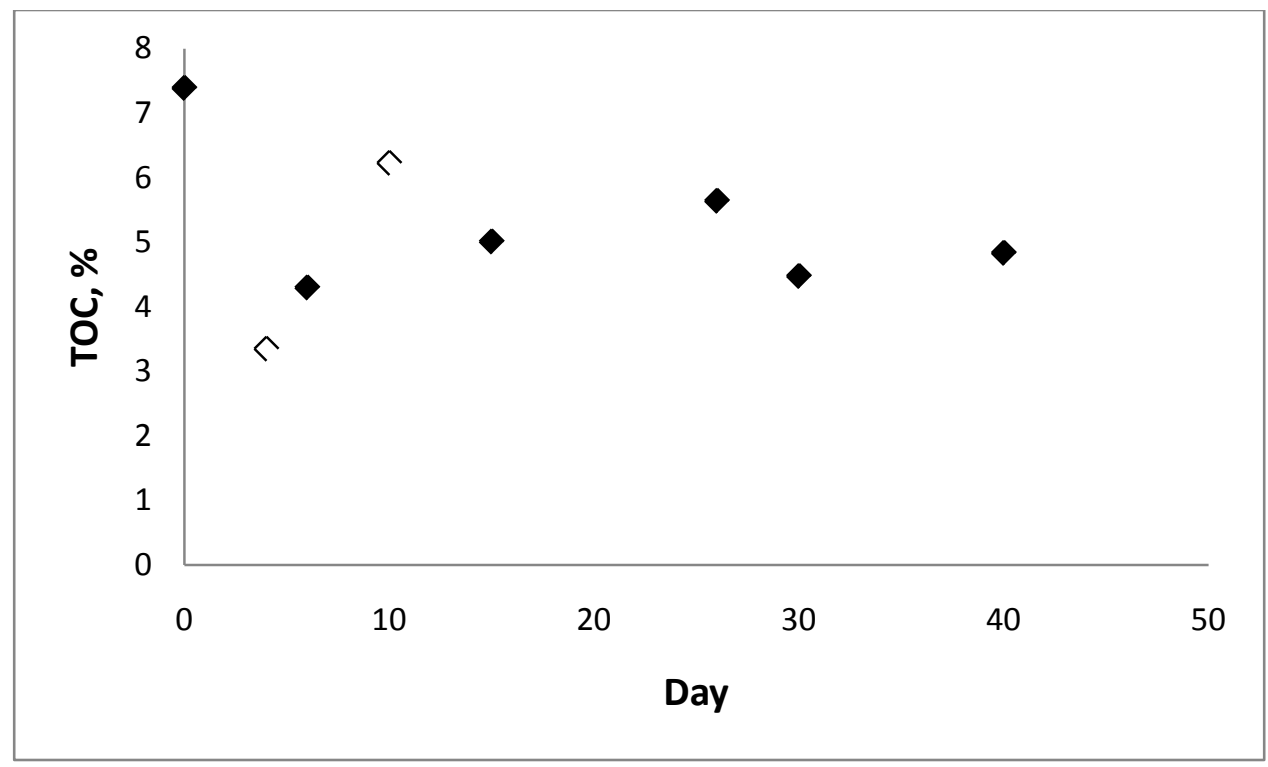

Figure A.27 TOC measurements from the 29.0-31.0 cm slice

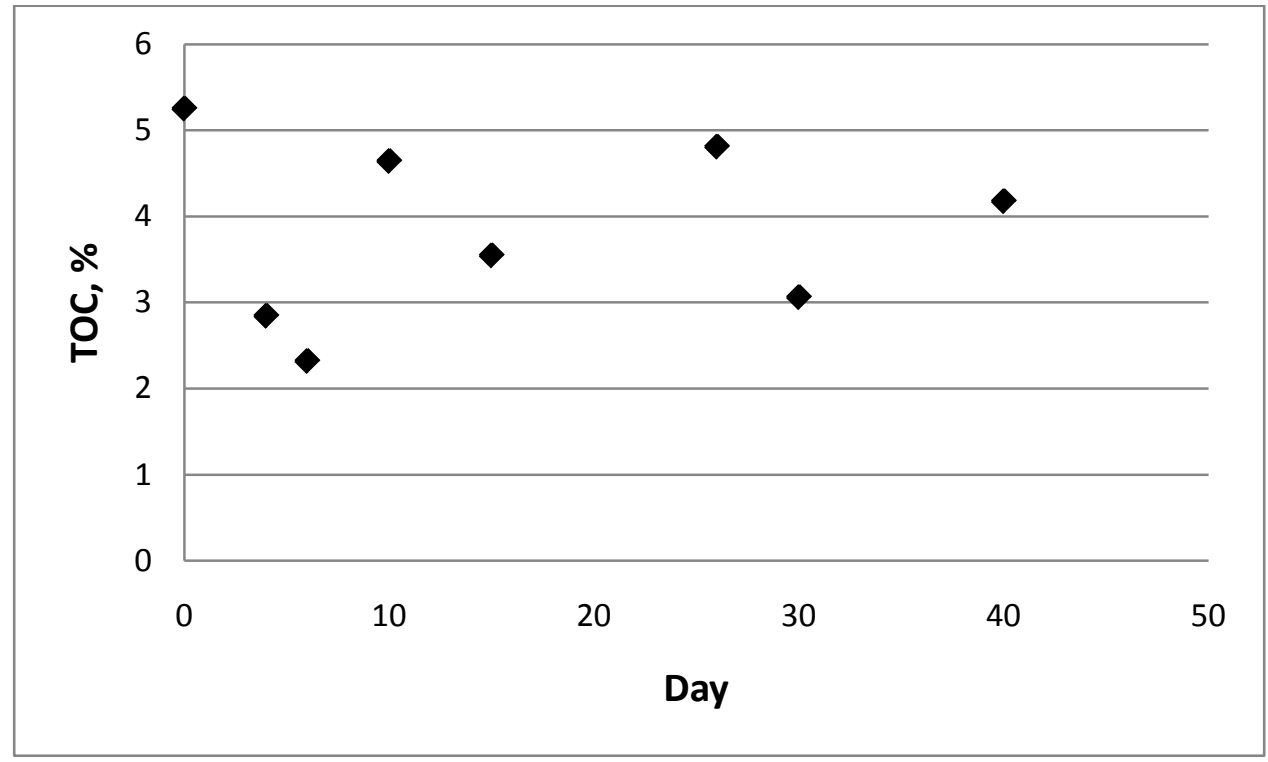

Figure A.28 TOC measurements from the 39.0-41.0 cm slice 


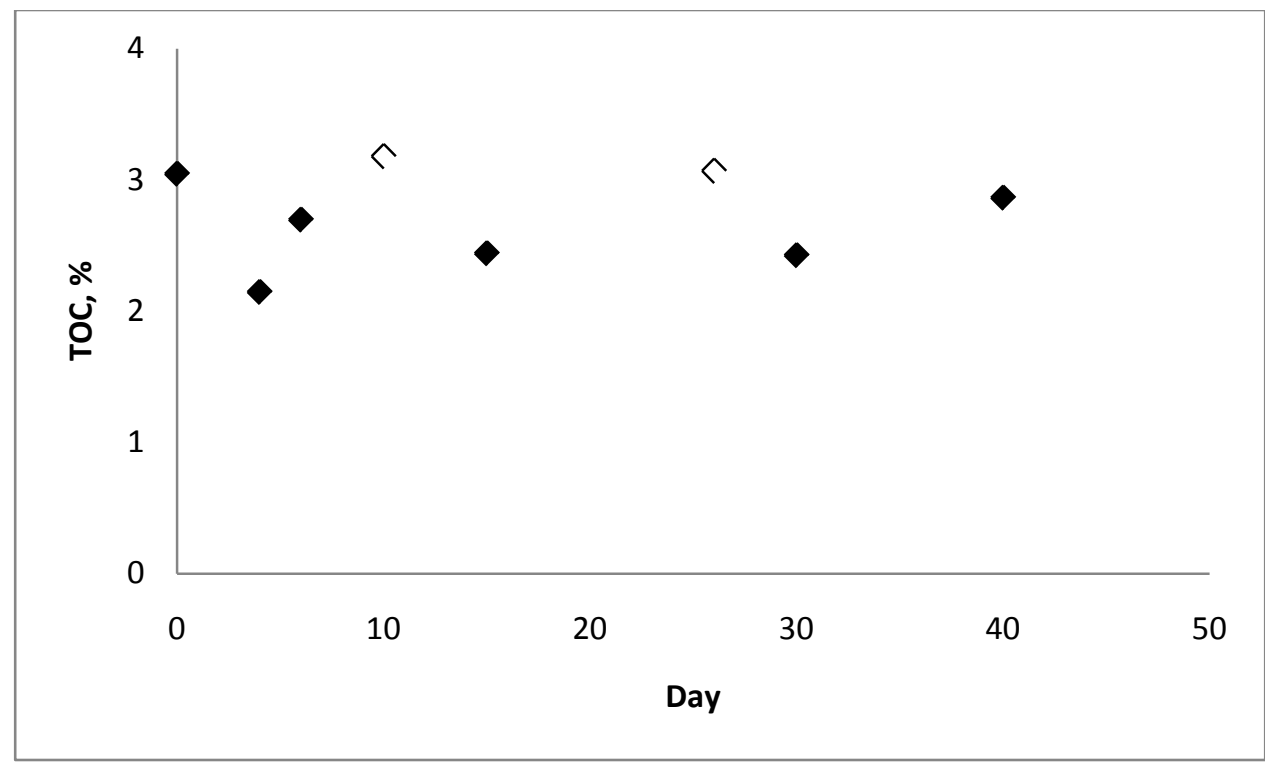

Figure A.29 TOC measurements from the $52.0-53.0 \mathrm{~cm}$ slice 


\section{Sediment Trap Material}

Oxic

\begin{tabular}{|l|l|l|l|l|l|l|}
\hline Table A.19 Lability of Sediment Trap Material Under Oxic Conditions \\
\hline Bottle & 50 & 57 & 117 & 141 & 142 & 144 \\
\hline Initial TOC & 10.31 & 10.31 & 10.31 & 10.31 & 10.31 & 10.31 \\
\hline Final TOC & 1.31 & 1.39 & 0.87 & 1.22 & 1.18 & 0.85 \\
\hline \%Labile & 87.3 & 86.5 & 91.6 & 88.2 & 88.6 & 91.8 \\
\hline Average Lability \\
\hline \multicolumn{79}{|l|}{ Standard Deviation }
\end{tabular}

\section{Anoxic}

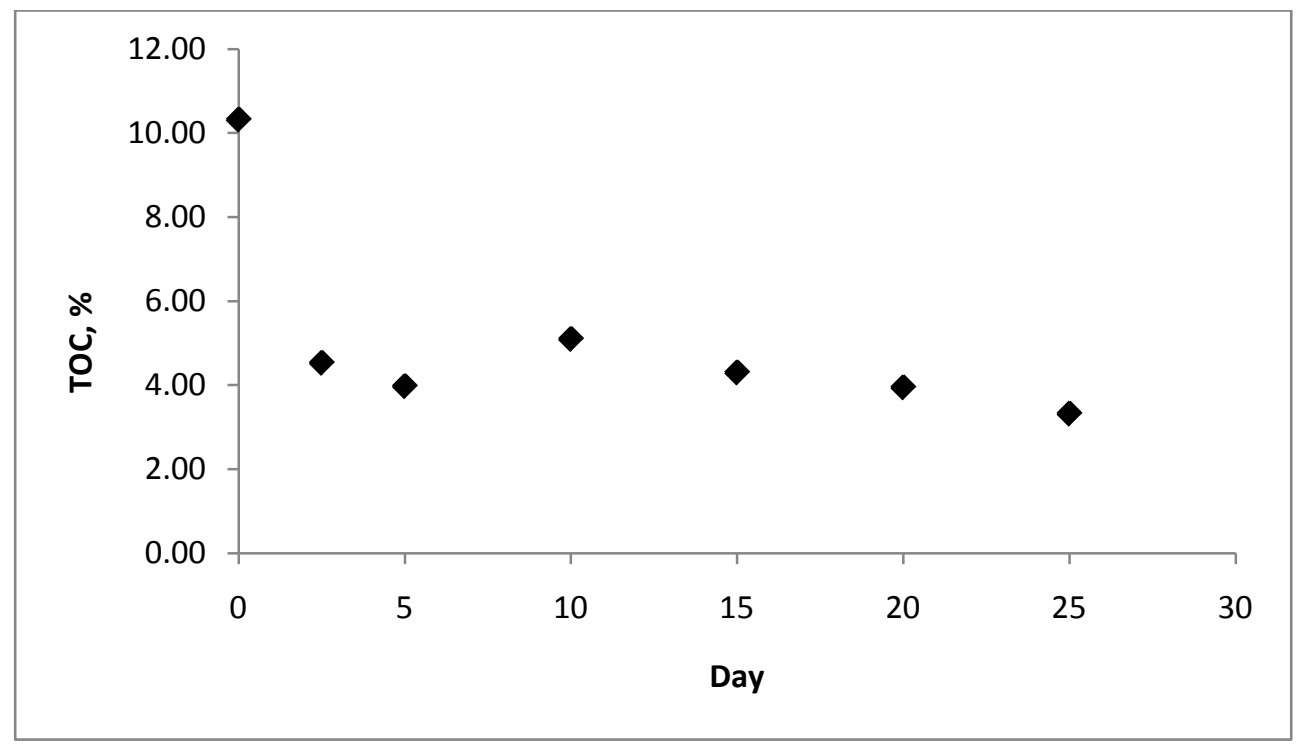

Figure A.30 TOC consumed from the sediment trap material 
Appendix B: Methods

Oxic Respiration Procedure

1. Mix sediment slice into a homogeneous material.

2. Weigh sediment, place into BOD bottles.

3. Fill to lip with Artificial Lake Water.

4. Bubble bottles with oxygen for 20 minutes to remove accumulated reduced species.

5. Perform a Wet Weight/Dry Weight analysis on the sediment slice.

6. Measure the initial oxygen concentration, seal the bottle.

7. Place bottle within the rotator.

8. At intervals, measure the oxygen level within the bottle.

9. Measure the level of nitrate within the bottle.

10. Reaerate the bottles to ensure that anoxia does not occur.

The nitrate concentration can be converted to an equivalent oxygen consumption by multiplying it by 4.57 . This is subtracted from the total oxygen consumption.

Multiplying the corrected oxygen consumption by $12 / 32$ converts the oxygen to the equivalent carbon consumption, giving the total carbon consumed. The experiment ends when the asymptote of oxygen consumption occurs, giving a total TOC mineralized. 
Methanogenesis Procedure

1. Place a measured amount of sediment into a glass vial.

2. Bubble with nitrogen to remove the oxygen from the vial.

3. Seal the anoxic vial.

4. Place in rotating device.

5. Harvest the samples at scheduled intervals.

6. Place the contents of the vial into a plastic tin.

7. Dry the sample in the 60 degree oven overnight.

8. Follow the TOC Fumigation procedure to prepare the sample for measurement. 


\section{TOC Fumigation Procedure}

1. Place the sediment into a pre-weighed plastic pan.

2. Weigh the pan and sample, subtract out the weight of the pan.

3. Dry in the 60 degree oven over night, until dry.

4. Remove samples from the oven and allow to cool in the dessicator. Measure the dry weight of the sediment.

5. Place the pans inside the chamber, on the rack above the strong acid placed in the bottom of the emptied dessicator.

6. Once the sediment changes color from the acid exposure, place in the drying oven again.

7. Remove sample from the oven, place in the dessicator for one hour to cool. Measure the corrected dry weight.

8. The sample is now ready to be placed in the elemental analyzer, which will give the machine measured TOC listed below.

The ratio of the dry weights gives a correction factor that allows for the conversion of the machine measured TOC to the actual TOC. The calculation is as follows:

$\mathrm{TOC}_{\mathrm{act}}=\mathrm{TOC}_{\text {machine }} *\left(\mathrm{~W}_{\mathrm{f}} / \mathrm{W}_{\mathrm{o}}\right)$

Where,

$$
\begin{aligned}
& \mathrm{TOC}_{\text {act }}=\text { Actual sample } \\
& \mathrm{TOC}_{\text {machine }}=\text { Machine measured TOC } \\
& W_{f}=\quad \text { Dry weight after fumigation } \\
& W_{0}=\quad \text { Initial Dry weight }
\end{aligned}
$$

Source: Stromquist 1996 


\section{Appendix C: TOC Profile}

\section{Table C.1. TOC Profile of Onondaga Lake}

\begin{tabular}{|c|c|c|c|c|c|c|c|c|}
\hline $\begin{array}{l}\text { Mean } \\
\text { Depth }\end{array}$ & $\begin{array}{c}\text { Corrected } \\
\text { TOC }\end{array}$ & $\begin{array}{l}\text { Standard } \\
\text { Deviation }\end{array}$ & $\begin{array}{l}\text { Mean } \\
\text { Depth }\end{array}$ & $\begin{array}{c}\text { Corrected } \\
\text { TOC }\end{array}$ & $\begin{array}{l}\text { Standard } \\
\text { Deviation }\end{array}$ & $\begin{array}{l}\text { Mean } \\
\text { Depth }\end{array}$ & $\begin{array}{c}\text { Corrected } \\
\text { TOC }\end{array}$ & \begin{tabular}{|l|} 
Standard \\
Deviation
\end{tabular} \\
\hline 0.25 & 4.8 & 0.06 & 24.5 & 9.6 & 0.18 & 65 & 6.1 & 0.27 \\
\hline 0.75 & 3.1 & 0.02 & 25.5 & 5.3 & 0.51 & 67 & 6.0 & 0.25 \\
\hline 1.25 & 4.7 & 0.02 & 26.5 & 9.4 & 0.38 & 69 & 5.7 & 0.20 \\
\hline 1.75 & 4.6 & 0.06 & 27.5 & 8.5 & 0.29 & 71 & 3.6 & 0.12 \\
\hline 2.25 & 5.1 & & 28.5 & 13.8 & 0.89 & & & \\
\hline 3.25 & 5.1 & 0.51 & 29.5 & 11.6 & 0.61 & & & \\
\hline 4.25 & 5.2 & 0.09 & 30.5 & 11.4 & 0.02 & & & \\
\hline 5.25 & 7.2 & & 31.5 & 11.1 & 0.51 & & & \\
\hline 5.75 & 5.8 & 0.31 & 32.5 & 12.3 & 0.36 & & & \\
\hline 6.25 & 6.3 & 0.22 & 33.5 & 10.4 & 0.61 & & & \\
\hline 6.75 & 4.8 & 0.46 & 34.5 & 14.7 & 0.56 & & & \\
\hline \begin{tabular}{l|l}
7.5 \\
\end{tabular} & 5.9 & 0.34 & 35.5 & 9.0 & 0.85 & & & \\
\hline 8.25 & 4.8 & 0.41 & 36.5 & 8.8 & 0.19 & & & \\
\hline 8.75 & 4.3 & 0.37 & 37.5 & 11.6 & 0.09 & & & \\
\hline 9.25 & 4.6 & 0.11 & 38.5 & 11.8 & 0.11 & & & \\
\hline 9.75 & 5.6 & 0.19 & 39.5 & 8.0 & 0.87 & & & \\
\hline 10.25 & 6.0 & 0.32 & 40.5 & 10.0 & 0.08 & & & \\
\hline 10.75 & 5.1 & & 41.5 & 11.2 & & & & \\
\hline 11.25 & 4.9 & 0.17 & 43.5 & 12.2 & 0.40 & & & \\
\hline 11.75 & 6.9 & 0.30 & 44.5 & 8.9 & 0.47 & & & \\
\hline 12.25 & 4.7 & 0.12 & 45.5 & 11.1 & 0.35 & & & \\
\hline 12.75 & 4.0 & 0.11 & 46.5 & 6.1 & 0.46 & & & \\
\hline 13.25 & 6.0 & 0.09 & 47.5 & 7.9 & 0.53 & & & \\
\hline 13.75 & 7.2 & 0.55 & 48.5 & 8.1 & 0.85 & & & \\
\hline 14.25 & 7.4 & 0.44 & 49.5 & 7.8 & 0.34 & & & \\
\hline 14.75 & 5.9 & 0.57 & 50.5 & 5.8 & 0.34 & & & \\
\hline 15.5 & 8.3 & 0.05 & 51.5 & 7.7 & 0.81 & & & \\
\hline 16.25 & 5.0 & 0.31 & 52.5 & 8.3 & 0.70 & & & \\
\hline 16.75 & 9.5 & 0.09 & 53.5 & 8.5 & 0.62 & & & \\
\hline 17.25 & 6.8 & 0.27 & 54.5 & 6.2 & 0.37 & & & \\
\hline 17.75 & 10.1 & 0.90 & 55.5 & 4.5 & 0.47 & & & \\
\hline 18.5 & 7.3 & 0.06 & 56.5 & 7.6 & 0.72 & & & \\
\hline 19.5 & 8.9 & 0.72 & 57.5 & 6.6 & 0.75 & & & \\
\hline 20.5 & 7.2 & 0.07 & 58.5 & 7.3 & 0.30 & & & \\
\hline 21.5 & 6.1 & 0.02 & 59.5 & 7.6 & 0.11 & & & \\
\hline 22.5 & 9.3 & 0.08 & 61 & 7.3 & 0.65 & & & \\
\hline 23.5 & 9.5 & 0.47 & 63 & 7.2 & 0.14 & & & \\
\hline
\end{tabular}


Appendix D: Artificial Lake Water Recipe

To ensure that the medium used in the experiments mimicked Onondaga Lake, an artificial lake water was used. Nitrate was kept absent from the artificial lake water to prevent denitrification during trials. The recipe for this lake water is shown in Table D.1 below.

\begin{tabular}{|l|r|r|}
\hline \multicolumn{3}{|c|}{ Table D.1 Artificial Lake Water } \\
\hline Constituent & $\begin{array}{l}\text { Concentration } \\
\text { (mg/L) }\end{array}$ & $\begin{array}{l}\text { Concentration } \\
\text { (mmol/L) }\end{array}$ \\
\hline $\mathrm{CaCl}_{2}$ & 648.36 & 5.84 \\
\hline $\mathrm{NaHCO}_{3}$ & 356.2 & 4.24 \\
\hline$\left(\mathrm{Na}_{2} \mathrm{SO}_{4}\right.$ & 237.21 & 1.67 \\
\hline $\mathrm{MgCl} 2.6 \mathrm{H}_{2} \mathrm{O}$ & 200.87 & 0.99 \\
\hline $\mathrm{KCl}$ & 32.43 & 0.44 \\
\hline $\mathrm{NaCl}$ & 187.45 & 3.21 \\
\hline $\mathrm{NaF}$ & 1.01 & 0.02 \\
\hline
\end{tabular}




\section{Appendix E: Calculation of Burial Velocity Using Sed2K}

The burial velocity of Onondaga Lake is required in this research to support the profile comparison and carbon residence time calculations. This is accomplished through application of SED2K (Chapra and Auer 2010) which calculates burial velocity as the net result of sedimentation and compaction.

The sedimentation rate is obtained from the data archive of the Upstate Freshwater Institute which measured sedimentation $\left(\mathrm{gTSS} \cdot \mathrm{m}^{-2} \cdot \mathrm{d}^{-1}\right)$ in Onondaga Lake using sediment traps deployed at approximately weekly intervals over the period April to October of 1980 - 2009. Inspection of those data revealed that rates in April and in OctoberNovember were 92 and $71 \%$ of the period-average measurement. Further, Penn and Auer (1997) measured the sedimentation rate under the ice and found it to be $\sim 25 \%$ of the summer rate. These characterizations of seasonality in deposition (Figure E.1) were applied in developing a factor (0.695) that was used in projecting summer (May September) measurements to represent an annual rate.

The rate of compaction is reflected in the downcore profile of porosity. A core collected in 2008 was utilized in establishing the porosity at the sediment surface $[\phi(0)$, dimensionless] and the terminal (no further compaction) porosity ( $\phi^{\prime}$, dimensionless). The porosity profile (Figure E.2) was then fit to an exponential function (Chapra and Reckhow 1983),

$\phi(z)=\phi(0) \cdot e^{-\beta \cdot z}+\phi^{\prime}$ 
providing a capacity to predict porosity as a function of depth in the core, as required by SED2K.

Finally, the dry sediment density $\left(\mathrm{kgDWm}^{-3}\right)$ was determined for the core collected in support of porosity measurements (Figure E.3). The resulting mean dry density was $2826 \pm 751 \mathrm{kgDW} \cdot \mathrm{m}^{-3}(\mathrm{n}=86)$. Downcore variations in dry sediment density likely reflect changes in the relative contribution of terrigenous materials and industrial waste (calcium carbonate) to the total suspended solids pool. The calculation is not particularly sensitive to variation in dry sediment density, i.e. $1-2 \mathrm{~cm}$ in vertical alignment for \pm 1 S.D. in dry sediment density.

Burial velocities were then calculated by entering the sedimentation rates, the porosity function and the sediment dry density into SED2K and running the model over the interval 1995-present. The suitability of this approach was tested by comparing a contemporary (2008) TOC profile with a similar profile obtained in 1995 and depthadjusted to 2008 using burial velocities as calculated using SED2K. That comparison, presented above as Figure 14, was deemed satisfactory based on the alignment of key stratigraphic markers (i.e. peaks in sediment TOC content) and no further adjustments were applied. 


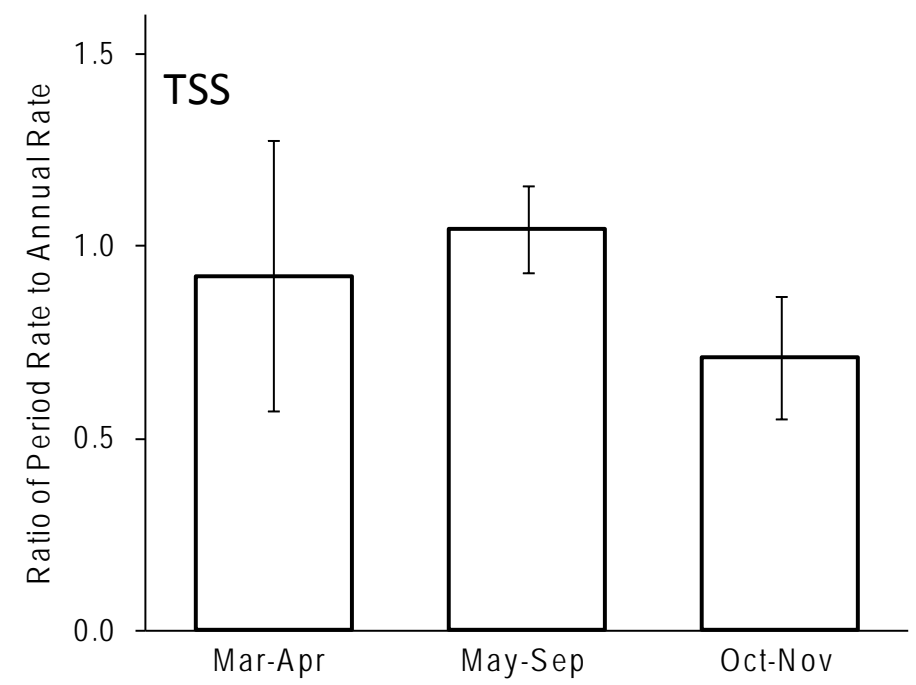

Figure E.1. The ratio of seasonal sedimentation rates (e.g. March - April) to those for the entire interval of sediment trap collection (March - November) as used in extending rate estimates to reflect their annual value.

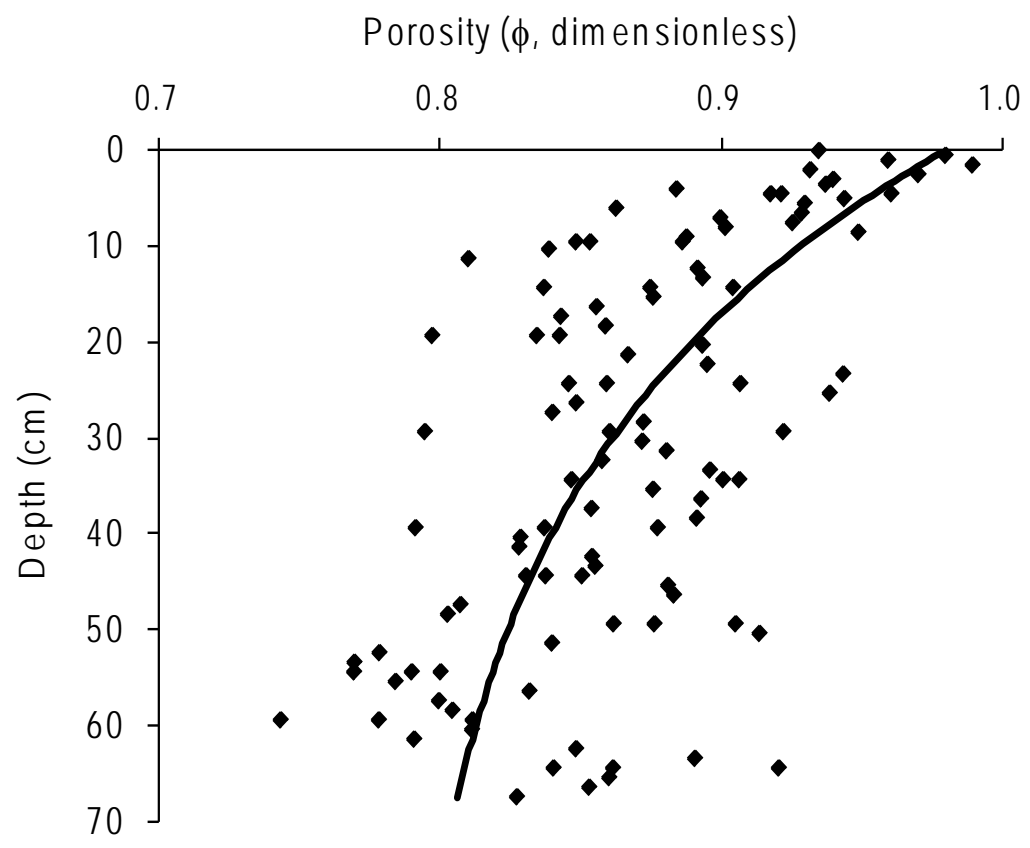

Figure E.2. Porosity profile for a sediment core collected in 2009. Solid line is the fit of the function presented above as Equation A1.1 to porosity data with $\phi(0)=0.98, \phi^{\prime}=$ 0.78 and $\beta=3 \mathrm{~m}^{-1}$. 


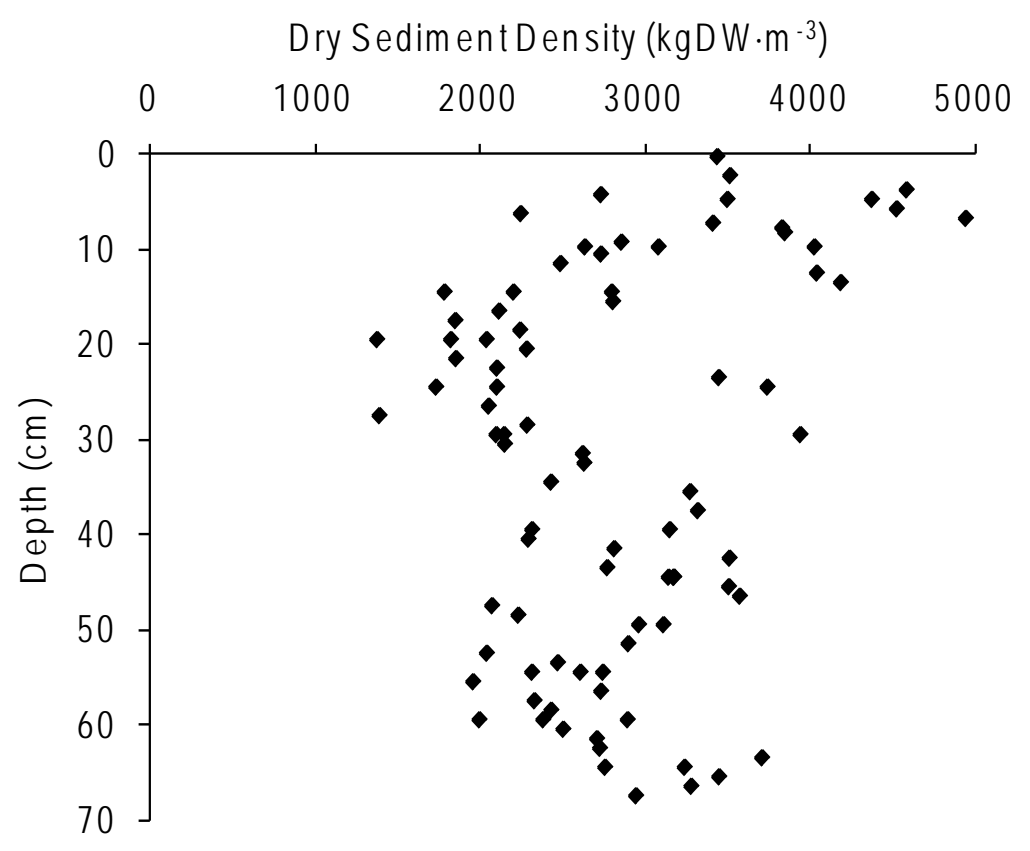

Figure E.3. Dry sediment density profile for a sediment core collected in 2009. 